\title{
Inventario Preliminar de Avifauna en la Región Centro-occidental del Ecuador
}

\section{Preliminary Avifauna Inventory of Central-western Ecuador}

Felipe Espinoza ', Emilio Testa 2, Carlos Cruz ${ }^{1}$, Alexander Matecki ${ }^{2}$, Julián Pérez ${ }^{1}$, Diego Manosalvas ${ }^{2}$, Carola Bohórquez ${ }^{2}$

INFORMACIÓN DEL

ARTÍCULO

Fecha de recepción: 20 de julio de 2018.

Fecha de aceptación: 5 de noviembre de 2018.

${ }^{1}$ Universidad Espíritu Santo, Escuela de
Ciencias Ambientales, Samborondón, Ecuador

${ }^{2}$ Investigador independiente.

\footnotetext{
Autor de correspondencia: Felipe Espinosa, Universidad de Especialidades Espíritu Santo. Escuela de Ciencias Ambientales. Vía La Puntilla $\mathrm{km} 2.5$. E-mail: fespinozadejanon@gmail.com Tlf.: (593-4) 2835630

ENLACE DOI

http://10.31095/investigatio.2018.11.9
}

\section{Resumen}

Latinoamérica es considerada una de las regiones de mayor importancia a nivel mundial en cuanto a diversidad de aves, debido a que cinco de los 10 países megadiversos del mundo se encuentran en la región. Dentro de estos países, Ecuador se destaca al tener la mayor diversidad del mundo por unidad de superficie, y poseer $48 \%$ de las especies de aves del subcontinente. El objeto de esta investigación fue levantar un inventario preliminar para la zona centro-occidental del Ecuador, una región no muy estudiada, a través del monitoreo de 23 sitios seleccionados como importantes para la presencia de avifauna en la zona de transición entre las regiones biogeográficas Jama-Zapotillo, Chocó Ecuatorial, Cordillera Occidental de los Andes y Cordillera Costera del Pacífico Ecuatorial, presente en cinco provincias: Guayas, Santa Elena, Cañar, Bolívar, y Azuay. El inventario preliminar registró 263 especies pertenecientes a 61 familias, incluyendo 32 especies endémicas regionales, 17 especies bajo amenaza, dos especies exóticas y una especie endémica de Ecuador. Se registraron además ocho especies nuevas para los sitios de muestreo, la mayoría en el sitio denominado BUCAY (Bosque Protector La Esperanza). Finalmente se realizó una compilación de listados de aves de la zona de estudio, publicados en fuentes secundarias, con los que se alcanzó un total de 569 especies para el sector, representando el $35 \%$ de las especies a nivel nacional en un área no mayor $15.000 \mathrm{~km}^{2}$.

\section{Palabras Clave:}

Aves, Ecuador, Listado, Especies, Diversidad.

Clasificación JEL: Q57.

\begin{abstract}
Latin America is considered one of the most important places for avian diversity in the world, mostly due to the fact that 5 of the 10 most biodiverse countries are located there. Within these countries, Ecuador stands out for having the highest biodiversity per area unit in the world, and also for having $48 \%$ of the bird species registered in the subcontinent. The aim of this paper is to make a preliminary inventory for central-western Ecuador, a region not commonly studied, through the monitoring of 23 selected sites. These sites where located in the transition area of 4 biogeographical regions of Jama-Zapotillo, Equatorial Choco, Western Andes, and Equatorial Pacific Coastal Mountain Range, located in 5 provinces: Guayas, Santa Elena, Cañar, Bolívar, and Azuay. The preliminary inventory, registered 263 species from 61 families, including 32 regional endemics, 17 threatened species, 2 exotic species and 1 Ecuadorian endemic. We also registered eight new species for the monitoring sites, most of them in the site BUCAY (Protected Forest La Esperanza). Finally, we compiled several published bird inventories for the area, reaching a total of 568 species, representing $35 \%$ of the Ecuadorian species in an area not larger than 15.000 square kilometers.
\end{abstract}

Keywords:

Birds, Ecuador, List, Species, Diversity.

JEL Classification: Q57.

113

INVESTIGATIO No. 11, noviembre 2018 Edición Especial, pp. 113-168,

ISSN: 1390 - 6399・ISSN-e: 2602 - 8336 


\section{Introducción}

En Latinoamérica se mantienen el $22 \%$ de los bosques nativos a nivel mundial, razón por la cual se encuentran a cinco de los diez países megadiversos (FAO, 2015). A nivel ornitológico, también es de suma importancia, al agrupar el $34 \%$ de las especies a nivel mundial (3.402 especies), incluyendo 551 especies endémicas y una Sociedad Ornitológica propia (SACC) (Clements et al., 2017; Freile et al., 2018; Remsen et al., 2018). En este contexto encontramos a Ecuador, el país con mayor biodiversidad por unidad de superficie del mundo, que cuenta con una cobertura forestal nativa del $46 \%$ de su territorio continental, llegando a las 12.883.459 hectáreas de bosque (FAO, 2015). El país cuenta con 56 áreas dentro del Sistema Nacional de Áreas Protegidas (SNAP) (MAE, 2016) y está considerado como el quinto país a nivel mundial en diversidad de aves, posee el 16\% de las especies de aves del mundo y el $48 \%$ de las aves de Latinoamérica con 1.622 especies, de las cuales 42 son endémicas del país de acuerdo a Birdlife International (2018).

La zona costera central del Ecuador está dominada por las formaciones vegetales del Pacífico Ecuatorial, que comprende 14 ecosistemas (MAE, 2015), además cuenta con una característica topográfica única, un estrechamiento de la planicie costera, acercando al océano Pacífico a dos tipos de formaciones vegetales adicionales (Chocó Ecuatorial y Cordillera Occidental de los Andes) (MAE, 2015) agregando un total de 22 ecosistemas adicionales conformando zonas de transición que van desde Bosques montanos hasta Manglares (Flanagan et al., 2005; MAE, 2016).

Adicionalmente, estos ecosistemas conforman tres Áreas de Endemismo para Aves (EBAs) de acuerdo a la clasificación de Birdlife International (2018): Chocó, Tumbesina, Andes Centrales del Sur. Estas tres áreas han sufrido pérdidas de hábitat importantes y están consideradas como de alta prioridad para estudios y conservación (Birdlife International, 2018), destacando a la región tumbesina como una de las EBAs en estado más crítico, relevante y amenazada a nivel mundial por mantener menos del $5 \%$ de su cobertura vegetal nativa debido a las actividades antrópicas que se han desarrollado históricamente en la zona (Parker et al., 1995). Añadido a esta problemática, el Guayas (que abarca la mayor parte del área de estudio) es la provincia más poblada del país y se estima que para 2020 concentre el $25 \%$ de la población nacional (INEC, 2011), esto supone un riesgo mayor para los remanentes ecosistémicos del sector.

A pesar de las características que hacen de la región centro-occidental del Ecuador un área de gran importancia para aves, no se encontraron inventarios de aves publicados para la zona, existen únicamente listados de avistamientos en plataformas como ebird, e inventarios localizados de algunas de las áreas protegidas: Cordillera Chongón Colonche, Cerro Blanco, Cerro Paraíso y Guayaquil (Agreda, 2012; López et al., 2015; Espinoza, 2016; Ruiz et al., 2017), ubicadas dentro de la zona de interés. El 
objetivo de esta investigación es generar un inventario que cubra los vacíos de información existentes sobre la composición de la avifauna en esta zona, cálculos referenciales de la revisión de los inventarios existentes permiten estimar que existen en la zona más de 500 especies de aves, representando el $34 \%$ de la avifauna continental ecuatoriana, que no ha sido sistematizada. Este estudio se enfoca en realizar un inventario de aves en diez áreas de importancia para aves (IBAs) en la región centro-occidental del Ecuador: Boque Protector Cerro Blanco, Isla Santay, Ciénagas de Guayaquil, Reserva Ecológica Manglares Churute, Cerro de Hayas-Naranjal, Manglares del Golfo de Guayaquil, Bosque Protector Molleturo Mollepungo, Tiquibuzo, Bosque Protector
Chongón-Colonche, y Engunga (Birdlife International, 2018); y tres Humedales de Importancia Internacional RAMSAR: Isla Santay, Manglares Churute, y Manglares del Estuario Interior del Golfo de Guayaquil "Don Goyo" (Ramsar Sites Information Service, 2018; MAE, 2018).

\section{Materiales y métodos}

\section{Selección de los sitios de muestreo}

Para la selección de los sitios de muestreo se realizó un taller con profesionales en inventarios biológicos y en registros de avifauna, que incluyó biólogos, guías de turismo y gestores gubernamentales, los cuales realizaron una propuesta conjunta de 33 sitios

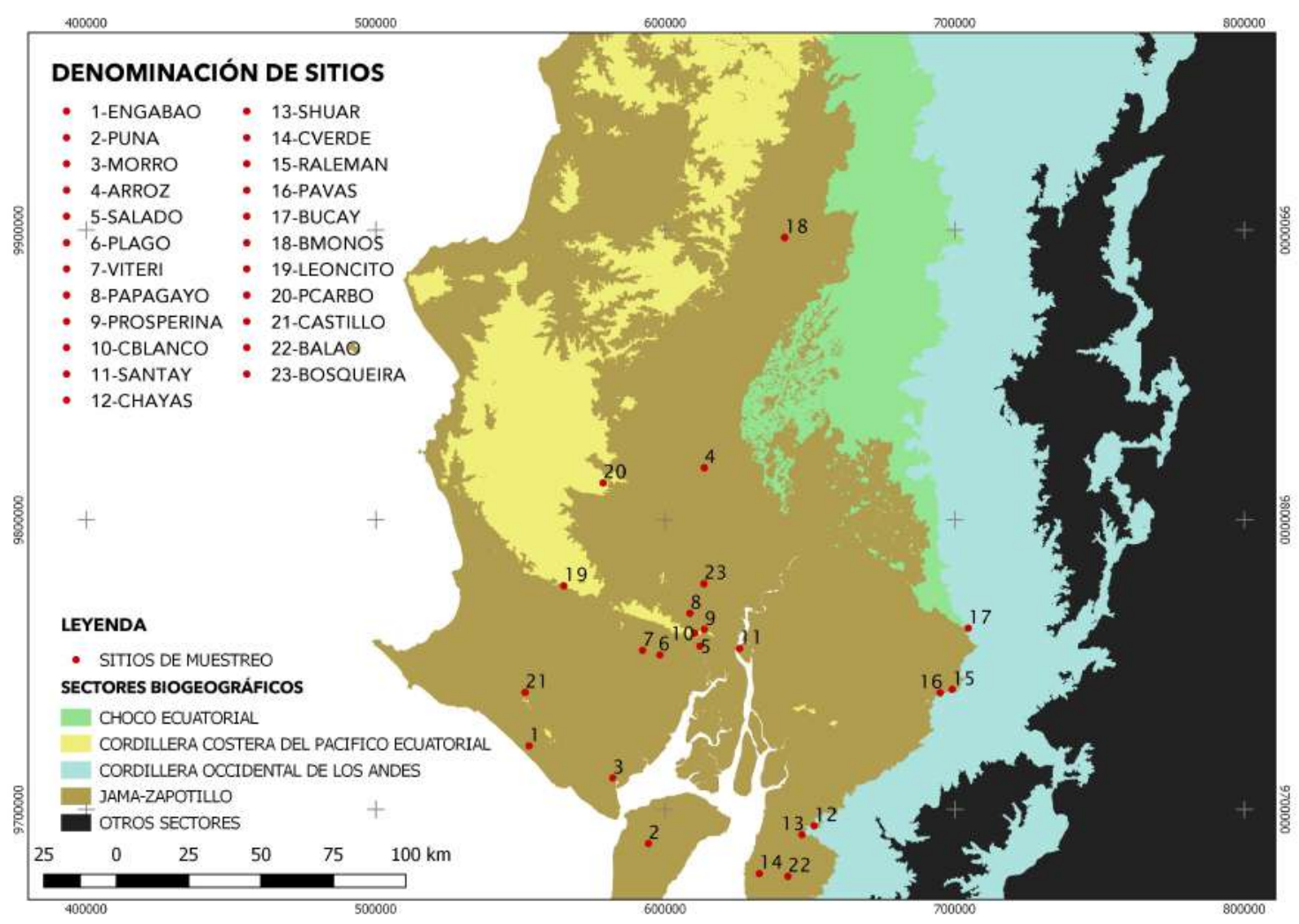

Figura 1. Mapa de la zona de estudio reflejando las unidades biogeográficas de interés. Se muestran las 23 localidades de muestreo (Modificado de MAE, 2013: Sectores biogeográficos).

115

INVESTIGATIO No. 11, noviembre 2018,

Edición Especial, pp. 113-168,

ISSN: 1390 - 6399・ISSN-e: 2602 - 8336 
potenciales para realizar el levantamiento. Los 33 sitios fueron posteriormente evaluados en conjunto con el panel, con base en diez criterios elaborados por el equipo investigador. Los sitios seleccionados alcanzaron un puntaje igual o mayor al $60 \%$ de cumplimiento, indicativo de la relevancia biológica y estado de conservación del sitio (ver criterios de calificación en el Anexo 1).

\section{Área de estudio}

Una vez seleccionados los sitios, el área de estudio comprendió aproximadamente $\quad 15.000 \quad \mathrm{~km}^{2}$, distribuidos en cinco provincias: Guayas, Santa Elena, Bolívar, Cañar y Azuay, y en cuatro sectores biogeográficos (MAE 2012; Figura 1). En el Anexo 2 se muestran las coordenadas y características de cada sitio.

De los 36 ecosistemas presentes en los cuatro sectores biogeográficos, los 23 sitios de muestreo representaron a 11 ecosistemas (Tabla 1).

Tabla 1.

Ecosistemas dominantes en los sitios de muestreo de acuerdo al mapa de ecosistemas del Ecuador continental del Ministerio del Ambiente, 2013.

\begin{tabular}{|c|c|c|c|}
\hline $\begin{array}{c}\text { SECTOR } \\
\text { BIOGEOGRÁFICO }\end{array}$ & $\begin{array}{c}\text { GRUPO DE } \\
\text { ECOSISTEMAS }\end{array}$ & ECOSISTEMAS & SITIOS \\
\hline $\begin{array}{l}\text { Cordillera costera del } \\
\text { pacífico ecuatorial }\end{array}$ & Pacífico ecuatorial & $\begin{array}{l}\text { Bosque Semideciduo de } \\
\text { Cordillera Costera del Pacífico } \\
\text { Ecuatorial }\end{array}$ & 2 \\
\hline $\begin{array}{l}\text { Cordillera costera del } \\
\text { pacífico ecuatorial }\end{array}$ & Pacífico ecuatorial & $\begin{array}{l}\text { Bosque Siempreverde Estacional } \\
\text { Piemontano de Cordillera } \\
\text { Costera del Pacífico Ecuatorial }\end{array}$ & 3 \\
\hline Jama zapotillo & Pacífico ecuatorial & $\begin{array}{l}\text { Bosque Bajo y Arbustal Deciduo } \\
\text { de Tierras Bajas de Jama - } \\
\text { Zapotillo }\end{array}$ & 1 \\
\hline Jama zapotillo & Pacífico ecuatorial & $\begin{array}{l}\text { Bosque Deciduo de Tierras Bajas } \\
\text { de Jama-Zapotillo }\end{array}$ & 2 \\
\hline Jama zapotillo & Pacífico ecuatorial & $\begin{array}{l}\text { Bosque Semideciduo de Tierras } \\
\text { Bajas de Jama -Zapotillo }\end{array}$ & 2 \\
\hline Jama zapotillo & Pacífico ecuatorial & $\begin{array}{l}\text { Bosque Siempreverde Estacional } \\
\text { de Tierras Bajas de Jama - } \\
\text { Zapotillo }\end{array}$ & 1 \\
\hline Jama zapotillo & Pacífico ecuatorial & $\begin{array}{l}\text { Herbazal Inundable Ripario de } \\
\text { Tierras Bajas de Jama -Zapotillo }\end{array}$ & 1 \\
\hline Jama zapotillo & Pacífico ecuatorial & Manglar de Jama -Zapotillo & 2 \\
\hline $\begin{array}{l}\text { Cordillera occidental de los } \\
\text { andes/chocó ecuatorial }\end{array}$ & Cordillera occidental & $\begin{array}{l}\text { Bosque Siempreverde Estacional } \\
\text { Piemontano de Cordillera } \\
\text { Occidental de los Andes }\end{array}$ & 2 \\
\hline $\begin{array}{l}\text { Cordillera occidental de los } \\
\text { andes/chocó ecuatorial }\end{array}$ & Cordillera occidental & $\begin{array}{l}\text { Bosque Siempreverde } \\
\text { Piemontano de Cordillera } \\
\text { Occidental de los Andes }\end{array}$ & 1 \\
\hline Todos & Todos & Intervención & 6 \\
\hline
\end{tabular}

116

INVESTIGATIO No. 11, noviembre 2018, Edición Especial, pp. 113-168, ISSN: 1390 - 6399 • ISSN-e: 2602 - 8336 
En la Tabla 1 se incluye una categoría extra que es Intervención, de acuerdo a la predominancia ecosistémica del sistema de clasificación del Ministerio del Ambiente (2013), especificando que dentro de esta categoría se encontraron mosaicos de áreas boscosas (en su mayoría parches o sucesiones ecológicas), cultivos (principalmente arroz y cacao), plantaciones forestales y zonas semi-urbanizadas presentes en los sitios: Bosque Protector Papagayo de Guayaquil, Hacienda El Castillo, Hacienda Camino Verde, Cerro de Hayas, Arrozales del Norte y Vecindades de Balao.

El régimen de precipitaciones $\mathrm{y}$ temperatura varió entre los sitios de muestreo, teniendo 12 sitios ubicados dentro del bioclima xérico, y 11 sitios dentro del bioclima pluviestacional. Los primeros se encuentran bajo un régimen de precipitaciones menor a los $1.000 \mathrm{~mm}$ por año, y presentan periodos secos de hasta ocho meses por año; los segundos, presentan también una época seca de menor duración (3-5 meses por año) y niveles de precipitación mayores a los $2.000 \mathrm{~mm}$ (MAE, 2012).

\section{Muestreo de aves}

Para registrar las especies de aves, se utilizó la metodología de conteo por puntos para detectar presencias y ausencias, complementados por recorridos a pie por senderos y caminos, priorizando claros en áreas boscosas, sotobosque y dosel de los diferentes tipos de formaciones vegetales (Gallina Tessaro \& Lopez - Gonzalez, 2011). En total se muestreo en 216 puntos de observación distribuidos entre los 23 sitios de muestreo (Ver Anexo 2). El conteo por puntos se realizó con una duración de 15 minutos por punto con un radio de observación de 50 metros, donde se encontraba alguna de las siguientes zonas de presencia de avifauna: flocks (grupos de aves de una misma especie forrajeando), leks (grupos de aves donde realizan exhibiciones para reproducción) o bandadas mixtas; lo cual fue complementado con transectos aleatorios de observación de distancia variable (González-García, 2011), permitiendo mayor registro de especies en cada sitio de muestreo.

Este muestreo se llevó a cabo por cuatro meses durante la transición entre la época de lluvias y la época de sequía (marzo a junio) durante los años 2014 y 2015. Siete sitios de muestreo no pudieron ser replicados entre un año y el siguiente por alteraciones en el paisaje (Pedro Carbo, Hacienda Camino Verde, Balao, Comunidad Shuar, Cerro de Hayas, Bosque Protector Papagayo de Guayaquil, y Área de Recreación Las Pavas) debido a que los sitios no contaban con algún tipo de protección o sufrieron cambios significativos en su cobertura vegetal, lo que incrementó la variabilidad en el esfuerzo de muestreo total.

\section{Identificación de especies}

Para la identificación de las especies se utilizaron varias guías de campo, listas rojas y listados de identificación de aves para el Ecuador (Ridgely et al., 1998; Granizo et al., 2002; Ridgely \& 
Greenfield. 2006; Haase, 2011; McMullan \& Navarrete 2013), y la verificación del estatus taxonómico, endemismo e identificación de gremios tróficos fue realizada en base a la Data Zone de la organización Birdlife International (versión 2018) en su sitio web. Se utilizó además el conocimiento empírico de los comuneros, finqueros y pobladores de las zonas muestreadas con la finalidad de realizar una identificación preliminar de especies previo al muestreo que posteriormente fue corroborada en campo vía fotografías y reconocimiento auditivo de la web https://www.xeno-canto.org.

\section{Análisis de datos}

Una vez realizado el inventario, se elaboró una curva de acumulación de especies para verificar que los resultados fueron significativos, esta se realizó en el software $R$ versión 3.5.1 ejecutado mediante RStudio versión 1.1.456, utilizando los paquetes vegan $\mathrm{y}$ BiodiversityR, y la función specaccum. El método que se utilizó para realizar la curva fue random (acumulación aleatoria) para reducir el impacto del esfuerzo de muestreo y la variabilidad ecosistémica en cada punto y el modelo Arrhenius que considera la relación de las especies esperadas con el tamaño muestral (Zuur et al., 2009).

Finalmente, el inventario levantado fue comparado y verificado con las especies reportadas por publicaciones de referencia en la zona de estudio (Ridgely et al., 1998; Granizo et al., 2002; Ridgely \& Greenfield, 2006; Haase, 2011; McMullan \& Navarrete, 2013) y con otros listados locales de áreas específicas (Agreda, 2012; López et al., 2015; Espinoza, 2016; Ruiz et al., 2017). El inventario preliminar de la zona incluyó el nombre científico de la especie (verificado en Birdlife International, 2018 y IUCN, 2018), nombre común en español e inglés (verificado en Birdlife International, 2018; IUCN, 2018; Ridgely \& Greenfield, 2006), familia, gremio trófico (con base en las categorías de Birdlife International, 2018), hábito (con base en las categorías de Birdlife International, 2018), estado de conservación (en base a las categorías IUCN, 2018), rango de distribución geográfica (con base en la distribución de IUCN, 2018 y Ridgely \& Greenfield, 2006), y hábitat primario (en base a las categorías de Birdlife International, 2018), los cuales fueron revisados y desagregados por sitios de muestreo para su análisis estadístico univariante (análisis de frecuencias).

\section{Resultados}

\section{Selección de sitios de muestreo}

La evaluación técnica-biológica de los sitios permitió la selección de 24 sitios prioritarios para levantar información de avifauna. Todos estos sitios alcanzaron un puntaje mayor o igual al $60 \%$ de los criterios como se muestra en la Tabla 2. Únicamente el sitio Reserva Ecológica Manglares Churute fue excluido del muestreo por dificultades en la obtención de permisos científicos para ingresar al área a realizar los inventarios en el tiempo establecido para la fase de campo del estudio. 
Tabla 2.

Criterios de selección de los sitios de muestreo.

CRITERIOS

\begin{tabular}{|c|c|c|c|c|c|c|c|c|c|c|c|c|c|c|}
\hline & SITIOS & 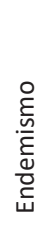 & 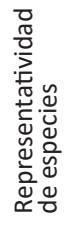 & 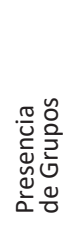 & 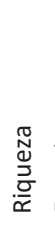 & 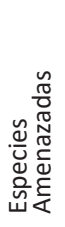 & 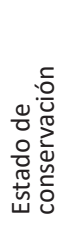 & 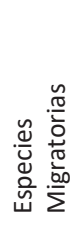 & 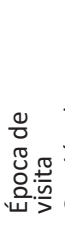 & 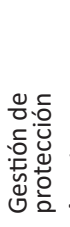 & 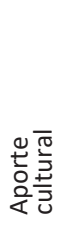 & $\begin{array}{l}\bar{\pi} \\
\stackrel{0}{\circ} \\
\stackrel{\circ}{5} \\
\backsim\end{array}$ & $\underset{\substack{x \\
\sum}}{\stackrel{O}{\Sigma}}$ & $\begin{array}{l}\frac{0}{\pi} \\
\stackrel{ \pm}{0} \\
\stackrel{0}{0} \\
0 \\
0\end{array}$ \\
\hline 1 & Área de Recreación Nacional Isla Santay & 2 & 2 & 3 & 2 & 1 & 2 & 3 & 3 & 3 & 2 & 23 & 30 & 77 \\
\hline 2 & Arrozales Este & 2 & 2 & 3 & 2 & 0 & 0 & 3 & 2 & 0 & 0 & 14 & 30 & 47 \\
\hline 3 & Salto del Armadillo & 3 & 1 & 1 & 1 & 0 & 3 & 2 & 2 & 2 & 2 & 17 & 30 & 57 \\
\hline 4 & Bosque de los Monos Aulladores & 3 & 2 & 1 & 3 & 1 & 3 & 3 & 3 & 3 & 1 & 23 & 30 & 77 \\
\hline 5 & Bosque Nublados de Bucay & 3 & 3 & 3 & 3 & 1 & 3 & 0 & 3 & 3 & 3 & 25 & 30 & 83 \\
\hline 6 & $\begin{array}{l}\text { Área Nacional de Recreación Los Samanes - } \\
\text { Jardín Botánico }\end{array}$ & 3 & 2 & 1 & 2 & 1 & 2 & 0 & 3 & 2 & 1 & 17 & 30 & 57 \\
\hline 7 & Bosque Protector Cerro Paraíso & 2 & 1 & 1 & 1 & 0 & 3 & 0 & 3 & 3 & 1 & 15 & 30 & 50 \\
\hline 8 & Bosque Protector Papagayo & 3 & 2 & 3 & 2 & 1 & 3 & 3 & 3 & 3 & 1 & 24 & 30 & 80 \\
\hline 9 & Bosque Protector La Prosperina & 3 & 3 & 1 & 3 & 2 & 3 & 0 & 3 & 3 & 1 & 22 & 30 & 73 \\
\hline 10 & Bosque Protector Bosqueira & 3 & 2 & 3 & 2 & 1 & 2 & 0 & 3 & 2 & 1 & 19 & 30 & 63 \\
\hline 11 & Hacienda Cacao el Alto (Cerecita) & 3 & 2 & 1 & 2 & 1 & 2 & 0 & 3 & 1 & 2 & 17 & 30 & 57 \\
\hline 12 & Isla Puná & 3 & 3 & 3 & 2 & 1 & 3 & 2 & 3 & 2 & 2 & 24 & 30 & 80 \\
\hline 13 & Sub cuenca del Río Chongón & 3 & 2 & 0 & 2 & 1 & 3 & 0 & 3 & 3 & 1 & 18 & 30 & 60 \\
\hline 14 & $\begin{array}{l}\text { Reversa de Producción Faunística Manglares } \\
\text { El Salado }\end{array}$ & 2 & 2 & 3 & 1 & 0 & 3 & 0 & 3 & 3 & 1 & 18 & 30 & 60 \\
\hline 15 & CRV S Laguna Park & 1 & 1 & 3 & 1 & 0 & 0 & 0 & 3 & 2 & 2 & 13 & 30 & 43 \\
\hline 16 & Refugio de Vida Silvestre El Morro & 0 & 2 & 3 & 2 & 0 & 3 & 3 & 2 & 3 & 3 & 21 & 30 & 70 \\
\hline 17 & Cerro del Muerto_Albarrada & 1 & 1 & 2 & 1 & 0 & 2 & 1 & 3 & 0 & 2 & 13 & 30 & 43 \\
\hline 18 & Hacienda el Castillo (Cerecita) & 3 & 3 & 1 & 3 & 0 & 3 & 0 & 3 & 2 & 1 & 19 & 30 & 63 \\
\hline 19 & Casas Viejas & 2 & 1 & 2 & 1 & 0 & 0 & 1 & 3 & 0 & 1 & 11 & 30 & 37 \\
\hline 20 & Área de Recreación Parque Lago & 3 & 2 & 3 & 2 & 1 & 2 & 1 & 3 & 3 & 1 & 21 & 30 & 70 \\
\hline 21 & Bosque Protector Cerro Blanco & 3 & 2 & 3 & 1 & 1 & 3 & 0 & 3 & 3 & 1 & 20 & 30 & 67 \\
\hline 22 & $\begin{array}{l}\text { Área de Importancia para la Conservación de } \\
\text { las Aves Cerro de Hayas }\end{array}$ & 3 & 1 & 1 & 1 & 1 & 3 & 0 & 3 & 3 & 2 & 18 & 30 & 60 \\
\hline 23 & Comunidad Shuar (Naranjal) & 3 & 2 & 1 & 2 & 1 & 3 & 0 & 3 & 2 & 3 & 20 & 30 & 67 \\
\hline 24 & Reserva Ecológica Manglares Churute & 2 & 3 & 3 & 3 & 2 & 3 & 3 & 3 & 3 & 3 & 28 & 30 & 93 \\
\hline 25 & $\begin{array}{l}\text { Bosque Protector Chongón Colonche - } \\
\text { Salto de Oro }\end{array}$ & 3 & 2 & 2 & 2 & 1 & 2 & 1 & 2 & 3 & 1 & 19 & 30 & 63 \\
\hline 26 & Engabao - Engunga & 3 & 2 & 3 & 2 & 1 & 3 & 1 & 3 & 0 & 1 & 19 & 30 & 63 \\
\hline 27 & Arrozales Norte & 2 & 2 & 3 & 2 & 0 & 0 & 3 & 3 & 0 & 3 & 18 & 30 & 60 \\
\hline 28 & Rancho Alemán & 2 & 1 & 3 & 2 & 2 & 2 & 2 & 2 & 0 & 2 & 18 & 30 & 60 \\
\hline 29 & Recinto Las Piedras & 1 & 2 & 2 & 2 & 3 & 1 & 1 & 3 & 1 & 1 & 17 & 30 & 57 \\
\hline 30 & Área de recreación Las Pavas & 2 & 1 & 3 & 2 & 2 & 2 & 2 & 2 & 2 & 2 & 20 & 30 & 67 \\
\hline 31 & Hacienda Camino Verde & 2 & 2 & 2 & 2 & 2 & 0 & 2 & 3 & 0 & 3 & 18 & 30 & 60 \\
\hline 32 & Área de Recreación El Guayacán & 2 & 2 & 2 & 2 & 2 & 2 & 2 & 3 & 2 & 0 & 19 & 30 & 63 \\
\hline 33 & Balao & 1 & 2 & 1 & 1 & 1 & 1 & 3 & 3 & 2 & 3 & 18 & 30 & 60 \\
\hline
\end{tabular}




\section{Curva de acumulación de especies}

Se construyó una curva de acumulación de especies para verificar la significancia del número de especies registrado en los 23 sitios de muestreo, dando como resultado que según el estimador de Chao, se podrían registrar un máximo de 294 especies, por lo que el inventario debe considerarse preliminar al cubrir el $89,5 \%$ del máximo de especies esperadas en la zona de muestreo de acuerdo a los supuestos utilizados (Figura 2; Anexo $3)$.

\section{Inventario preliminar}

Se registraron un total de 263 especies pertenecientes a 195 géneros y 61 familias (Anexo 4). Las cinco familias más frecuentes de cada tipo de área representaron el $54 \%$ del total de las especies registradas, teniendo la mayor frecuencia Thraupidae (12\%), seguida de Tyrannidae $(10 \%)$,
Accipitridae (6\%), Trochilidae (6\%), Columbidae (4\%), Ardeidae (4\%), Psittacidae (3\%), Icteridae (3\%), Picidae $(3 \%)$ y Furnariidae (3\%); en cuanto a la presencia de especies en los sitios de muestreo, las más frecuentes fueron Cathartes aura y Coragyps atratus en el $100 \%$ de los sitios, Campylorhynchus fasciatus y Furnarius leucopus en el 91,3\% de los sitios, Dives warszewiczi y Forpus coelestis en el $87 \%$ de los sitios, y, Troglodytes aedon y Tyrannus melancholicus en el $82,6 \%$ de los sitios (Tabla 3).

Se registraron además, ocho especies que no habían sido registradas en la zona de estudio: Aglaiocercus coelestis (en los sitios BUCAY y RALEMAN), Coeligena wilsoni (en el sitio BUCAY), Ocreatus underwoodii (en el sitio BUCAY), Rupicola peruvianus (en el sitio BUCAY), Tangara ruficervix (en los sitios BUCAY y RALEMAN), Eubucco

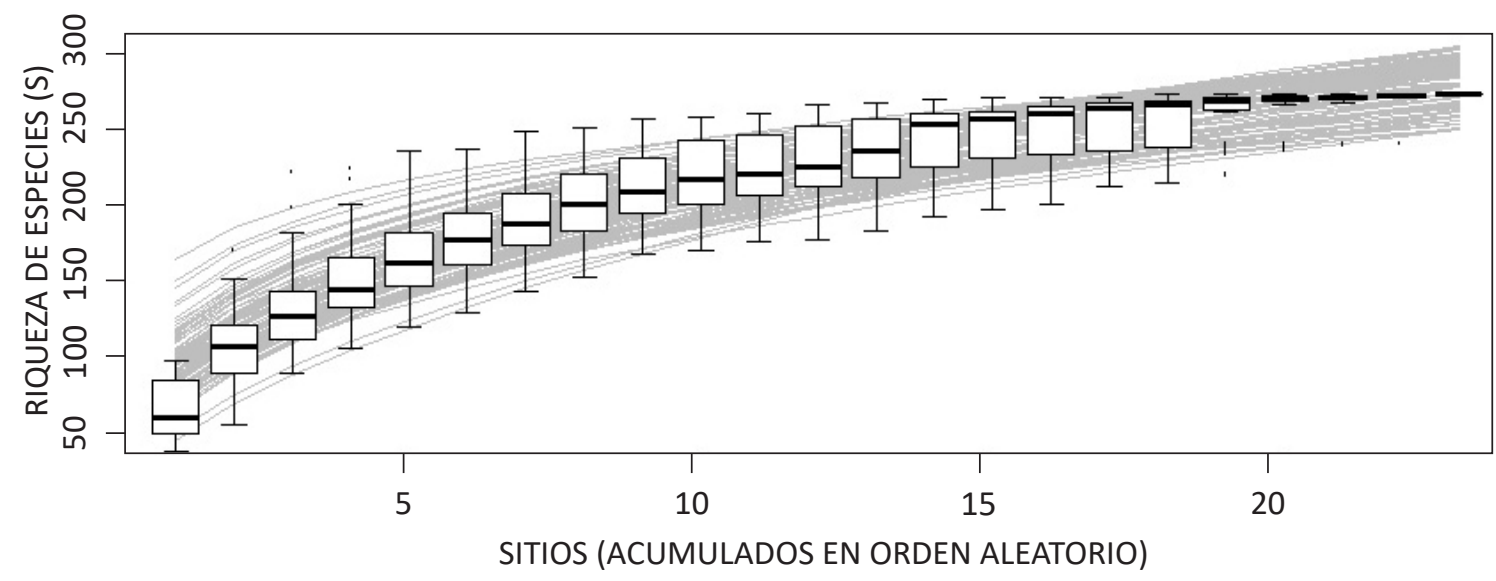

Figura 2. Curva de acumulación de especies ajustada al tamaño de la muestra con método aleatorio de acumulación (orden de los sitios). Los diagramas de cajas muestran un registro por debajo de la media en los primeros sitios de muestreo, un equilibrio en el número registrado de especies a partir del 5to sitio, un registro por sobre la media a partir del sitio 14vo y una baja en la detección de especies desde el sitio 19. 
Tabla 3.

Presencia (\%) acumulada de especies en los sitios de muestreo.

\begin{tabular}{cclc}
\hline$N^{\circ}$ & Familia & \multicolumn{1}{c}{ Especies } & $\begin{array}{c}\text { Presencia en sitios de } \\
\text { muestreo }\end{array}$ \\
\hline 1 & Cathartidae & Cathartes aura & $100,0 \%$ \\
2 & Cathartidae & Coragyps atratus & $100,0 \%$ \\
3 & Troglodytidae & Campylorhynchus fasciatus & $91,3 \%$ \\
4 & Furnariidae & Furnarius leucopus & $91,3 \%$ \\
5 & Icteridae & Dives warszewiczi & $87,0 \%$ \\
6 & Psittacidae & Forpus coelestis & $87,0 \%$ \\
7 & Troglodytidae & Troglodytes aedon & $82,6 \%$ \\
8 & Tyrannidae & Tyrannus melancholicus & $82,6 \%$ \\
9 & Tyrannidae & Myiozetetes similis & $78,3 \%$ \\
10 & Trochilidae & Amazilia amazilia & $73,9 \%$ \\
11 & Ardeidae & Ardea alba & $73,9 \%$ \\
12 & Tyrannidae & Camptostoma obsoletum & $73,9 \%$ \\
13 & Strigidae & Glaucidium peruanum & $73,9 \%$ \\
14 & Thraupidae & Tangara episcopus & $73,9 \%$ \\
15 & Ardeidae & Bubulcus ibis & $69,6 \%$ \\
16 & Icteridae & Molothrus bonariensis & $69,6 \%$ \\
17 & Tyrannidae & Pyrocephalus rubinus & $69,6 \%$ \\
18 & Icteridae & Cacicus cela & $65,2 \%$ \\
19 & Accipitridae & Parabuteo unicinctus & $65,2 \%$ \\
20 & Ardeidae & Butorides striata & $60,9 \%$ \\
\hline
\end{tabular}

bourcierii (en el sitio BUCAY), Henicorhina leucophrys (en los sitios BUCAY, RALEMAN y SHUAR) y Sicalis taczanowskii (en el sitio ENGABAO); una especie de distribución exclusiva amazónica Amazona ochrocephala (en el sitio PCARBO); y una subespecie de la costa pacífica colombiana y el nortoeste del Ecuador Veniliornis callonotus callonotus (en el sitio RALEMAN) distinta morfológicamente a la subespecie registrada en los sitios PLAGO, CBLANCO, PROSPERINA, BALAO, CASTILLO, PUNA y BOSQUEIRA (Veniliornis callonotus major) (Ver Anexo 5).

Referente al tipo de hábito (Birdlife
International 2018) presente en los sitios de muestreo se encontró que la mayoría $(84,4 \%)$ pertenece a aves terrestres (Terrestre), seguidos de aves acuáticas (Acuática 13,3\%), y en tercer lugar aves marinas (Marinas 2,3\%).

Desagregando la composición de especies por tipo de hábito para cada sitio, presentó una tendencia similar de dominancia de especies terrestres en todos los sitios, seguido de especies acuáticas, destacando el bajo porcentaje de las mismas en el sitio BUCAY, y con presencia de aves marinas (en menor porcentaje) en los sitios PAVAS, ENGABAO, PUNA, BUCAY, CVERDE, BMONOS y RALEMAN como se 


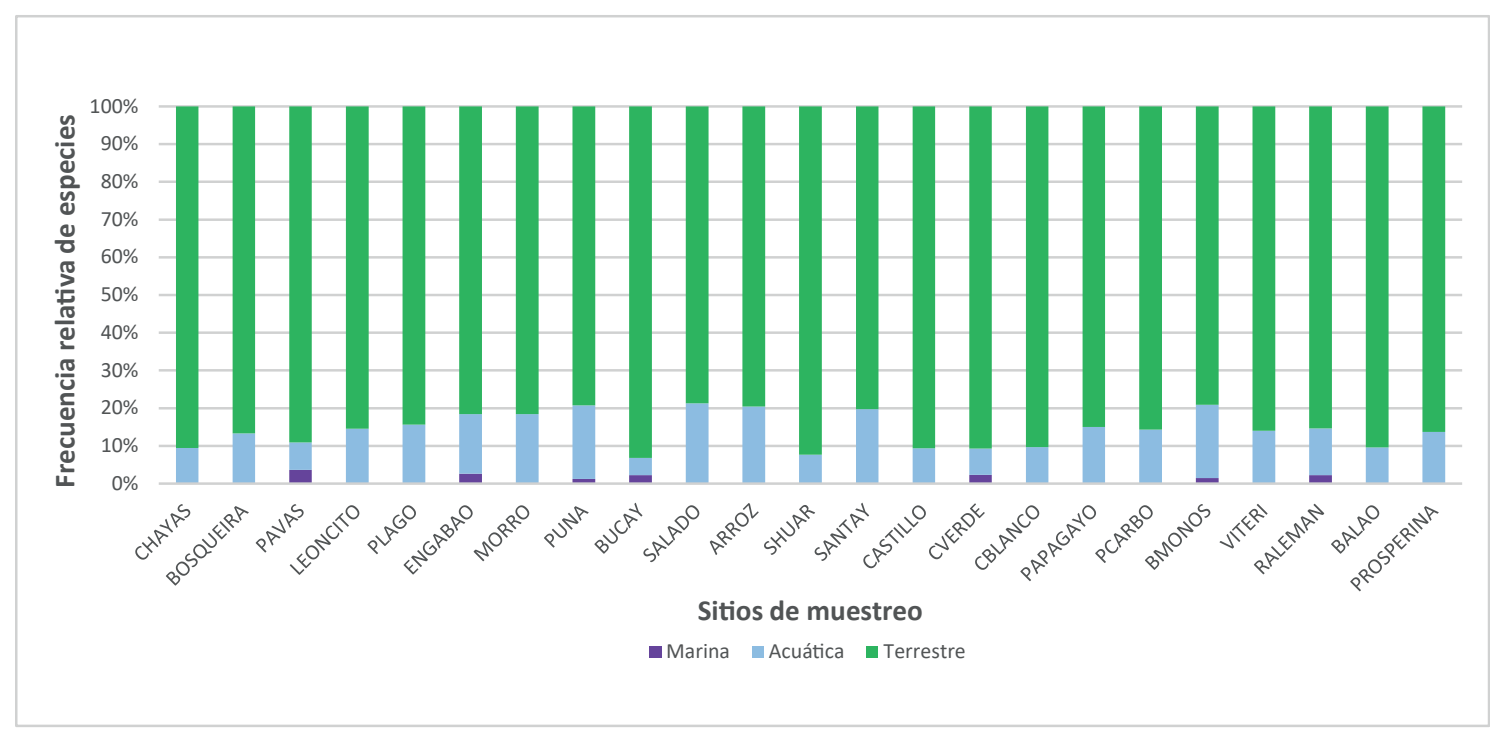

Figura 3. Composición de especies según hábito predominante por sitio de muestreo.

muestra en la Figura 3.

Además de la separación por hábito de las especies encontradas, también se clasificaron a las especies de acuerdo a su hábitat primario, dando como resultados siete hábitats primarios preferidos por las aves registradas: bosques $(56,3 \%)$, humedales $\quad(12,2 \%)$, ecosistemas artificiales (11\%), arbustos (11\%), marino-costero $(4,6 \%)$, pastizales $(2,7 \%)$ y sabanas $(2,3 \%)$. Desagregando estos totales por sitios, se obtuvieron composiciones diferentes, manteniendo la tendencia de predominancia de aves con preferencia de hábitats boscosos en todos los sitios con excepción de MORRO (predominancia de aves de hábitat humedal con $37 \%$ de las especies), SALADO (predominancia de aves de hábitat humedal con $40 \%$ de las especies), ARROZ (predominancia de aves de hábitat humedal con $41 \%$ de las especies), PAPAGAYO (predominancia de aves de hábitat humedal con 33\% de las especies) y BALAO (predominancia de aves de hábitat arbustivo con $27 \%$ de las especies). La presencia de especies con preferencia de hábitat marino-costero fue mayor en los sitios PLAGO, ENGABAO, MORRO, PUNA, SALADO, ARROZ, SANTAY y BMONOS, como se observa en la Figura 4.

Se procedió también a clasificar las especies de acuerdo a su rango de distribución geográfica, donde el mayor porcentaje de especies recayó sobre las especies nativas (46,8\%), seguido de especies migratorias (que incluye migratorias boreales, australes y altitudinales) con el $31,9 \%$ de las especies registradas, que además representan el $29 \%$ de las especies migratorias a nivel nacional (Birdlife International 2018), en tercer lugar se encuentran las especies nativas de rango restringido $(20,2 \%)$ que incluyen a las especies de distribución exclusiva dentro de una EBA (en este caso la región Tumbesina presentó en el inventario 
preliminar el 50,9\% de las especies de esta zona de endemismo en todos los sitios de muestreo, y se encontraron 6,5\% de las especies de la zona de endemismo del Chocó entre los sitios CHAYAS, BUCAY y RALEMAN - ver Figura 5), también se encontraron especies exóticas con un $0,8 \%$ (dos especies), y $0,4 \%$ con la única especie endémica del Ecuador registrada Amazona lilacina.
Desagregando la composición de especies por rango de distribución geográfico para cada uno de los sitios, la principal diferencia es la presencia de especies exóticas y endémicas, estando las primeras presentes en los sitios BOSQUEIRA, SANTAY, CVERDE, CBLANCO, PCARBO, VITERI y PROSPERINA; y las segundas en los sitios SALADO, CBLANCO y SANTAY.

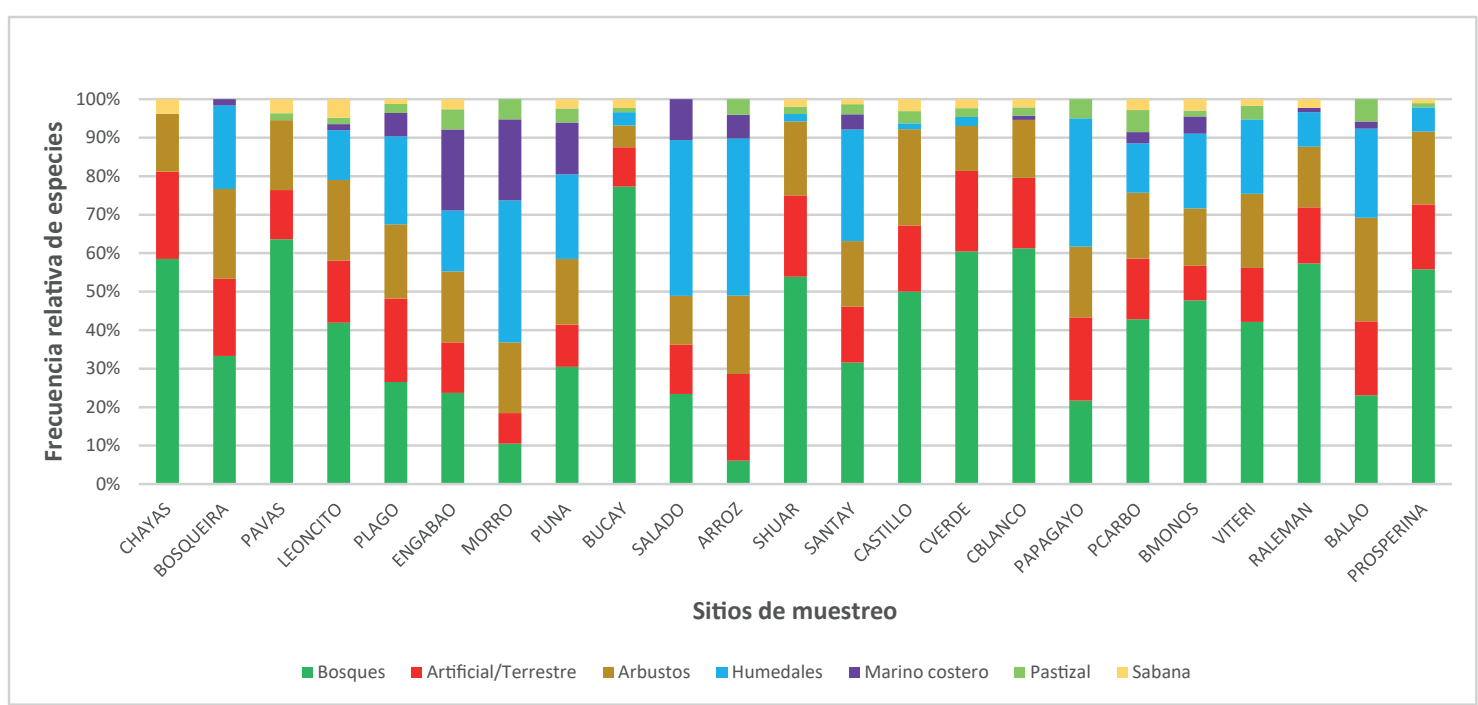

Figura 4. Composición de especies según hábitat primario por sitio de muestreo.

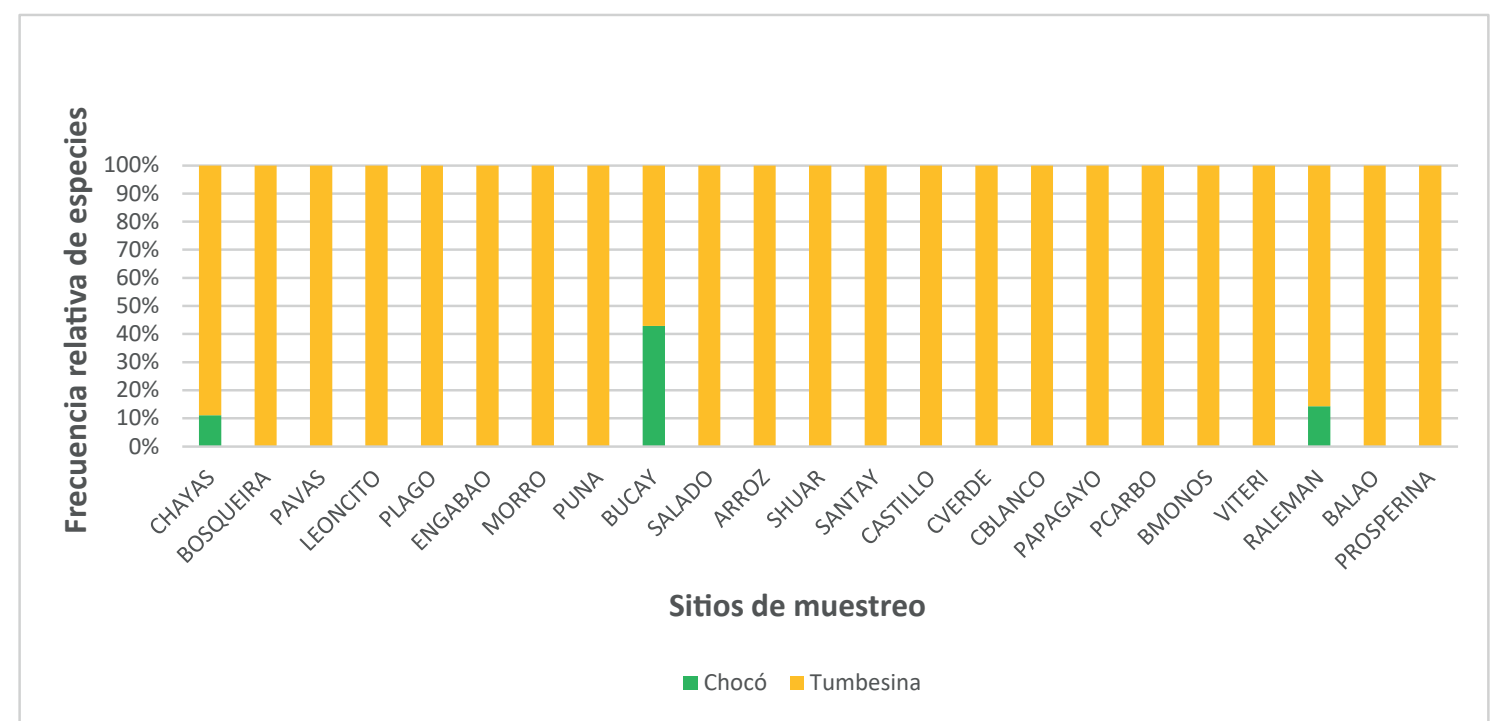

Figura 5. Composición de especies según su rango de distribución restringido por sitio de muestreo. 
El sitio que presentó una dominancia de especies nativas frente al resto de especies fue BUCAY con un 63,6\%; los sitios con mayor porcentaje de especies de rango restringido de distribución fueron CASTILLO $(37,5 \%) \quad y$ PROSPERINA $(34,7 \%)$ como se muestra en la Figura 6.

En cuanto a la clasificación por gremios alimenticios, diez gremios fueron identificados entre las especies registradas en el inventario preliminar, en términos generales el gremio dominante fue Omnívoro con $31,6 \%$ de las especies, seguido de Insectívoros con el 20,2\% y Carnívoros con $14,4 \%$, presentes en todos los sitios de muestreo. Se presentaron diferencias en la presencia de Nectarívoros, ausentes en el sitio

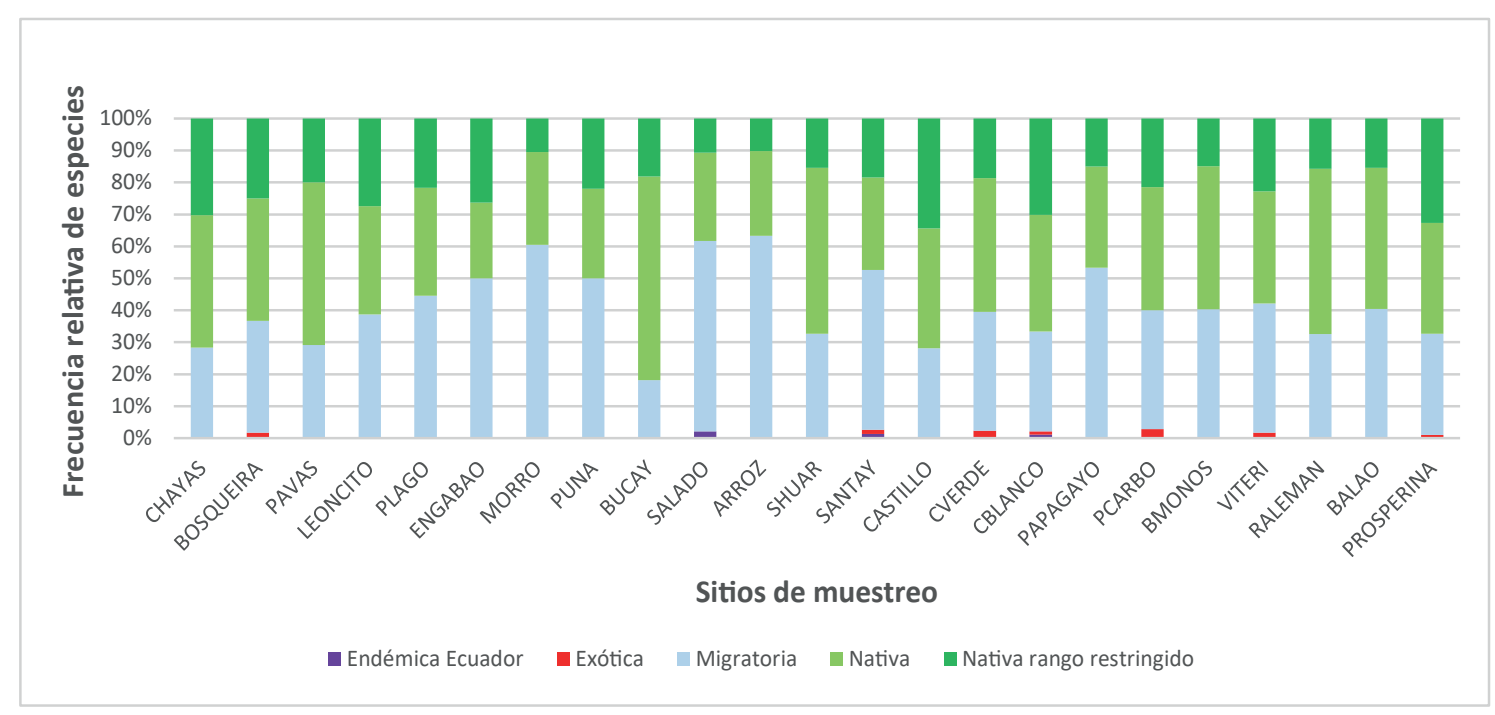

Figura 6. Composición de especies según su rango de distribución geográfica por sitio de muestreo.

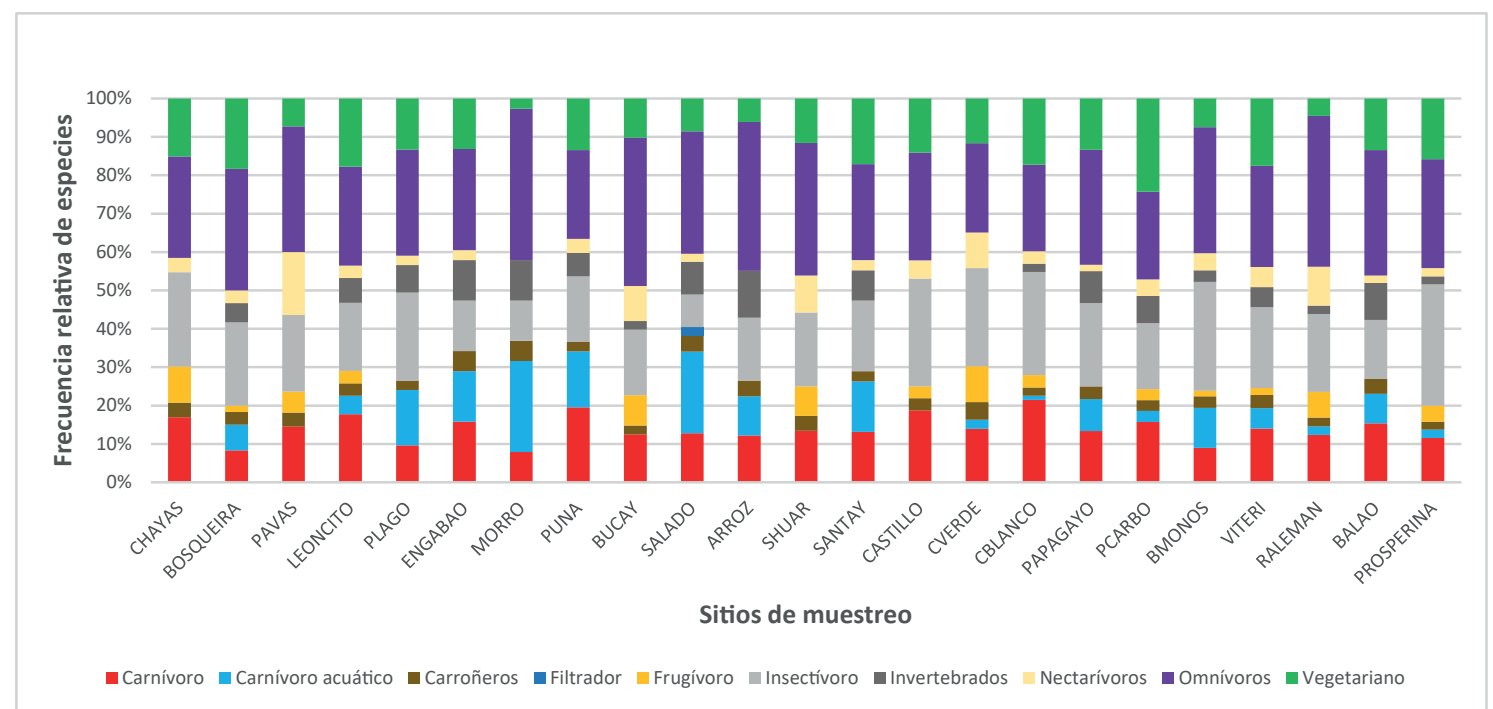

Figura 7. Composición de especies según su gremio alimenticio por sitio de muestreo. 
ARROZ; Invertebrados ausentes en los sitios CHAYAS, PAVAS, SHUAR, CASTILLO y CVERDE; Filtrador únicamente presente en el sitio SALADO (con la especie Phoenicopterus chilensis); Carnívoro acuático ausente en los sitios CHAYAS, PAVAS, BUCAY, SHUAR y CASTILLO (Ver Figura 7).

Finalmente, para cubrir la composición de especies, estas fueron clasificadas también por su grado de amenaza, a lo que se encontró que el $93,5 \%$ de las especies presentes (246) no se encuentran bajo ningún tipo de amenaza; de las especies restantes se encontró un $1,5 \%$ de las especies en la categoría Vulnerable, un $2,7 \%$ de las especies en Casi amenazada, y un 2,3\% de las especies registradas En Peligro. Además, se contrastaron las especies registradas con los totales nacionales, obteniendo como dato más relevante que en el área se encuentra el 30,4\% de las especies En Peligro del país (Ver Tabla 4).
De manera desagregada, las especies bajo la categoría Preocupación menor fueron las predominantes en todos los sitios de muestreo, siendo el sitio MORRO el único que no presentó especies bajo algún grado de amenaza. Los sitios con mayor número de especies incluidas bajo algún grado de amenaza fueron CHAYAS, CVERDE, CBLANCO, PCARBO y PROSPERINA (Ver Figura 8).

Tabla 4.

Composición porcentual de especies según su categoría de amenaza en el inventario preliminar y su representatividad a escala nacional.

\begin{tabular}{lcr}
\hline $\begin{array}{c}\text { Categoría de } \\
\text { Amenaza }\end{array}$ & $\begin{array}{c}\text { Inventario } \\
\text { Preliminar }\end{array}$ & Nacional \\
\hline Casi & $2,7 \%$ & $8,2 \%$ \\
amenazada & $2,3 \%$ & $30,4 \%$ \\
En Peligro & $0,5 \%$ \\
$\begin{array}{l}\text { Preocupación } \\
\text { menor }\end{array}$ & $93,5 \%$ & $0,0 \%$ \\
Vulnerable & $1,5 \%$ & $9,0 \%$ \\
\hline
\end{tabular}

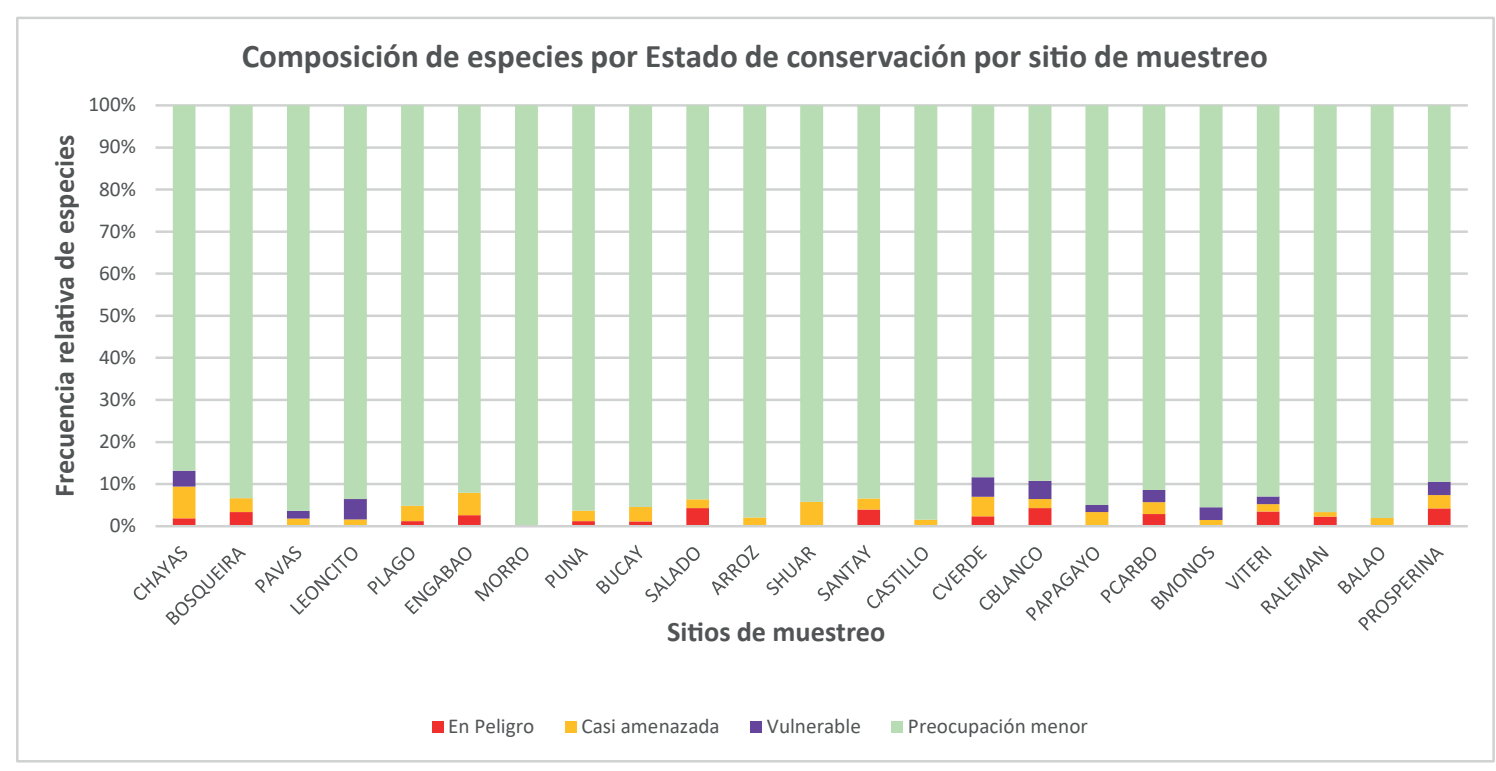

Figura 8. Composición de especies según su grado de amenaza por sitio de muestreo.

$$
125
$$

INVESTIGATIO No. 11, noviembre 2018,

Edición Especial, pp. 113-168,

ISSN: 1390 - 6399・ISSN-e: 2602 - 8336 


\section{Discusión}

La zona de estudio posee características únicas dentro del Ecuador, además de la intersección de áreas de endemismo para aves (TUMBESINA, CHOCÓ y ANDES CENTRALES DEL SUR), es una zona que cuenta con la mayor cuenca hidrográfica de la vertiente occidental del Pacífico en América del Sur (cuenca del Guayas) (Tapia, 2012), la presencia de dos cordilleras (la cordillera costera Chongón-Colonche y el piedemonte de la cordillera de los Andes) (Ministerio del Ambiente, 2016), la región más poblada del país (provincia del Guayas) (INEC, 2010), y una matriz de producción agrícola diversificada (Ministerio del Ambiente, 2016). En general es un área considerada como intervenida y deforestada por la clasificación de cobertura boscosa de Ministerio del Ambiente, y se consideran como áreas naturales únicamente los remanentes boscosos bajo algún esquema de protección (Prefectura del Guayas, 2013).

El inventario preliminar reveló alta diversidad de especies de aves en la zona de estudio (16,2\% de las especies a nivel nacional con $2 \%$ de endemismo), que ha sido ligada únicamente a las áreas protegidas del sector (Greenfield et al., 2006; Greenfield et al., 2010), reconocidas como sitios oficiales de avistamiento de aves, o sitios de importancia para las aves (IBAs) (BirdLife International, 2018). Se desconocía de la ocurrencia de algunas de las especies registradas en una zona tan intervenida y con influencia antrópica, lo que se puede atribuir a la falta de estudios de biodiversidad en esta zona del Ecuador continental (en referencia a las ocho especies no reportadas anteriormente para la zona y las subespecies norteñas también presentes).

Además de las 263 especies registradas en el presente estudio, 307 especies más han sido reportadas en listados locales (Urquizo et al., 2011; Zavala, 2017) y publicaciones ornitológicas de carácter nacional (Ridgely \& Greenfield, 2001; McMullan \& Navarrete, 2013) (el listado consolidado se incluye en el Anexo 6, mas no fue utilizado en las estadísticas al no tener ninguna medida de riqueza específica por sitio), lo que demuestra también una falta de centralización y difusión de la información existente sobre la avifauna local, sumado al factor de que muchas de las listas de aves, incluso las de áreas protegidas, no se encuentran publicadas oficialmente, dificultando su recopilación y revisión.

De las 61 familias encontradas, la zona mostró una composición que incluyó a varias especies de familias indicadoras de buena calidad ecosistémica como Thraupidae, Accipitridae, Trochilidae y Psittacidae (Vásquez \& David, 2017). A diferencia del resto del país, donde la familia Tyrannidae es la más abundante, en la zona de estudio, la familia Thraupidae fue la más diversa, con 15 géneros distintos (Chlorophanes, Chlorornis, Coereba, Dacnis, Hemithraupis, Pipraeidea, Poospiza, Ramphocelus, Rhodospingus, Saltator, Sicalis, Tachyphonus, Tangara y Volatinia), 
denotando la riqueza existente en los remanentes boscosos en las zonas de piedemonte andino y en los ecosistemas secos.

A pesar de estos hallazgos alentadores, es probable que estas observaciones y los registros locales hayan subestimado la diversidad real de la zona por algunas razones. La primera, se debe a que no se consideraron criterios de muestreo como temporadas de reproducción, frecuencias de sonido y muestreos nocturnos, lo que podría reducir significativamente la detectabilidad de las especies de sotobosque y nocturnas, así como también de algunas familias específicas (Bochio \& Anjos, 2012). En segundo lugar, no se consideraron criterios específicos para aumentar la detectabilidad de especies migratorias, como la rotación de la hora de muestreo y la duración del punto de conteo, que en varios estudios han demostrado ser factores clave para registrar especies boreales migratorias raras (Lynch, 1995).

Por otro lado, la curva de acumulación de especies ajustada a los sitios de muestreo, demostró una buena tasa de detectabilidad (un 89,5\% del máximo de especies presentes), denotando efectividad en las técnicas de muestreo utilizadas para un inventario preliminar. A pesar de que se utilizaron supuestos de aleatorización para reducir el impacto del esfuerzo de muestreo desigual por sitio, el estimado debe ser considerado conservador respecto a la diversidad real, y el inventario preliminar deberá ser ahora validado incrementando los sitios de muestreo por tipo de ecosistema o utilizando los listados pre existentes en las áreas protegidas del sector de estudio.

No se recomienda la separación del inventario por tipo de ecosistema, ya que a pesar de existir una dominancia de especies nativas generalistas, seguidas por especies tumbesinas (un $50,9 \%$ de todas las especies endémicas de la región tumbesina presentes) (Birdlife International, 2018b), frente a un $6,5 \%$ de las especies endémicas del Chocó (Birdlife International, 2018a) y 0\% de las especies endémicas de los Andes Centrales del Sur (Birdlife International, 2018c), la influencia de las otras dos EBAs, del ecosistema de Manglar del Golfo y de especies migratorias, es evidente en sitios como ENGABAO, RALEMAN, SHUAR, BALAO, CVERDE, ARROZ y BUCAY, que otorgan una composición particular y enriquecida de especies respecto a su ubicación geográfica (Ver Anexo 7 de fotografías de los sitios de muestreo).

Respecto a las especies bajo alguna categoría de amenaza (17), existieron hallazgos interesantes, por ejemplo la especie Brotogeris pyrrhoptera considerada En Peligro (Birdlife International, 2016a), fue encontrada presente en 12 de los 17 sitios muestreados incluyendo sitios donde según la última evaluación de la especie por la IUCN (2018) ya no se encontraba presente, pudiendo denotar cierta estabilidad en su distribución, y que los criterios evaluados se refieren únicamente a reducciones de abundancia, 
y necesitan ser actualizados. En segundo lugar, se encontró con una alta presencia en los sitios de muestreo ( 7 de 23 ) a la especie también clasificada En Peligro Brotogeris versicolorus, con la particularidad de que se trata de una especie exótica, nativa de la cuenca amazónica (BirdLife International, 2016b) que se muestra en proceso o ya adaptada a las condiciones ecosistémicas del occidente de la cordillera de los Andes (basado en su presencia en ecosistemas de bosque secos como PCARBO, PROSPERINA, CBLANCO, plantaciones de cacao como CVERDE, y en humedales como SANTAY y BOSQUEIRA), y que ya ha sido reportada en otros países como especie introducida y en algunos casos invasora (Woodward \& Quinn, 2011).

En referencia a otra especie detectada, importante de mencionar, es la Amazona lilacina, única especie endémica del Ecuador (Birdlife International, 2016) presente en el inventario preliminar, la cual fue registrada en tres sitios que coinciden con sus requerimientos de hábitat (bosque seco y manglar) (Pilgrim, 2010; Pilgrim \& Biddle 2016), en los sitios CBLANCO, SANTAY y SALADO. Otra especie relevante de mencionar del género Amazona, es la Amazona ochrocephala, especie amazónica registrada en el sitio PCARBO, de la cual se desconoce su procedencia y si ha conformado una población viable, residente o ha sido recientemente introducida. Durante esta investigación, fueron encontradas ocho parejas forrajeando árboles de Cochlospermum vitifolium y sobrevolando el sector Las Piedras en el sitio PCARBO.

Finalmente se puede concluir que, el inventario preliminar levantado presenta novedades y características de interés para ampliar el presente estudio con la inclusión de más sitios de muestreo y listas actualizadas de biodiversidad para mejorar la detectabilidad de especies que fue afectada principalmente por limitaciones metodológicas y temporales; así como el registro de la abundancia de las mismas para poder realizar análisis poblacionales que sirvan de insumo para las instituciones encargadas de la conservación del patrimonio natural del Ecuador.

\section{Referencias}

Agreda, A. (2012). Check list de las Aves de la Cordillera Chongón Colonche y Áreas Protegidas en la Provincia del Guayas, Santa Elena y Manabi. The Nature Conservancy, Aves \& Conservación-Birdlife International en Ecuador. Guayaquil Ecuador, 40.

BirdLife International. (2018). Country profile: Ecuador. Disponible en: http://www.birdlife.org/datazone/country /ecuador.Checked: 2018-10-02

BirdLife International. (2018a). Endemic Bird Areas factsheet: Chocó. Disponible en: http://www.birdlife.org on 02/10/2018.

BirdLife International. (2018b). Endemic Bird Areas factsheet: Tumbesian region. Disponible en: http://www.birdlife.org on 02/10/2018.

BirdLife International. (2018c). Endemic Bird Areas factsheet: Southern Central Andes. Disponible en: http://www.birdlife.org on 02/10/2018. 
BirdLife International. (2016). Amazona lilacina. The IUCN Red List of Threatened Species 2016: e.T22728296A94978463. Disponible en:

http://dx.doi.org/10.2305/IUCN.UK.201 6- 3.RLTS.T22728296A94978463.en

BirdLife International. (2016a). Brotogeris pyrrhoptera. The IUCN Red List of Threatened Species 2016: e.T22685966A93094507. Disponible en:

http://dx.doi.org/10.2305/IUCN.UK.201 6-3.RLTS.T22685966A93094507.en

BirdLife International. (2016b). Brotogeris versicolurus. The IUCN Red List of Threatened Species 2016: e.T22685959A93094097. Disponible en: http://dx.doi.org/10.2305/IUCN.UK.201 6-3.RLTS. T22685959A93094097.en.

Bochio, G. M., \& Anjos, L. (2012). The importance of considering bird detectability for assessing biological integrity. Natureza \& Conservação, 10(1), 72-76.

Clements, J. F., T. S. Schulenberg, M. J. Iliff, D. Roberson, T. A. Fredericks, B. L. Sullivan, and C. L. Wood. (2017). The eBird/Clements checklist of birds of the world: v(2017). Disponible en: http://www.birds.cornell.edu/clementsch ecklist/download/

Espinoza, W. K. (2016). Análisis parcial de la diversidad de aves en el bosque $y$ vegetación protectora Cerro El Paraíso. Tesis de Pregrado. Facultad de Ciencias Naturales. Universidad de Guayaquil. Guayaquil, Ecuador

FAO. (2015). Evaluación de los recursos forestales mundiales 2015. Informe Nacional: Ecuador.

Flanagan, J. N., Franke, I., \& Salinas, L. (2005). Aves y endemismo en los bosques relictos de la vertiente occidental andina del norte del Perú y sur del Ecuador. Revista peruana de biología, 12(2), 239-248.
Freile, J., Ahlman, R., Ridgely, R., Solano -Ugalde, A., Brinkhuizen, D. \& Navarrete, L. (2018). Species lists of birds for South American countries and territories: Ecuador. Version 15/Feb/2018. Disponible en: http://www.museum.lsu.edu/ Remsen/S ACCCountryLists.htm

Gallina-Tessaro, S., \& Lopez-Gonzalez, C. (2011). Manual de Técnicas para el estudio de la Fauna. México.

González-García, F. (2011). Métodos para contar aves terrestres. Manual de Técnicas para el estudio de la Fauna, 1, 128-147.

Granizo, T., Pacheco, C., Ribadeneira, M. B., Guerrero, M., \& Suárez, L. (2002). Libro rojo de las aves del Ecuador. Quito: Simbioe.

Greenfield, P., Krohnke, B., Campbell, I., Dávalos, A., \& Guerra, K. (2010). Actualización de la estrategia nacional de aviturismo. Ecuador: Ministerio de Turismo. Disponible en: http://suia. ambiente. gob. ec/documents/783967/890253/Actualizac $\mathrm{i} \% \quad \mathrm{C} 3 \% \quad \mathrm{~B} 3 \mathrm{n}+\mathrm{de}+\mathrm{la}+$ Estrategia+ Nacional + de + Aviturismo. PDF/0f436463-c0c7-43c7-b024-395a751 $5 \mathrm{flf} 9$.

Greenfield, P., Rodríguez, O., Krohnke, B., \& Campbell, I. (2006). Estrategia nacional para el manejo y desarrollo sostenible del aviturismo en Ecuador. Quito, Ecuador: Mindo Cloudforest Foundation.

Haase, B. J. M. (2011). Aves marinas de Ecuador continental y acuáticas de las piscinas artificiales de Ecuasal. Aves \& Conservación, BirdLife International and Ecuasal SA: Guayaquil.

Instituto Nacional de Estadísticas y Censos. (2010). VII Censo de Población y VI de Vivienda.

Instituto Nacional de Estadísticas y Censos. (2011). ¿Cómo crecerá la población en Ecuador? 
IUCN. (2018). The IUCN Red List of Threatened Species. Version 2018-1. Disponible en: $<\mathrm{http}$ ://www.iucnredlist.org $>$.

López, J., Quinteros, A., \& Castro, J. (2015). Aves endémicas tumbesinas en la zona de visitantes de Cerro Blanco en Guayaquil 2013-2015. Revista DELOS Desarrollo Local Sostenible. ISSN, 1988, 5245.

Lynch, J. (1995). Effects of point count duration, time-of-day, and aural stimuli on detectability of migratory and resident bird species in Quintana Roo, Mexico. En: Ralph, C.; Sauer, J.; Droege, S., technical editors.1995. Monitoring bird populations by point counts. Gen. Tech. Rep. PSW-GTR-149. Albany, CA: US Department of Agriculture, Forest Service, Pacific Southwest Research Station: p. 1-6, 149.

McMullan, M., \& Navarrete, L. (2013). Fieldbook of the Birds of Ecuador: including the Galápagos Islands. Fundación de conservación Jocotoco.

Ministerio del Ambiente. (2016). Análisis de la deforestación en el Ecuador continental 1990 - 2014. Quito - Ecuador.

Ministerio del Ambiente. (2015). Estadísticas de Patrimonio Natural. Quito - Ecuador.

Ministerio del Ambiente. (2018). Informe nacional sobre la aplicación de la convención de Ramsar sobre los humedales. Informes Nacionales de la $13^{\text {a }}$ Reunión de la Conferencia de las Partes Contratantes. Dubái (Emiratos Árabes Unidos).

Ministerio del Ambiente. (2012). Mapa de sectores biogeográficos del Ecuador continental.

Ministerio del Ambiente (2013). Metodología para la Representación Cartográfica de los Ecosistemas del Ecuador Continental.

Parker III, T. A., Schulenberg, T. S., Kessler, M., \& Wust, W. H. (1995). Natural history and conservation of the endemic avifauna in north-west Peru. Bird Conservation International, 5(2-3), 201-231.

Pilgrim, M. (2010). An Investigation into the taxonomic status of Amazona autumnalis lilacina using a multidisciplinary approach. Tesis Doctoral. Liberpool John Moores University.

Pilgrim, M. \& Biddle, R., eds. (2016). EAZA Best practice guidelines for Ecuadorian Amazon Parrot, Amazona lilacina, European Association of Zoos and Aquaria. Disponible en:

http://www.eaza.net/assets/Uploads/CCC /2016-Ecuadorian-amazon-EAZA-Best-P ractice-Guidelines-Approved.pdf

Prefectura del Guayas. (2013). Análisis de vacios de conservación para la provincia del Guayas y mapa de vegetación y uso de suelo.

RAMSAR. (2018). Annotated List of Wetlands of International Importance. Ramsar Sites Information Service Annotated List of Wetlands of International Importance. Ecuador.

Remsen, J. V., Jr., J. I. Areta, C. D. Cadena, S. Claramunt, A. Jaramillo, J. F. Pacheco, M. B. Robbins, F. G. Stiles, D. F. Stotz, and K. J. Zimmer. Version 17-Julio (2018). A classification of the bird species of South America. American Ornithologists' Union. Disponible en: http://www.museum.lsu.edu/ Remsen/S ACCBaseline.htm

Ridgely, R., \& Greenfield, P. (2006). Aves del Ecuador. Guía de campo, 1.

Ridgely, R. S., Guerrero, M., \& Greenfield, P. J. (1998). Una lista anotada de las Aves del Ecuador Continental. Fundacion Ornitologica del Ecuador, CECIA.

Ruiz, J. L., Murillo, J. R., \& Merino, J. A. (2017). Diversidad de aves en gradientes 
urbanos, potencial uso recreativo $y$ aviturístico en la ciudad de Guayaquil. Turismo y Desarrollo Local, (22).

Tapia Aldas, J. C. (2012). Modelización hidrológica de un área experimental en la cuenca del Río Guayas en la producción de caudales y sedimentos. Tesis Doctoral. Facultad de Ciencias Agrarias y Forestales. Universidad Nacional de La Plata.

Urquizo, R., Viejó, L., Carvajal, R., Salas, J., \& Bustamante, M. (2011). Biodiversidad del Guayas: conociendo nuestra verdadera riqueza. Guayaquil: Gobierno Provincial del Guayas-Dirección de Medio Ambiente. Poligráfica y Finding Species.

Vásquez, C., \& David, L. (2017). Perturbación ambiental analizada por medio de bioindicadores en un fragmento de bosque seco tropical (Bs-T) localizado en el área perimetral del aeropuerto Jorge Isaacs (Albania, La Guajira, Colombia).

Woodward, S. L., \& Quinn, J. A. (2011). Encyclopedia of invasive species: from Africanized honey bees to zebra mussels (Vol. 2). ABC-CLIO.

Zavala-Becilla, E. (2017). Aves de la isla Santay (Guayas-Ecuador): Lista de especies./ Birds of Santay island (Guayas-Ecuador): Species checklist. Versión 2017.1.

Zuur, A., Ieno, E., Walker, N., Saveliev, A., \& Smith, G. (2009). Mixed effects models and extensions in ecology. R. Gail M, Krickeberg K, Samet JM, Tsiatis A, Wong W, editors. New York, NY: Spring Science and Business Media. 
Felipe Espinoza, Emilio Testa, Carlos Cruz, Alexander Matecki, Julián Pérez, Diego Manosalvas, Carola Bohórquez

Anexo 1. Criterios de calificación de los sitios de muestreo.

\begin{tabular}{|c|c|c|c|c|c|}
\hline & \multicolumn{4}{|c|}{ Calificación } \\
\hline & Criterios & 3 & 2 & 1 & 0 \\
\hline & Nivel de endemismo & Alto & Medio & Bajo & Nulo \\
\hline 2 & Representatividad de especies & $\begin{array}{c}\text { Alto \% de especies } \\
\text { representativas de } \\
\text { la zona }\end{array}$ & & $\begin{array}{l}\text { Bajo \% de especies } \\
\text { representativas de } \\
\text { la zona }\end{array}$ & $\begin{array}{l}\text { Sin especies } \\
\text { representativas de } \\
\text { la zona }\end{array}$ \\
\hline 3 & Presencia de grupos & $\begin{array}{l}\text { Sitio conocido por } \\
\text { albergar grandes } \\
\text { grupos de } 1 \\
\text { especie }\end{array}$ & $\begin{array}{c}\text { Sitio conocido por } \\
\text { albergar grandes } \\
\text { grupos de varias } \\
\text { especies }\end{array}$ & $\begin{array}{l}\text { Sitio conocido por } \\
\text { albergar grupos } \\
\text { pequeños de varias } \\
\text { especies }\end{array}$ & $\begin{array}{c}\text { No se han } \\
\text { observado grupos } \\
\text { en el sitio }\end{array}$ \\
\hline 4 & Riqueza de especies (S) & Alta riqueza & Media riqueza & $\begin{array}{l}\text { Baja riqueza con } \\
\text { especies raras }\end{array}$ & Baja riqueza \\
\hline 5 & Especies amenazadas & $\begin{array}{c}\text { Con más de } 3 \\
\text { especies } \\
\text { amenazadas }\end{array}$ & $\begin{array}{l}\text { Con } 2 \text { especies } \\
\text { amenazadas }\end{array}$ & $\begin{array}{l}\text { Con } 1 \text { especie } \\
\text { amenazada }\end{array}$ & $\begin{array}{l}\text { Sin especies } \\
\text { amenazadas }\end{array}$ \\
\hline 6 & Estado de conservación & Muy bueno & Bueno & Regular & Malo \\
\hline 7 & Especies migratorias & $\begin{array}{c}\text { Con más de } 5 \\
\text { especies } \\
\text { migratorias }\end{array}$ & $\begin{array}{c}\text { Entre } 3-5 \text { especies } \\
\text { migratorias }\end{array}$ & $\begin{array}{l}1-3 \text { especies } \\
\text { migratorias }\end{array}$ & $\begin{array}{l}\text { Sin especies } \\
\text { migratorias }\end{array}$ \\
\hline 8 & Época de visita & Todo el año & Entre 8-10 meses & Entre 6-8 meses & Menos de 6 meses \\
\hline 9 & Subsistema de protección & $\begin{array}{l}\text { Área protegida } \\
\text { constituida }\end{array}$ & $\begin{array}{c}\text { Área protegida en } \\
\text { proceso de } \\
\text { constitución }\end{array}$ & $\begin{array}{c}\text { Área de } \\
\text { conservación } \\
\text { privada }\end{array}$ & $\begin{array}{l}\text { Sin algún tipo de } \\
\text { protección }\end{array}$ \\
\hline 10 & Aporte cultural a la población & $\begin{array}{c}\text { Cuenta con } \\
\text { poblaciores locales } \\
\text { que reconocen a la } \\
\text { avifauna }\end{array}$ & $\begin{array}{c}\text { Cuenta con } \\
\text { poblaciones locales } \\
\text { que no reconocen } \\
\text { a la avifauna }\end{array}$ & $\begin{array}{c}\text { Cuenta con } \\
\text { investigadores } \\
\text { conocedores de la } \\
\text { avifauna local }\end{array}$ & $\begin{array}{l}\text { No cuenta con } \\
\text { poblaciones locales } \\
\text { ni investigadores }\end{array}$ \\
\hline
\end{tabular}

Anexo 3. Código de elaboración de la curva de acumulación d especies en R.

\#Instalación de paquetes

install.packages("vegan")

install.packages("BiodiversityR")

library(BiodiversityR)

library(vegan)

\#Cargado de bases de datos (conteo y ambiental)

BirdData<-read.csv("Aves.csv", header=TRUE, sep= ";", row.names=1)

BirdData.env<-read.csv("Eco.csv", header=TRUE, sep= ";", row.names=1)

\#Curva con método aleatorio de acumulación (peso en el número de observaciones por sitio)

sp2 <- specaccum(BirdData, "random", w = BirdData.env\$OBS)

boxplot(sp2, col="yellow", add=TRUE, pch="+")

\#Curvas de acumulación superpuestas basadas en el modelo Arrhenius de especie/tamaño de muestra

mods $<$ - fitspecaccum(sp2, "arrh")

plot(mods, col="grey", ylab = "Species richness")

boxplot(sp2, col = "white", border = "black", lty=1, cex=0.3, add= TRUE)

132

INVESTIGATIO No. 11, noviembre 2018,

Edición Especial, pp. 113-168,

ISSN: 1390 - 6399・ISSN-e: 2602 - 8336 


\begin{tabular}{|c|c|c|c|c|c|c|c|c|c|c|c|c|c|c|c|c|c|c|c|c|c|c|}
\hline$\frac{3}{4}$ & $\stackrel{్}{\circ}$ & 只 & 点 & $\vec{m}$ & 帝 & -7 & $\stackrel{\circ}{\circ}$ & 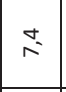 & 品 & t & $\stackrel{m}{\stackrel{m}{I}}$ & $\stackrel{\text { : }}{\text { D }}$ & 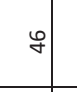 & 点 & 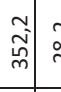 & ט. & & 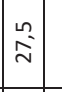 & ธิ & A & $\bar{f}$ & in \\
\hline 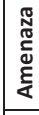 & $\stackrel{\bar{g}}{\Sigma}$ & 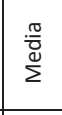 & $\frac{\mathbb{0}}{4}$ & $\underline{z}$ & \begin{tabular}{|l|l|} 
\\
\end{tabular} & $\frac{\pi}{4}$ & $\frac{\frac{.0}{0}}{\mathrm{w}}$ & 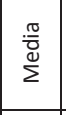 & 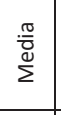 & $\frac{0}{4}$ & $\frac{0}{4}$ & $\frac{0}{4}$ & $\frac{\mathbb{s}}{2}$ & $\left.\frac{⿱ 乛}{4}\right]$ & $\frac{\pi}{4}$ & \begin{tabular}{r|r|}
$\frac{\pi}{0}$ & $\frac{\pi}{\pi}$ \\
\end{tabular} & & $\frac{1}{2}$ & $\frac{\pi}{4}$ & $\frac{\tilde{z}}{z}$ & & 嗬 \\
\hline 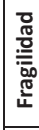 & $\frac{\pi}{4}$ & $\begin{array}{l}\frac{.0}{\overline{0}} \\
\frac{10}{2}\end{array}$ & $\frac{\pi}{4}$ & $\frac{s}{2}$ & 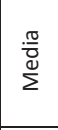 & \begin{tabular}{|l|l}
$\frac{4}{50}$ \\
3 \\
3
\end{tabular} & $\frac{\tilde{T}}{\bar{\sigma}}$ & 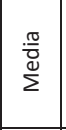 & $\frac{\tilde{J}}{4}$ & $\frac{\tilde{J}}{4}$ & $\frac{\mathrm{J}}{4}$ & $\frac{\pi}{4}$ & $\frac{\mathbb{s}}{z}$ & $\sum_{\substack{\frac{2}{n} \\
\sum}}$ & $\frac{\pi}{4}$ & 童 & & $\frac{\pi}{z}$ & $\frac{\pi}{4}$ & $\frac{s}{z}$ & & $\frac{\pi}{4}$ \\
\hline \begin{tabular}{|l}
$\bar{z}$ \\
$\underline{\underline{E}}$
\end{tabular} & 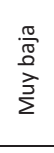 & 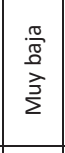 & 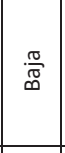 & $\frac{\pi}{z}$ & 施 & 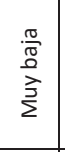 & 需 & 涼 & 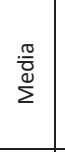 & 产餝 & 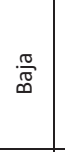 & 儒 & $\frac{\mathbb{s}}{z}$ & 埕| & $\left.\frac{\pi}{\pi}\right)$ & 需 & & $\frac{s}{z}$ & 漶 & $\frac{s}{z}$ & 离 & 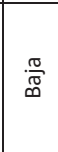 \\
\hline 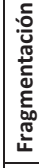 & 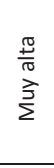 & $\frac{\pi}{4}$ & $\frac{\pi}{4}$ & $\frac{\pi}{z}$ & 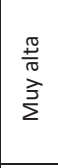 & \begin{tabular}{|l}
$\frac{5}{50}$ \\
$\bar{\sum}$ \\
$\sum$
\end{tabular} & $\frac{\mathbb{\pi}}{\sqrt{0}}$ & 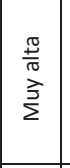 & 童 & $\frac{\pi}{4}$ & $\frac{5}{4}$ & $\frac{\pi}{4}$ & $\frac{s}{z}$ & 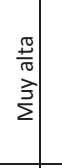 & $\frac{\pi}{4}$ & 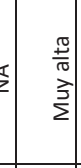 & & $\frac{\pi}{2}$ & $\frac{\sqrt{\frac{\pi}{4}}}{4}$ & $\frac{\xi}{z}$ & $\sum_{\Sigma}^{2}$ & $\frac{\pi}{4}$ \\
\hline 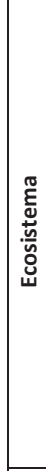 & 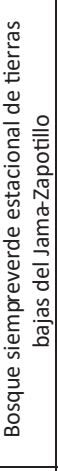 & 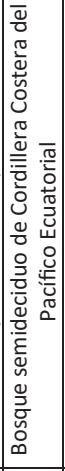 & 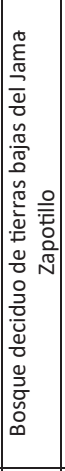 & 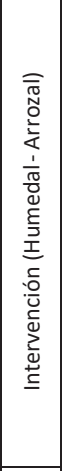 & 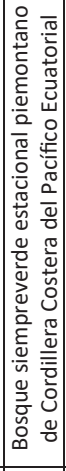 & 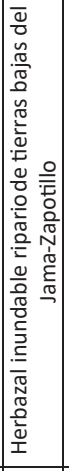 & 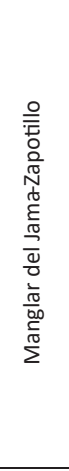 & 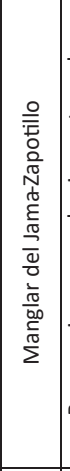 & 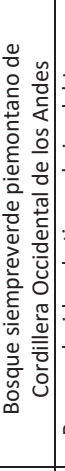 & 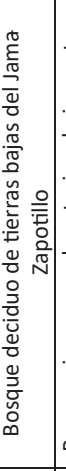 & 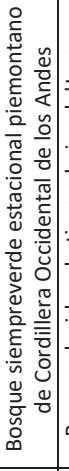 & 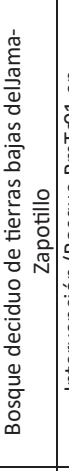 & 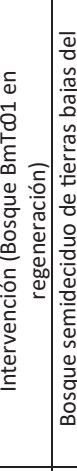 & 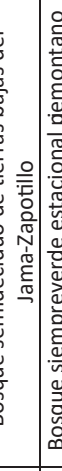 & 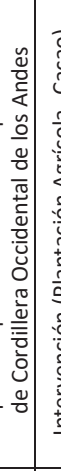 & 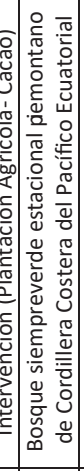 & 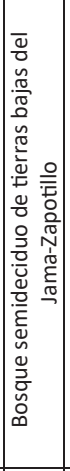 & 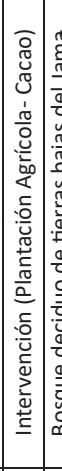 & 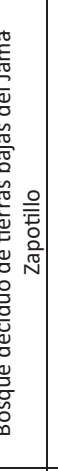 & 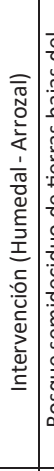 & 离 & 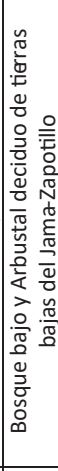 \\
\hline - & & $\approx$ & $r$ & $\sigma$ & $\stackrel{m}{\sim}$ & 요 & 0 & $\infty$ & 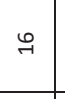 & $\infty$ & $\sigma$ & & $m$ & เ & 凡 & $m$ & & r & $\approx$ & $\infty$ & $\stackrel{m}{m}$ & $\infty$ \\
\hline$>$ & 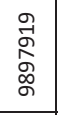 & 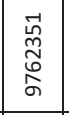 & 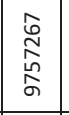 & 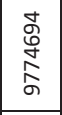 & 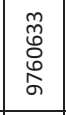 & 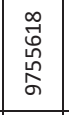 & $\begin{array}{l}\infty \\
\infty \\
\omega \\
\vdots \\
\sigma\end{array}$ & 边 & 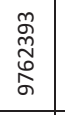 & $\begin{array}{l}\text { 志 } \\
\text { 趸 } \\
\text { a }\end{array}$ & 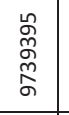 & 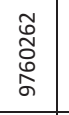 & 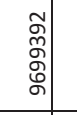 & 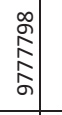 & 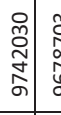 & 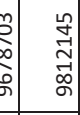 & & 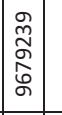 & & 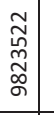 & 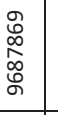 & 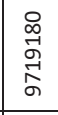 \\
\hline$\times$ & $\stackrel{m}{\Phi}$ & \begin{tabular}{|l}
0 \\
0 \\
0 \\
0 \\
0 \\
\end{tabular} & 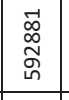 & 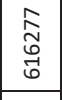 & 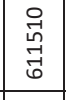 & 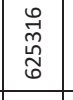 & $\begin{array}{l}\overrightarrow{0} \\
\stackrel{0}{0} \\
\stackrel{0}{0}\end{array}$ & & $\begin{array}{l}7 \\
\text { t } \\
\text { g. } \\
\end{array}$ & $\begin{array}{l}\text { o } \\
\text { o. } \\
0 \\
\end{array}$ & 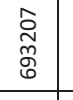 & & 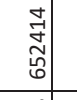 & $\begin{array}{l}0 \\
0 \\
0 \\
0 \\
0\end{array}$ & \begin{tabular}{c|c}
0 & \\
0 \\
0 \\
$o$ \\
0 \\
0
\end{tabular} & 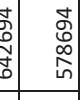 & & $\begin{array}{l}\hat{\Xi} \\
\tilde{0} \\
0 \\
\end{array}$ & & 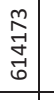 & 离 & 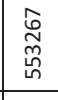 \\
\hline 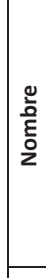 & 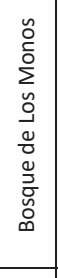 & 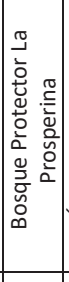 & 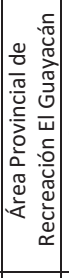 & & 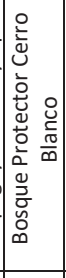 & 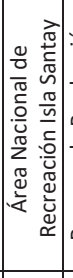 & 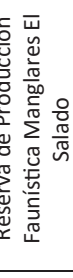 & 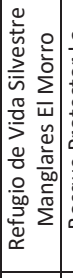 & 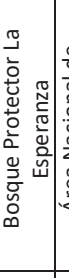 & 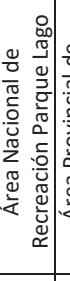 & 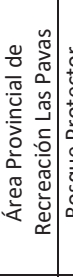 & 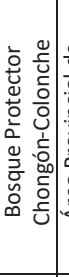 & 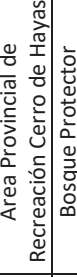 & & 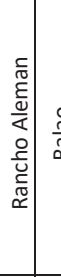 & 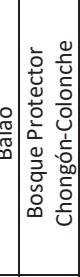 & 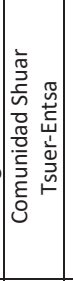 & 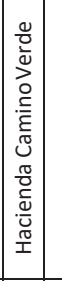 & $z$ & 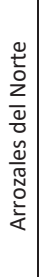 & $\bar{a}$ & 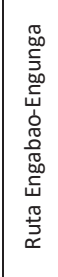 \\
\hline$\frac{0}{5}$ & & 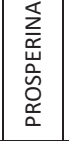 & \begin{tabular}{|l}
$\overline{\bar{x}}$ \\
岁
\end{tabular} & 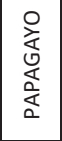 & 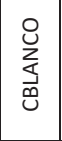 & 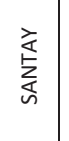 & 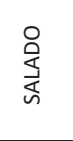 & 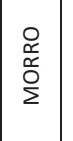 & 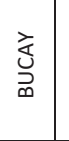 & 过 & $\sum_{\substack{a \\
a}}^{u}$ & 号 & 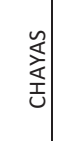 & 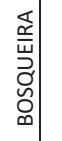 & 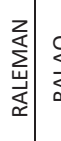 & 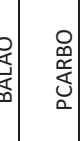 & & 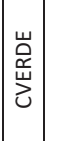 & & 就 & $\frac{1}{3}$ & 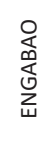 \\
\hline
\end{tabular}


Felipe Espinoza, Emilio Testa, Carlos Cruz, Alexander Matecki, Julián Pérez, Diego Manosalvas, Carola Bohórquez

\begin{tabular}{|c|c|c|c|c|c|c|c|c|c|c|c|c|c|c|c|c|c|c|c|c|c|c|c|c|c|c|c|}
\hline & 递 & 离 & 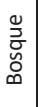 & 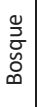 & & & & 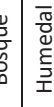 & 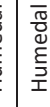 & 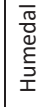 & 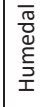 & 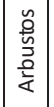 & $\begin{array}{l}\frac{0}{3} \\
\text { o } \\
0\end{array}$ & 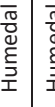 & 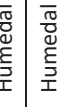 & \begin{tabular}{|l} 
产 \\
总
\end{tabular} & 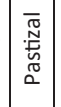 & 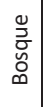 & 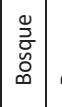 & & 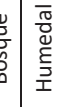 & & \begin{tabular}{|l|}
$\frac{\pi}{0}$ \\
$\frac{w}{0}$ \\
$\tilde{d}$ \\
\end{tabular} & $\begin{array}{l}\text { 总 } \\
\text { : } \\
\text { a }\end{array}$ & 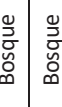 & & \\
\hline & 总 & 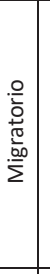 & 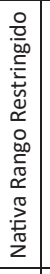 & 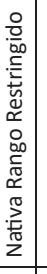 & 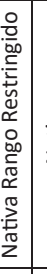 & 眼 & 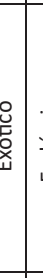 & 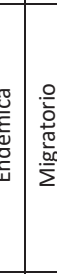 & 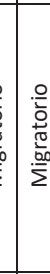 & 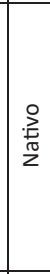 & 总 & 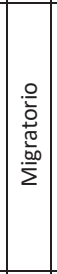 & 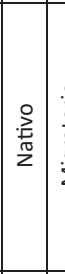 & $\sum^{\frac{60}{\Sigma}}$ & 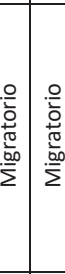 & 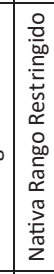 & 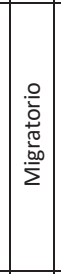 & $\mid \begin{array}{l}\frac{F}{\pi} \\
z\end{array}$ & 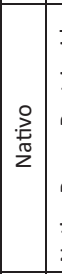 & & 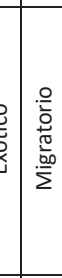 & 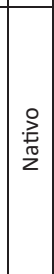 & 奱 & 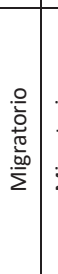 & & & \\
\hline & & : & u & $u$ & u & 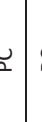 & 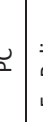 & 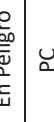 & u & a & 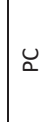 & u & $u$ & $\begin{array}{l}u \\
a\end{array}$ & u & u & u & $u$ & 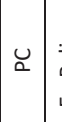 & 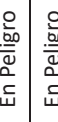 & 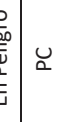 & u & u & : & $\begin{array}{c}u \\
a\end{array}$ & L & ? \\
\hline & & 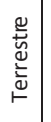 & 总 & 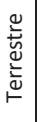 & & & $\bar{\Sigma}$ & 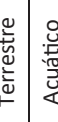 & 䇏 & 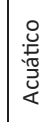 & 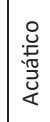 & 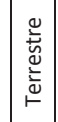 & 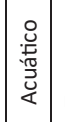 & & 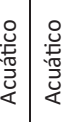 & 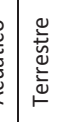 & 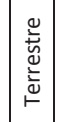 & 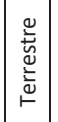 & 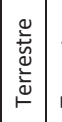 & & 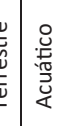 & 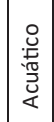 & 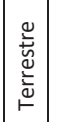 & 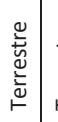 & & 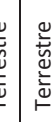 & \\
\hline & & 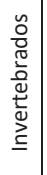 & $\stackrel{\vec{u}}{\underline{z}}$ & 焉 & & & & 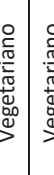 & 5 & 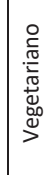 & 高 & 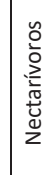 & 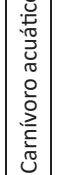 & $\underline{\underline{\underline{z}}}$ & 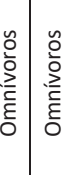 & 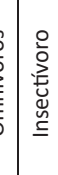 & 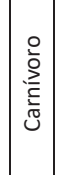 & $\bar{\Psi}$ & 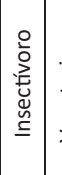 & 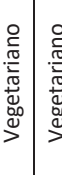 & 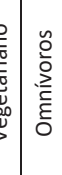 & 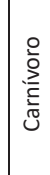 & 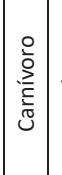 & S & 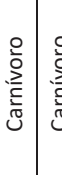 & 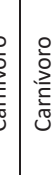 & 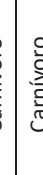 \\
\hline
\end{tabular}

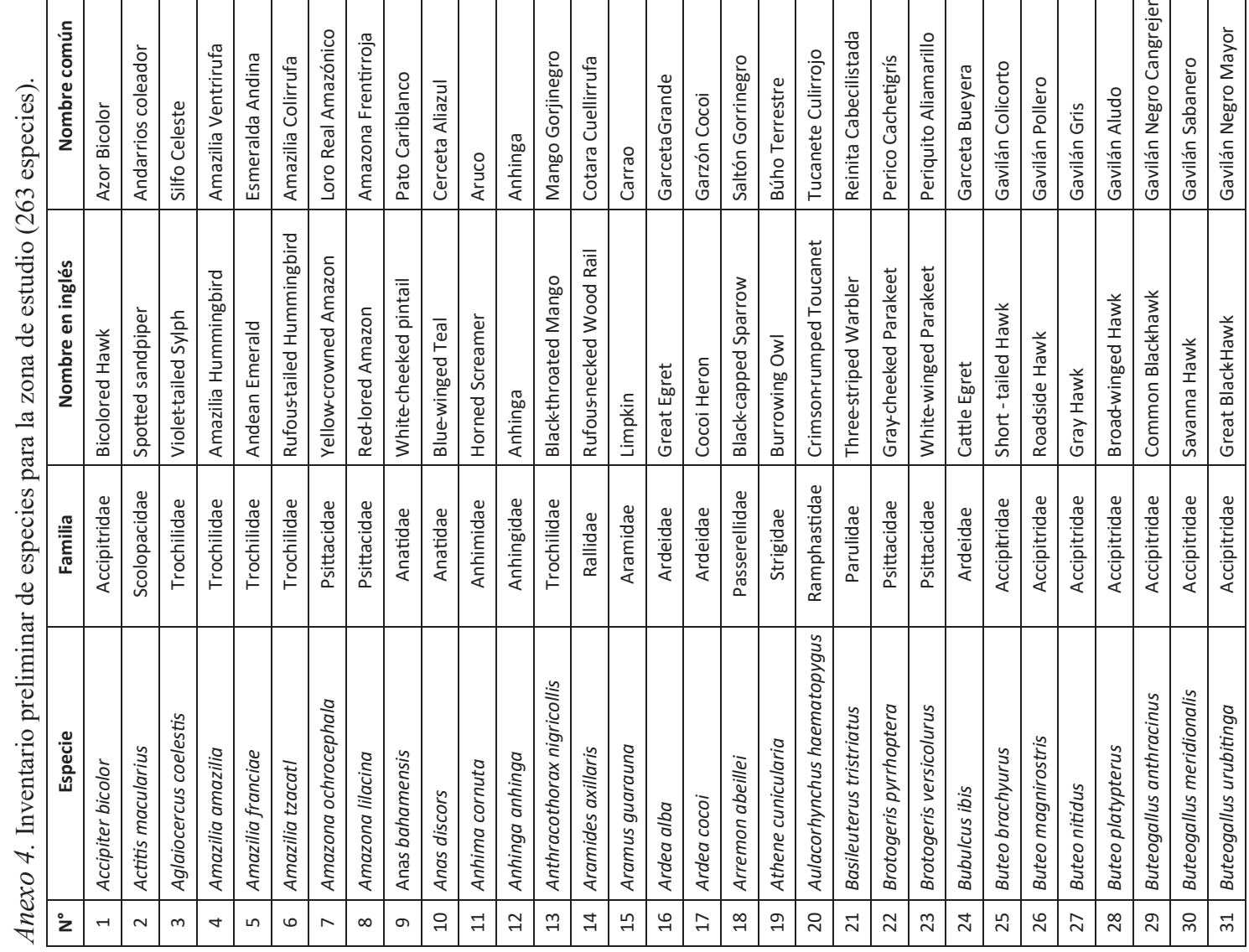

134

INVESTIGATIO No. 11, noviembre 2018 ,

Edición Especial, pp. 113-168,

ISSN: 1390 - 6399・ISSN-e: 2602 - 8336 


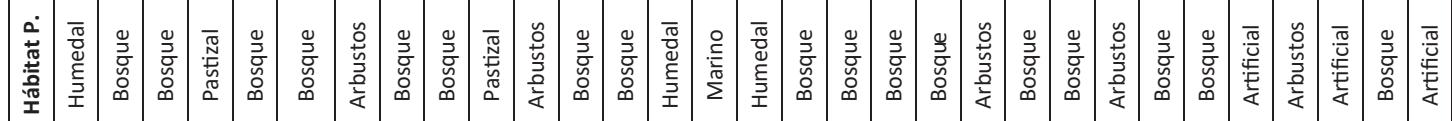

$\frac{1}{3}$

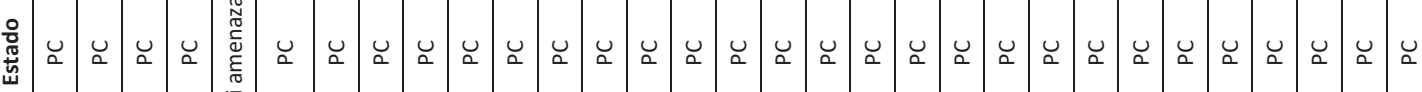

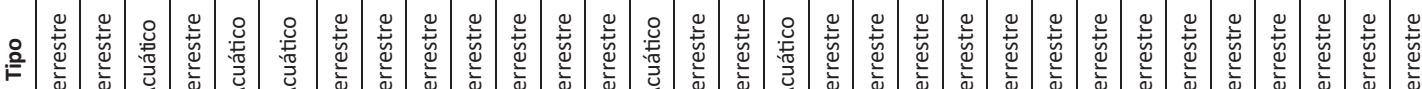

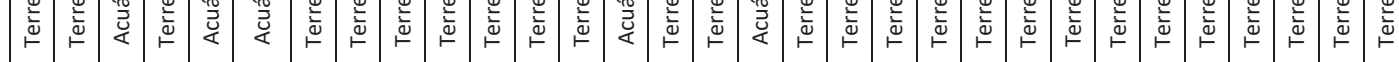

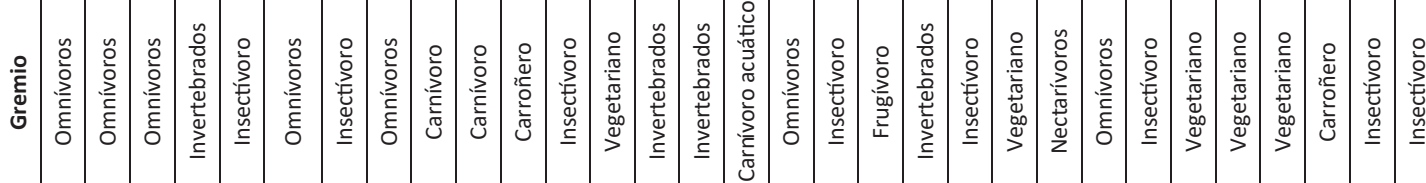

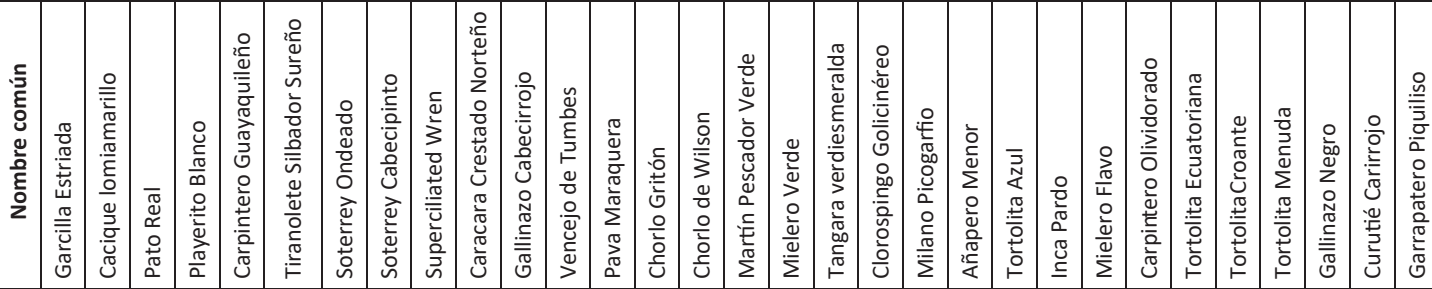

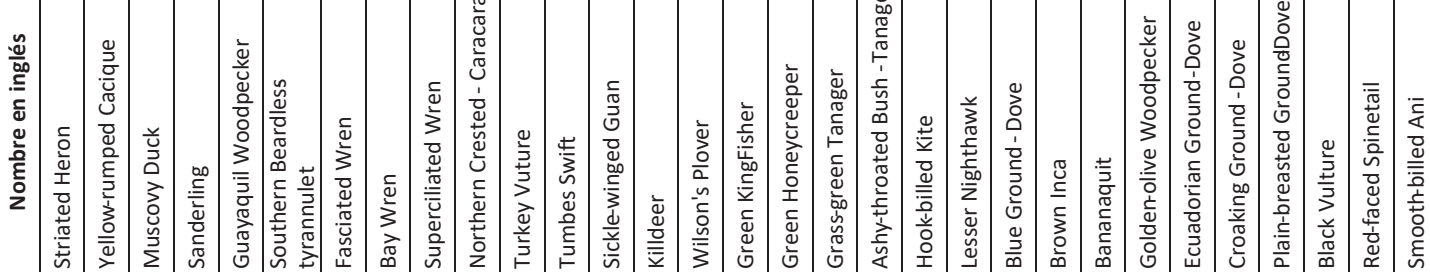

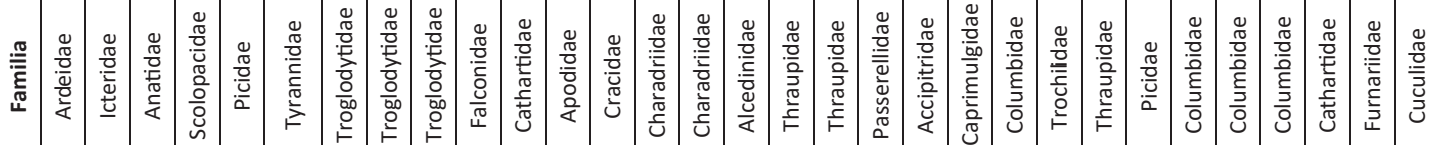

\begin{tabular}{|c|c|c|c|c|c|c|c|c|c|c|c|c|c|c|c|c|c|c|c|c|c|c|c|}
\hline & & & & & & & & & & & & & & & & & & & & & & & \\
\hline$\overline{\mathrm{J}}$ & & 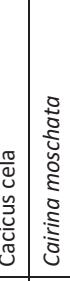 & & 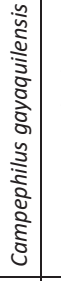 & 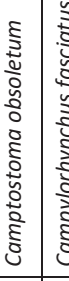 & 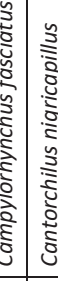 & 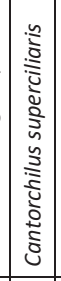 & 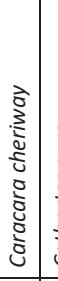 & 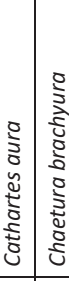 & 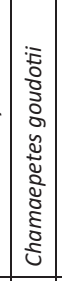 & 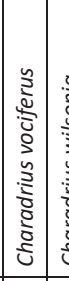 & 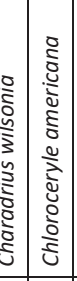 & 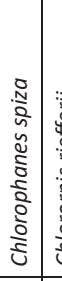 & 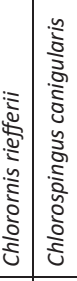 & 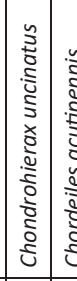 & 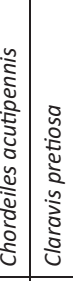 & 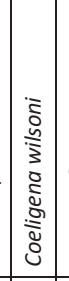 & 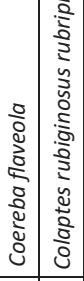 & 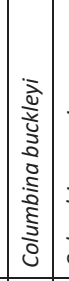 & & 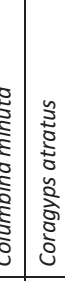 & 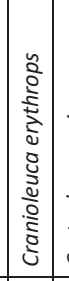 & \\
\hline$\stackrel{2}{z}$ & $\begin{array}{ll}\tilde{m} & \approx\end{array}$ & \begin{tabular}{lll}
$m$ & \multirow{m}{m}{}
\end{tabular} & & $\stackrel{m}{m}$ & \begin{tabular}{l|l}
$\hat{m}$ & 尺े
\end{tabular} & \begin{tabular}{c|l}
$\infty$ & 9 \\
\end{tabular} & q & \begin{tabular}{l|l}
7 & 3
\end{tabular} & \begin{tabular}{l|l}
$f$ & $\eta$
\end{tabular} & J & मf & \begin{tabular}{l|l|}
$y$ & $f$ \\
$y$
\end{tabular} & \begin{tabular}{l|l}
$\stackrel{\infty}{\alpha}$ & 5
\end{tabular} & \begin{tabular}{l|l}
$g$ & in
\end{tabular} & $\vec{n}$ & 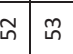 & 至 & & in & \begin{tabular}{l|l}
$\infty$ & 0 \\
$\sim$
\end{tabular} & $\begin{array}{lll}\Omega & 8\end{array}$ & & $\widetilde{\sigma}$ \\
\hline
\end{tabular}




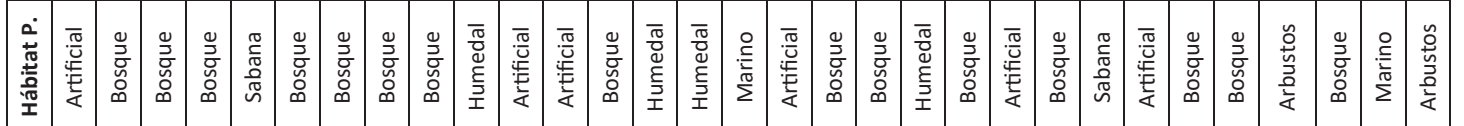

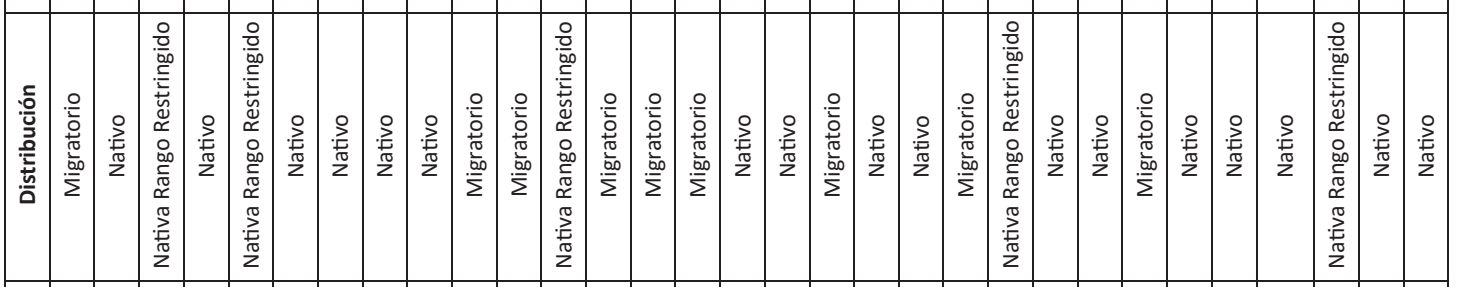

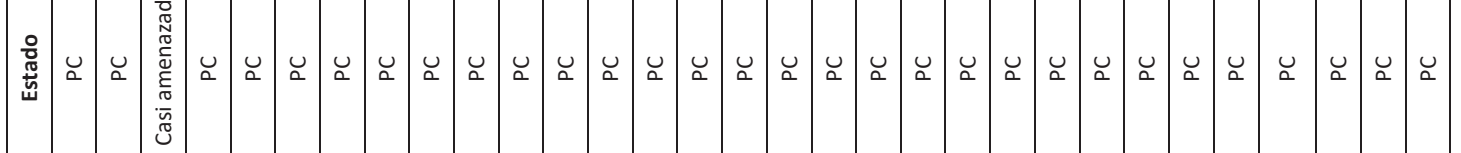

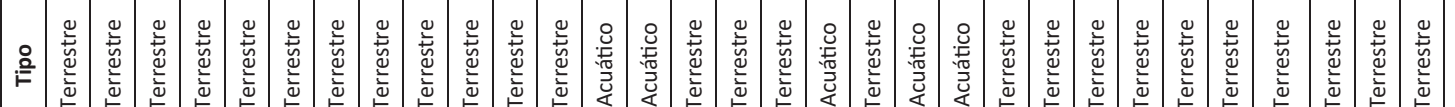

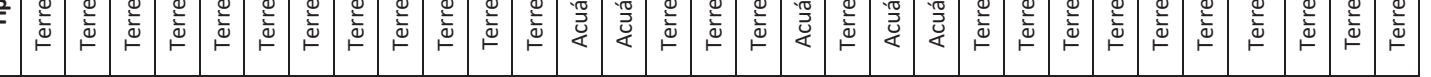

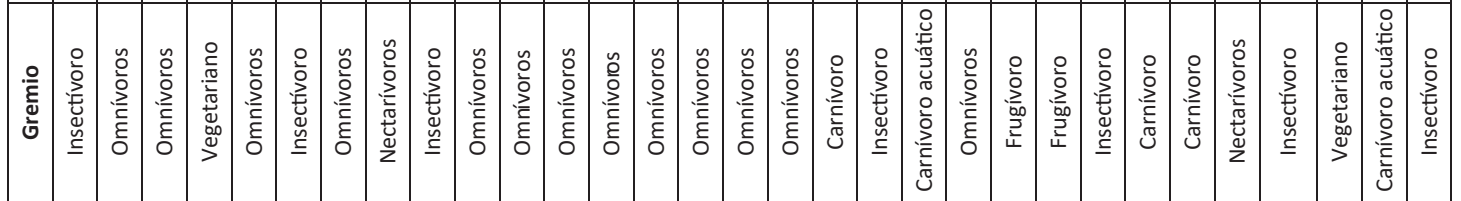

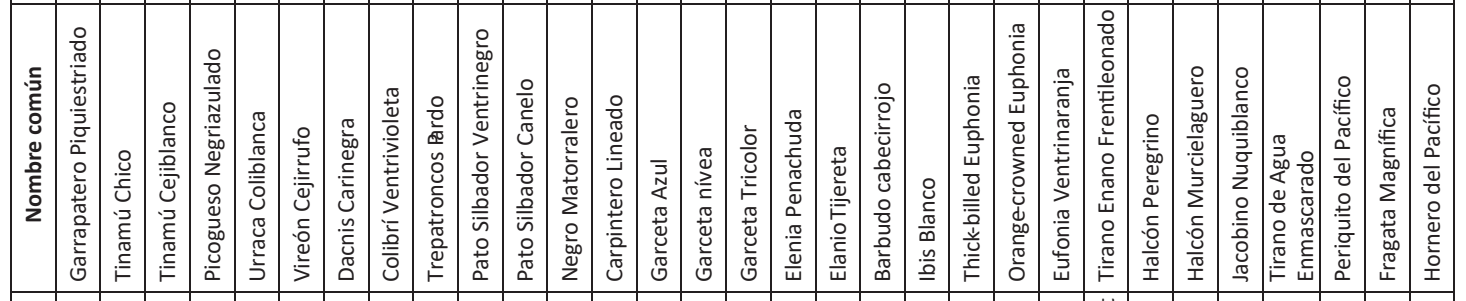

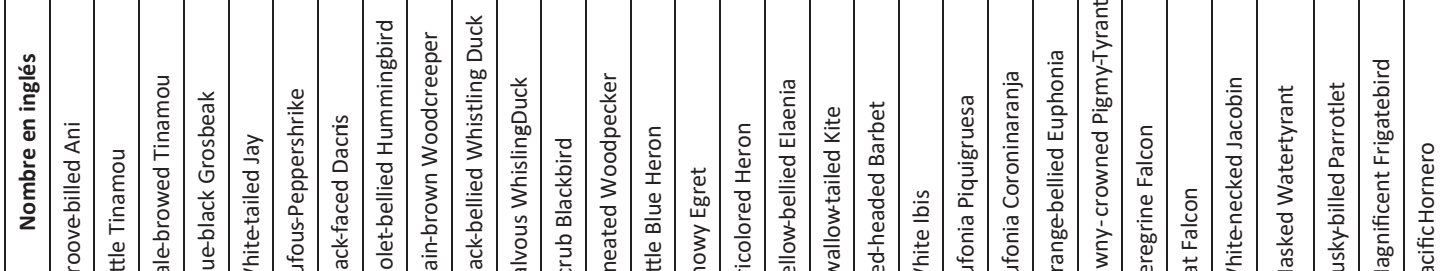

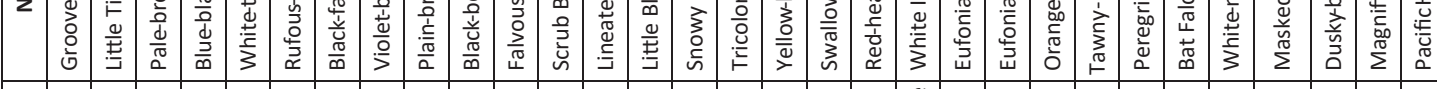

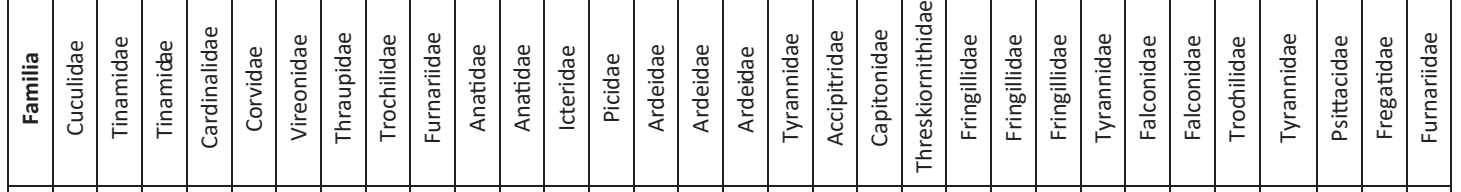

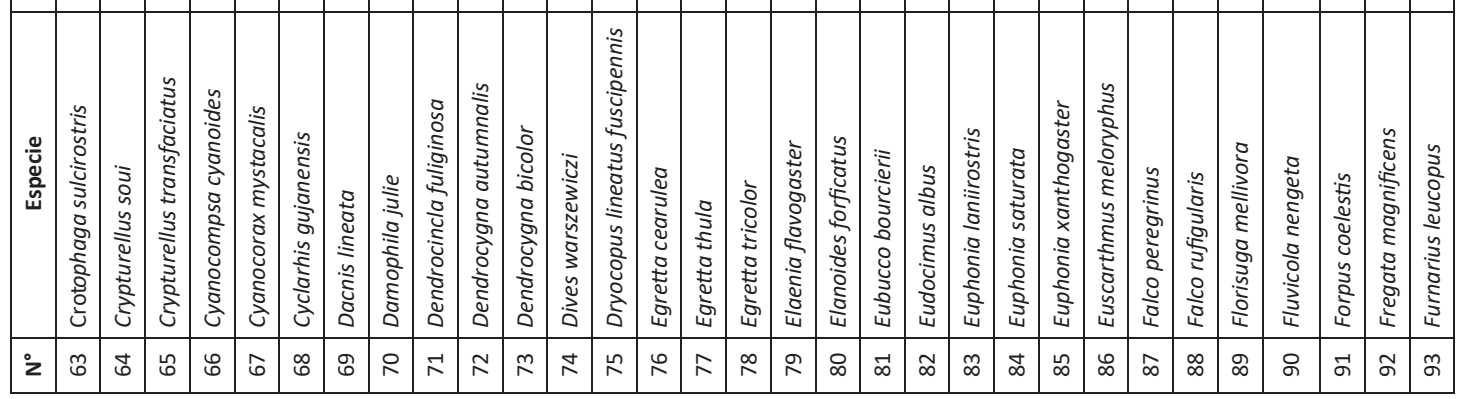




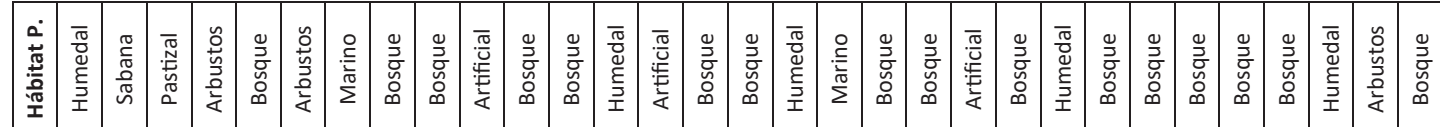

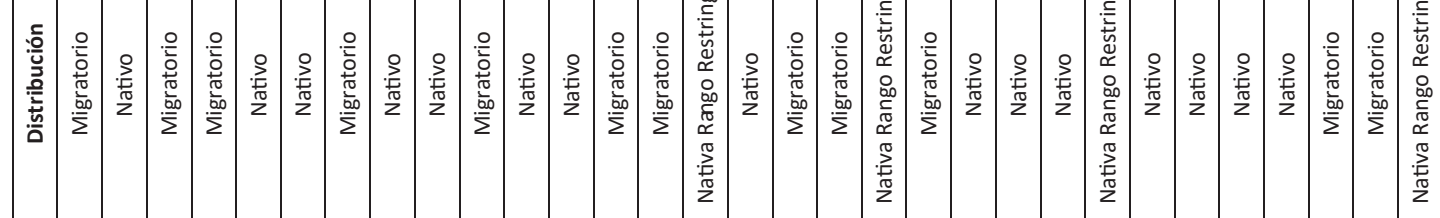

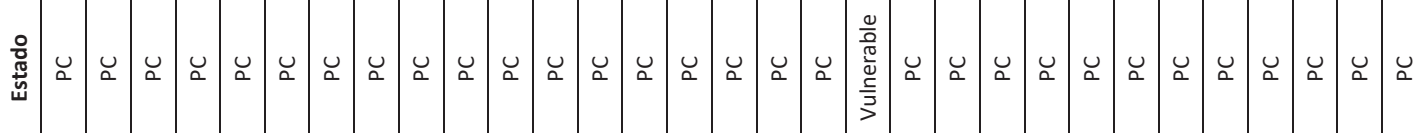

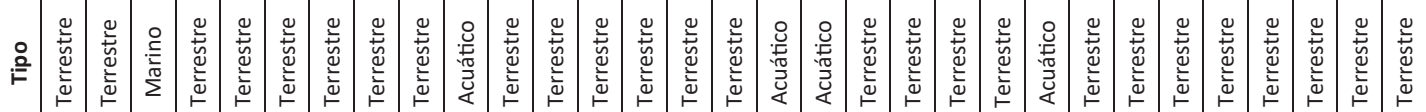

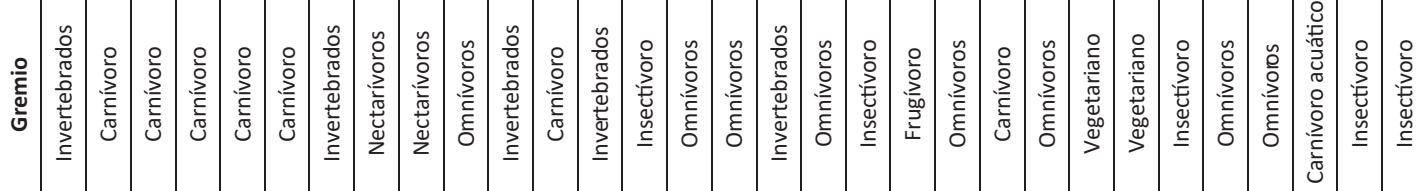

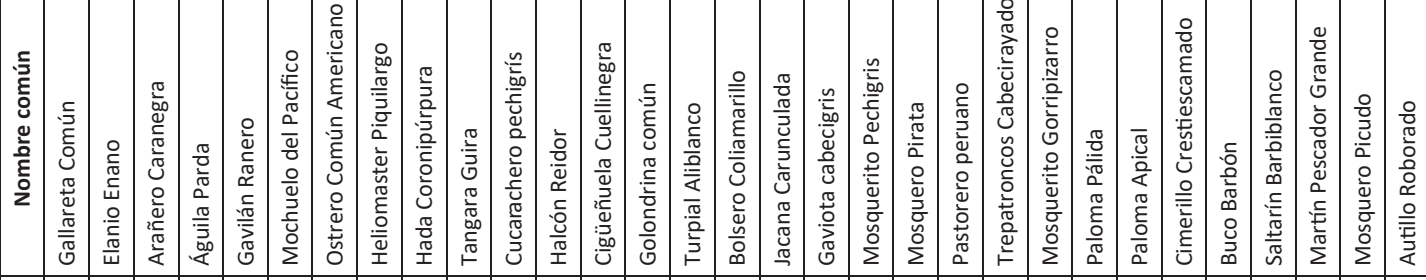

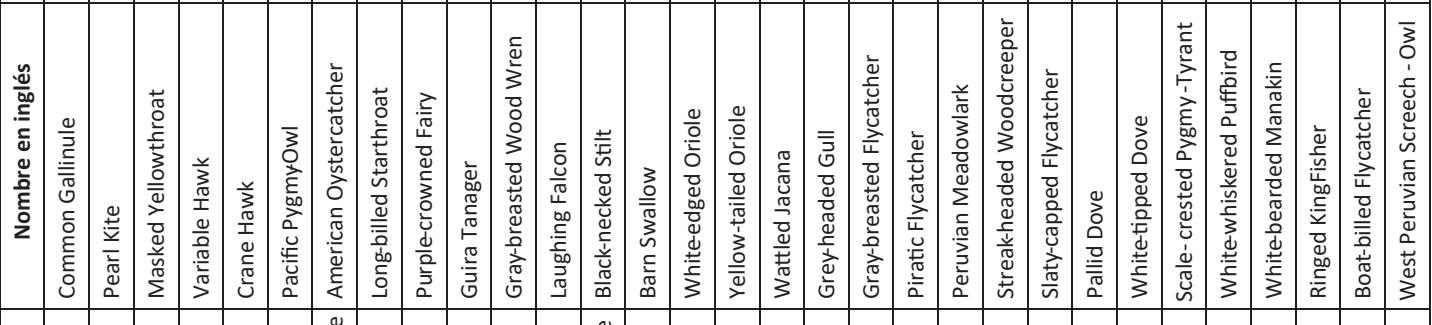

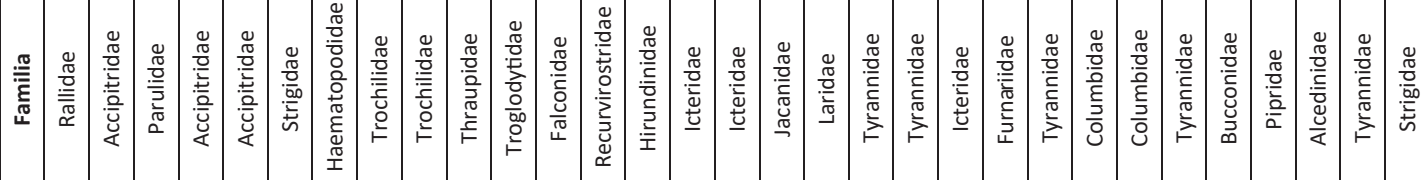

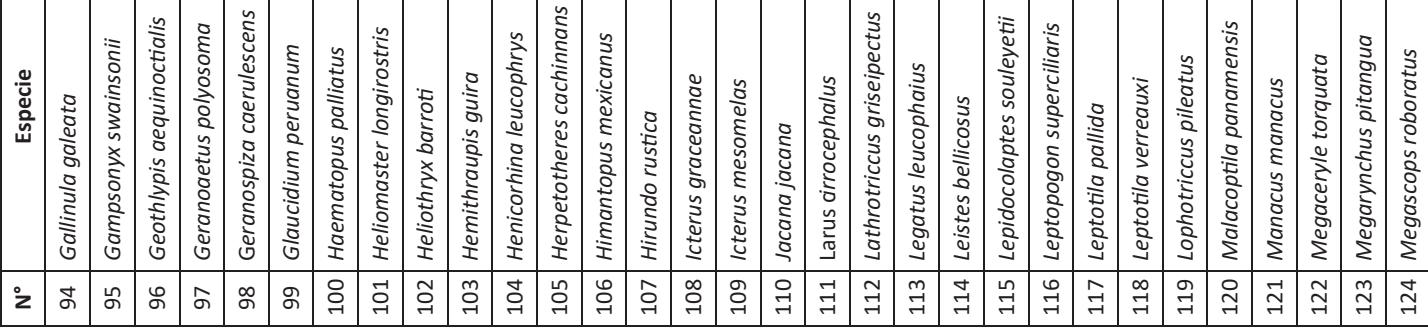

137

INVESTIGATIO No. 11, noviembre 2018,

Edición Especial, pp. 113-168,

ISSN: 1390 - 6399 • ISSN-e: 2602 - 8336 


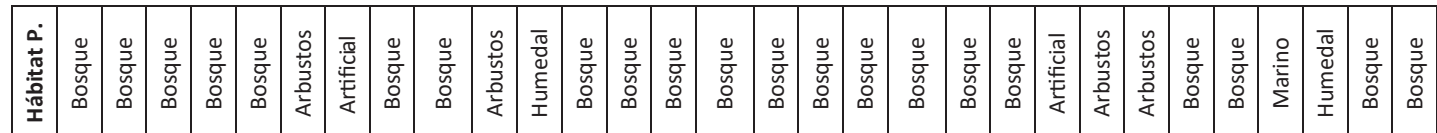

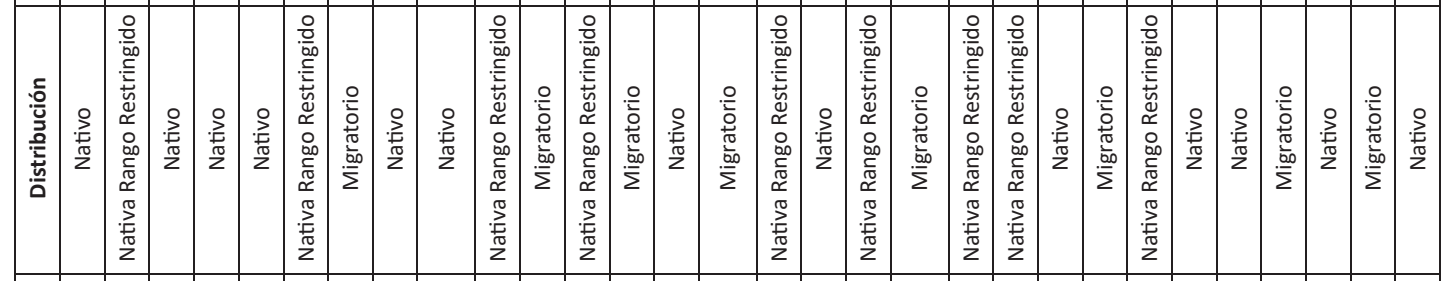

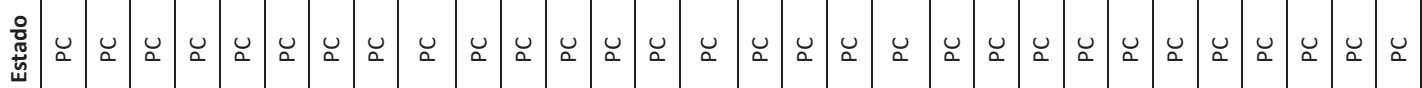

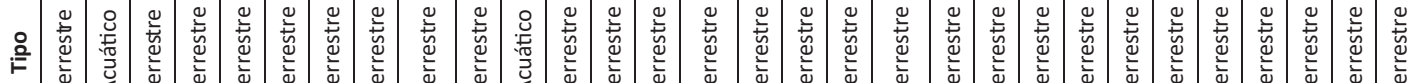

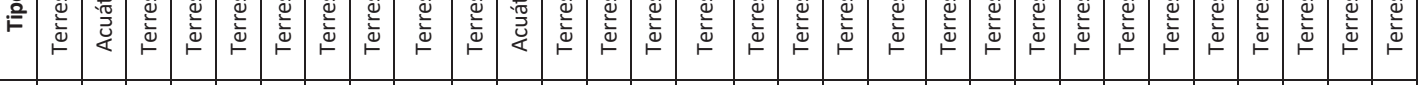

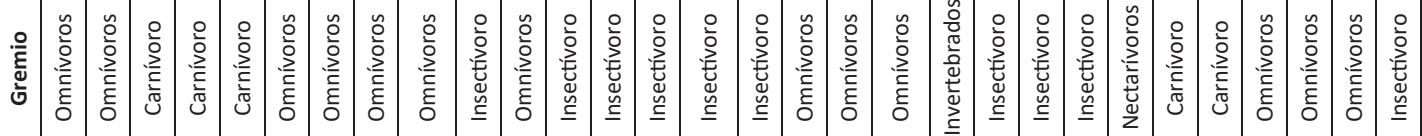

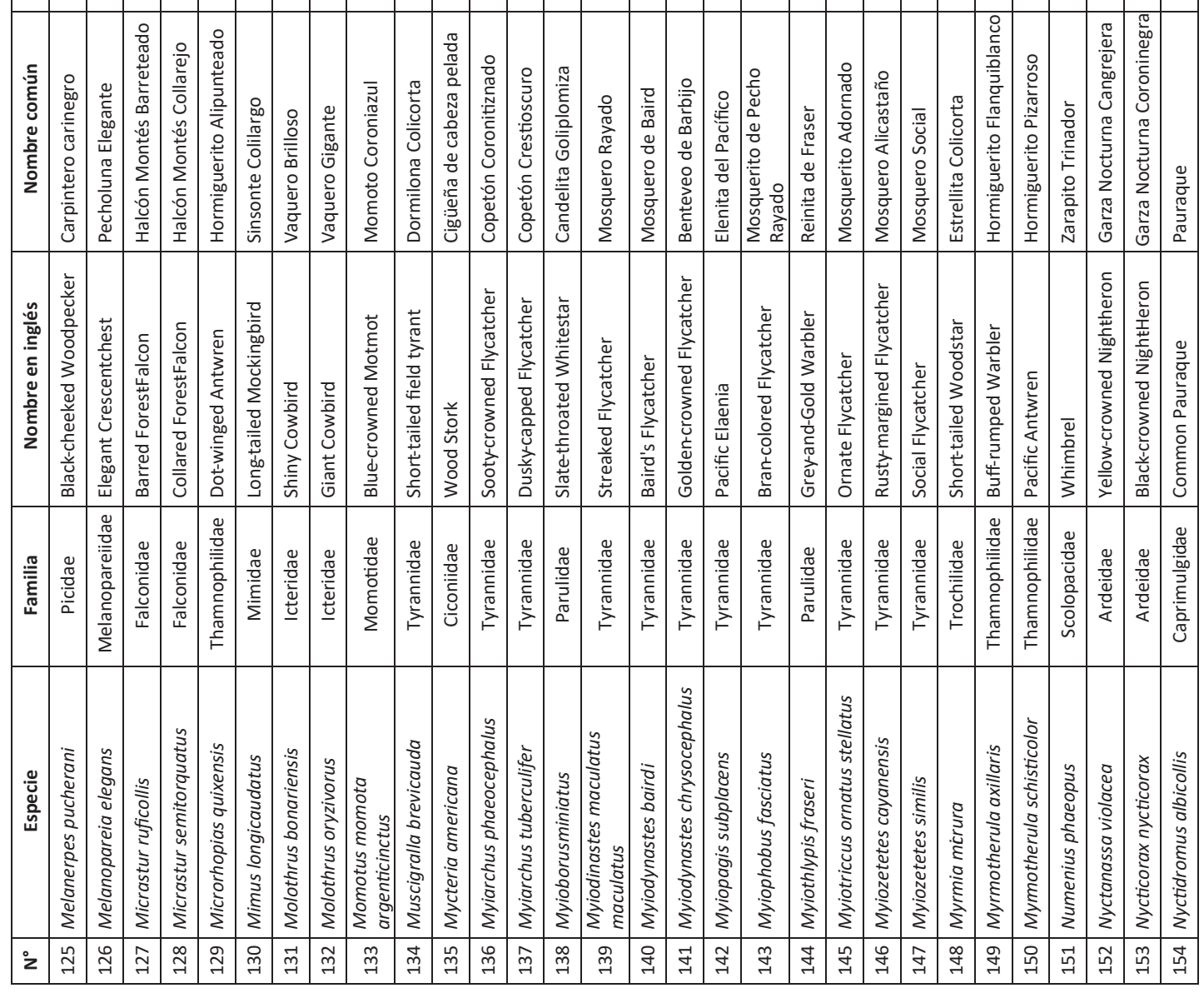

138

INVESTIGATIO No. 11, noviembre 2018 ,

Edición Especial, pp. 113-168,

ISSN: 1390 - 6399・ISSN-e: 2602 - 8336 


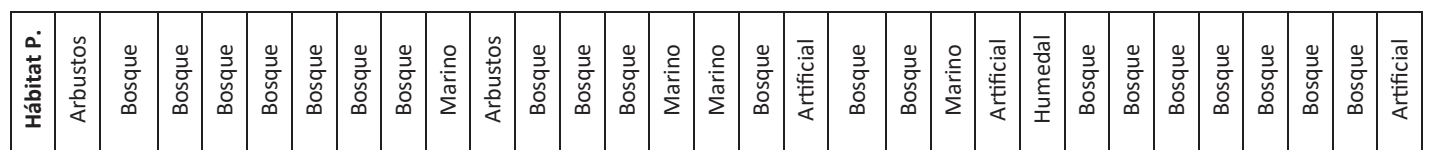

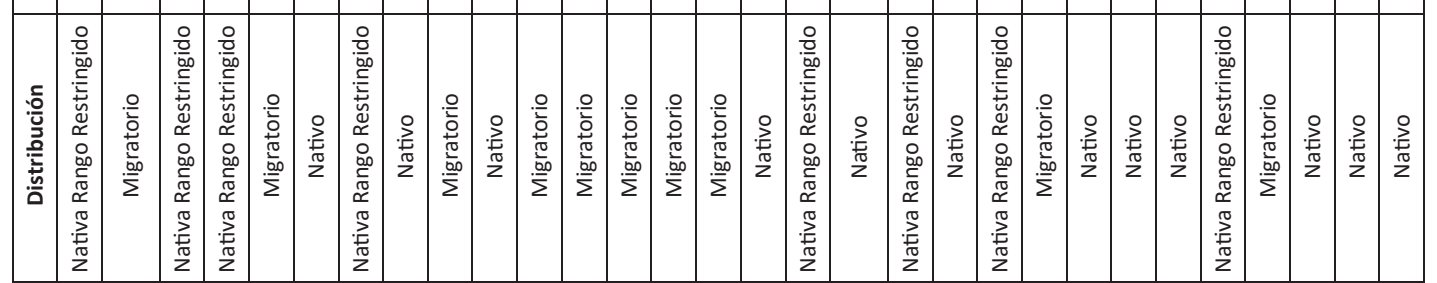

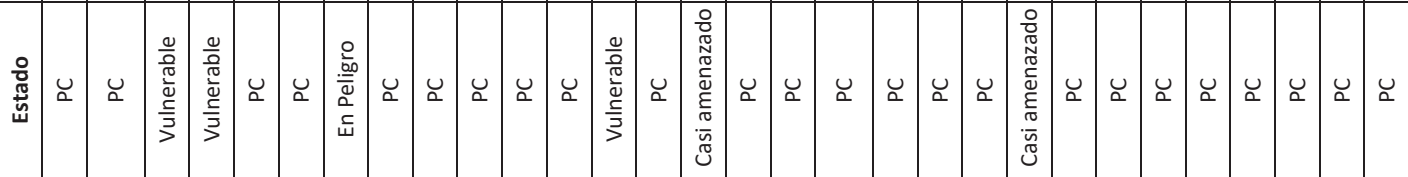

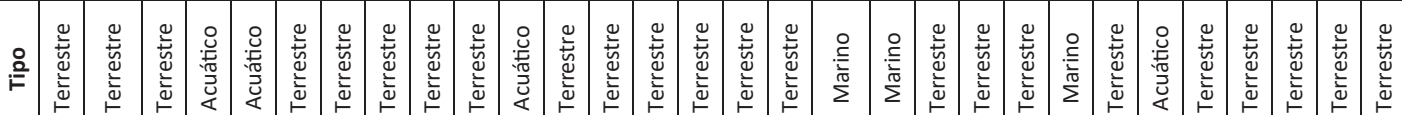

$\frac{6}{2} \ln 2$

$\frac{1}{3}$

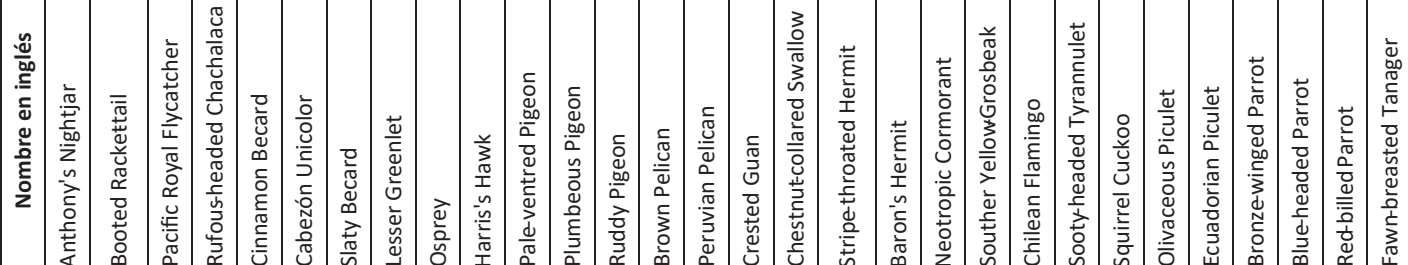

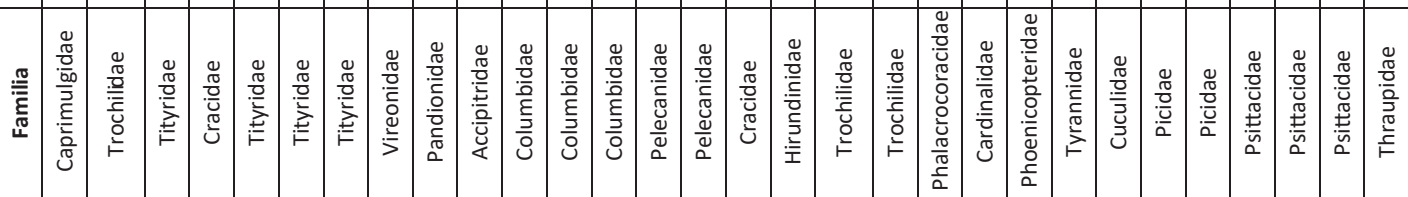

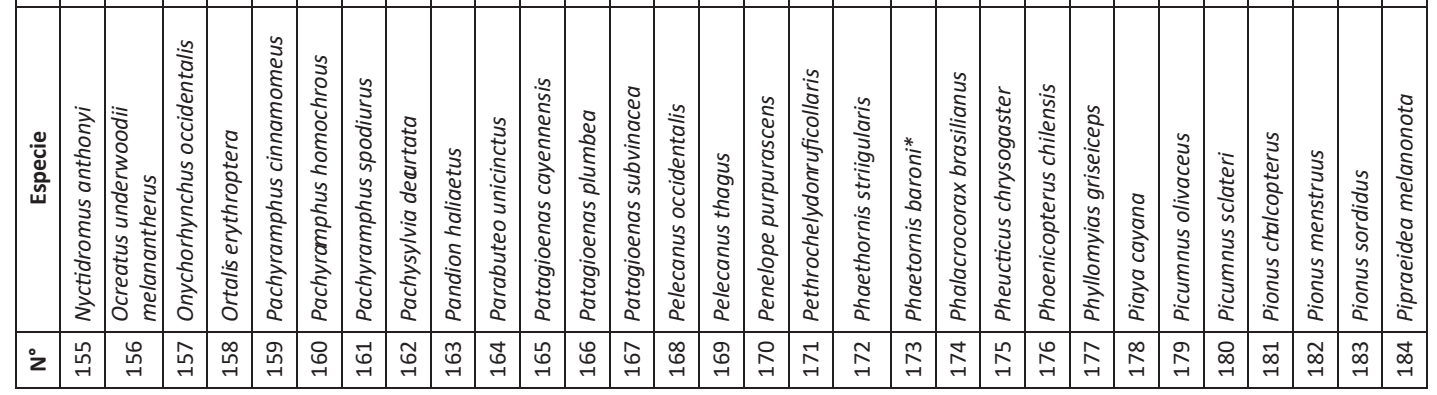




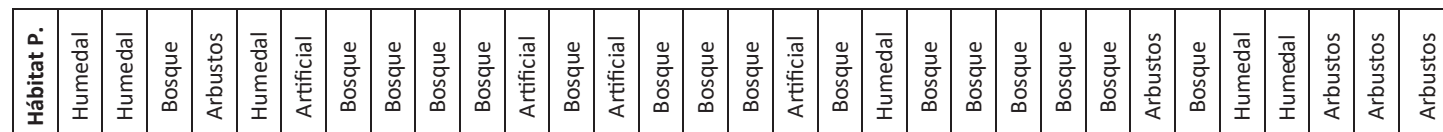

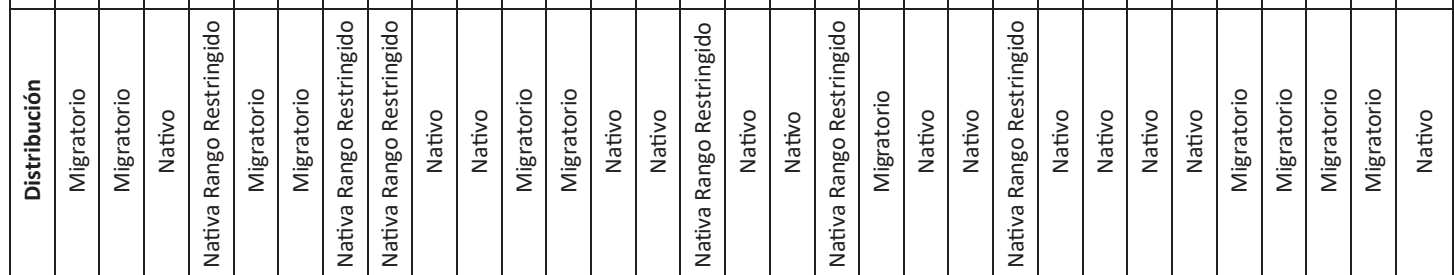

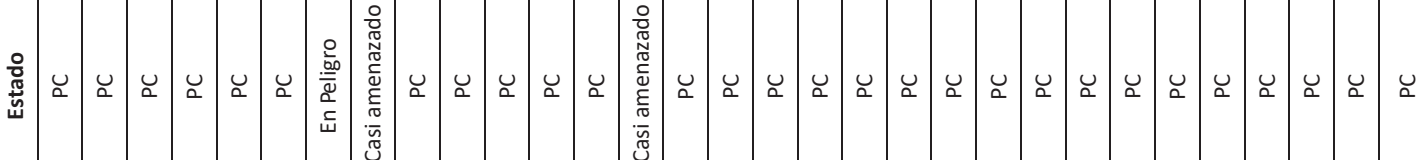

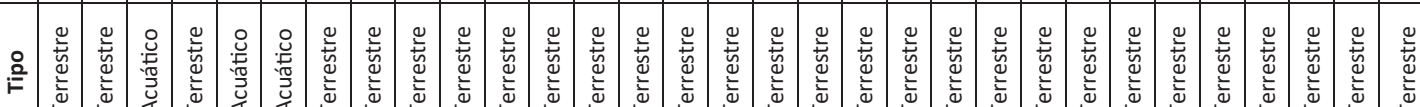

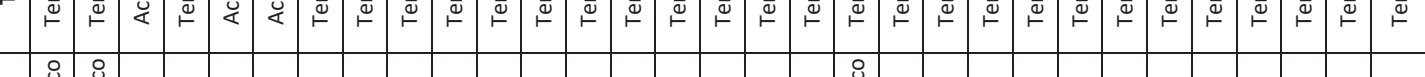

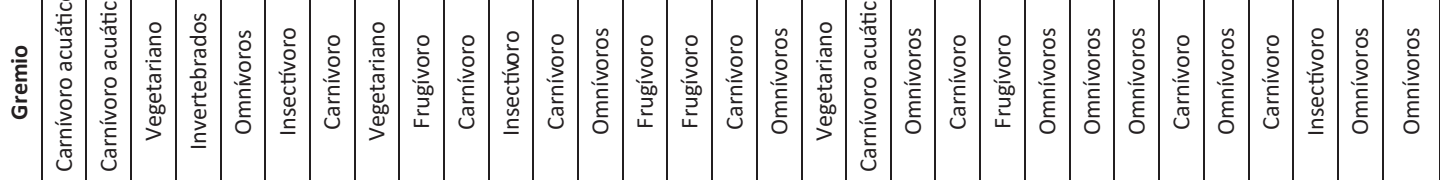

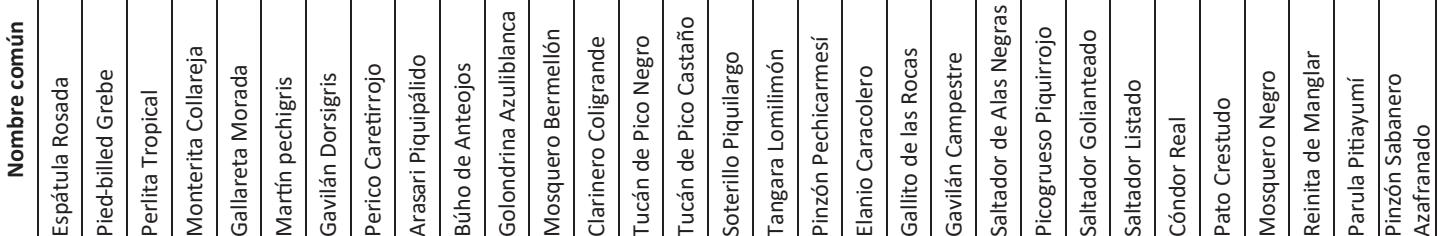

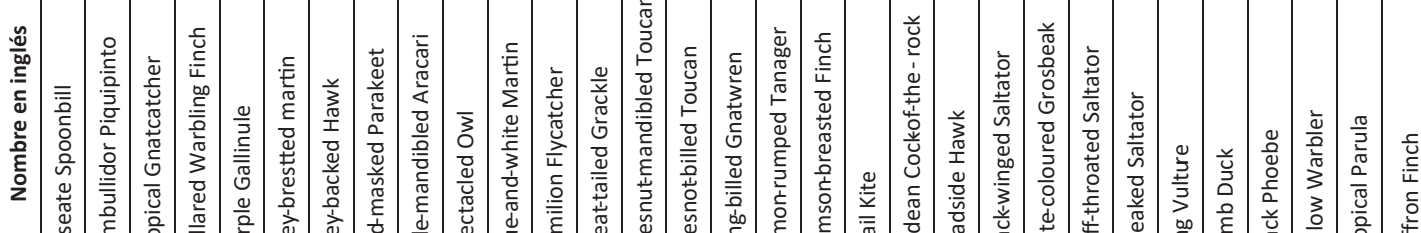

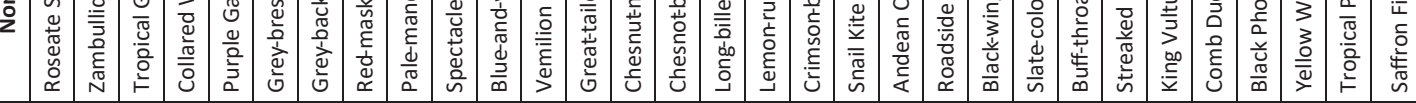

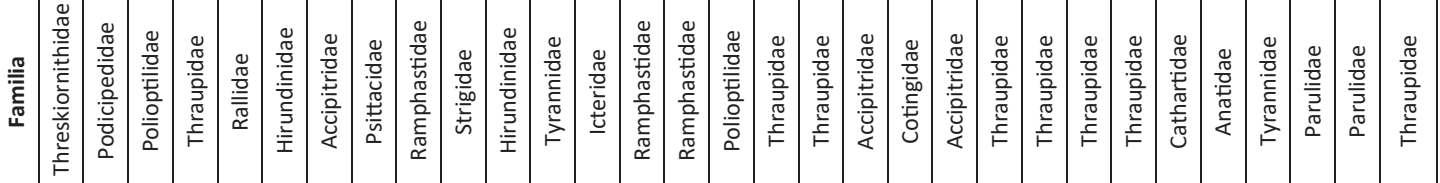

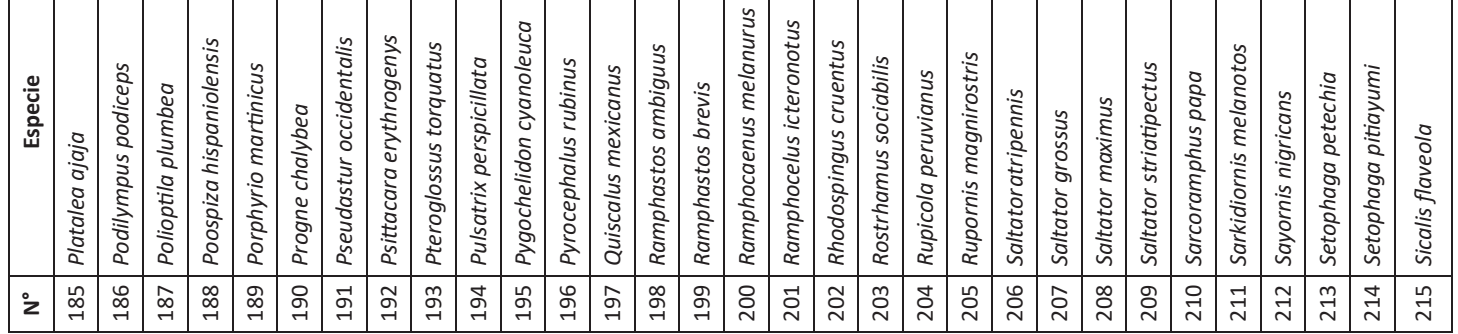




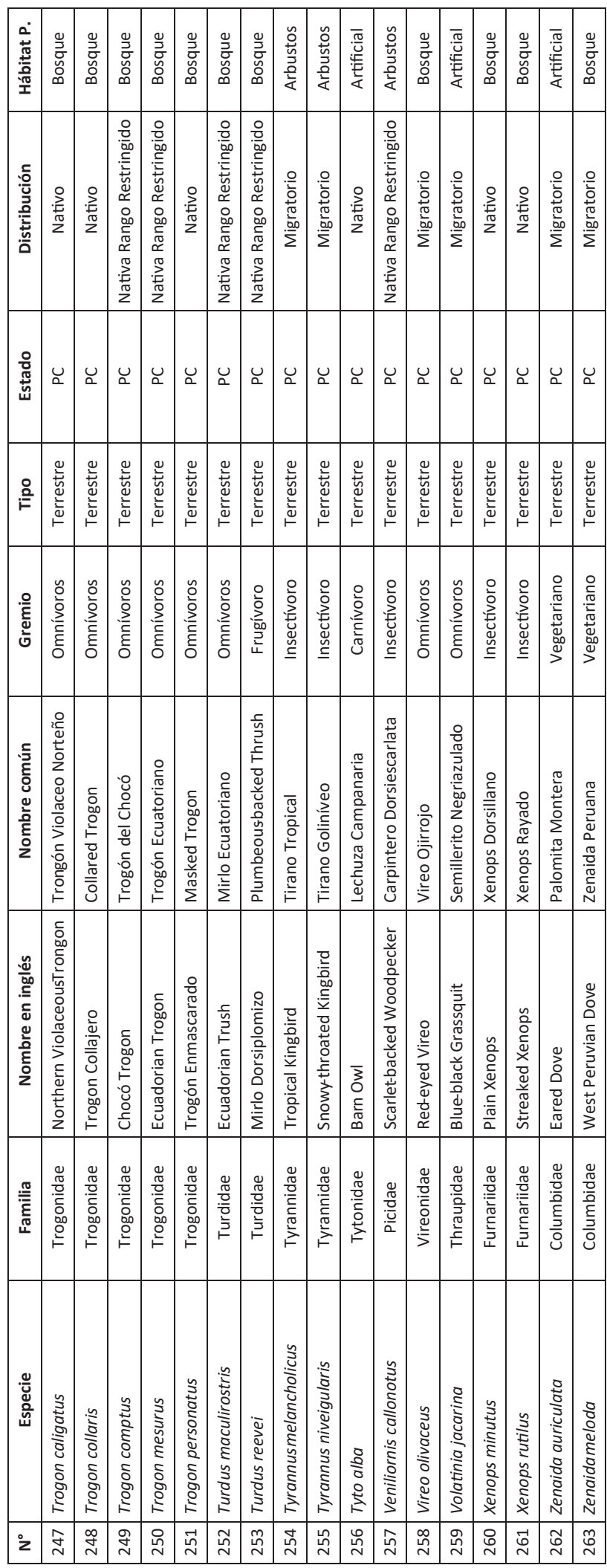

142

INVESTIGATIO No. 11, noviembre 2018,

Edición Especial, pp. 113-168,

ISSN: 1390 - 6399 • ISSN-e: 2602 - 8336 
Anexo 5. Fotografías de especies no reportadas para la zona.

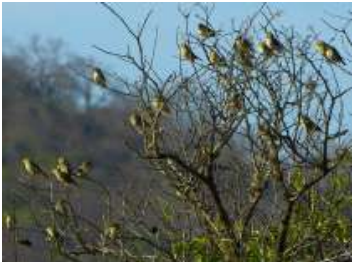

Sicalis taczanoskii (Engabao)

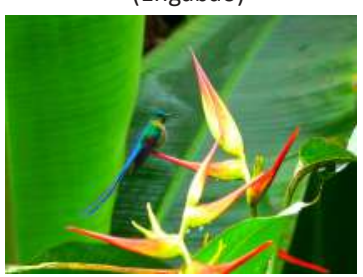

Aglaiocercus coelestis (Bucay)

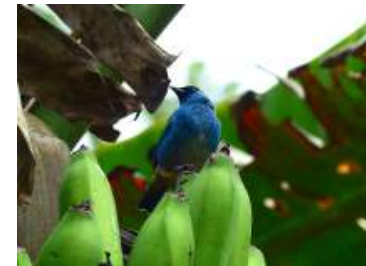

Tangara ruficervix (Bucay)

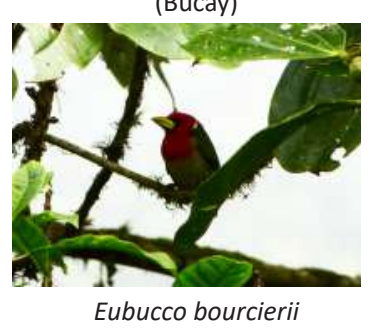
(Bucay)

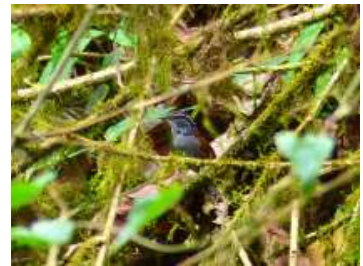

Henicorhina leucophrys (Rancho Alemán)

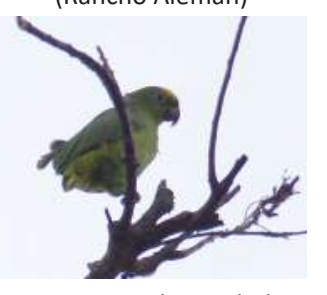

Amazona ochrocephala (Pedro Carbo)

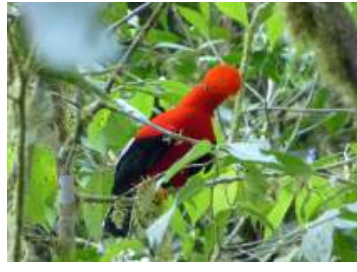

Rupicola peruvianus

(Bucay)

Tabla de abreviaturas y equivalencias para Anexo 6.

\begin{tabular}{|c|l|}
\hline \multicolumn{2}{|c|}{ IUCN } \\
\hline LC & Preocupación Menor \\
\hline NT & Casi Amenazada \\
\hline VU & Vulnerable \\
\hline EN & En Peligro \\
\hline
\end{tabular}

\begin{tabular}{|c|l|}
\hline \multicolumn{2}{|c|}{ CITES } \\
\hline I & Apéndice I \\
\hline II & Apéndice II \\
\hline III & Apéndice III \\
\hline - & Sin Apéndice \\
\hline
\end{tabular}

\begin{tabular}{|c|l|}
\hline \multicolumn{2}{|c|}{ Endemismo } \\
\hline An & Endémica Andina \\
\hline Ch & Endémica del Chocó \\
\hline Ec & Endémica Ecuatoriana \\
\hline I & Introducida \\
\hline Ls & Endémica de Ladera Sur \\
\hline Ln & Endémica de Ladera Norte \\
\hline $\mathrm{Ma}$ & Migratoria Austral \\
\hline $\mathrm{Mb}$ & Migratoria Boreal \\
\hline $\mathrm{N}$ & Nativa \\
\hline $\mathrm{Tu}$ & Endémica Tumbesina \\
\hline
\end{tabular}

\section{3}

INVESTIGATIO No. 11, noviembre 2018,

Edición Especial, pp. 113-168,

ISSN: 1390 - 6399・ISSN-e: 2602 - 8336 


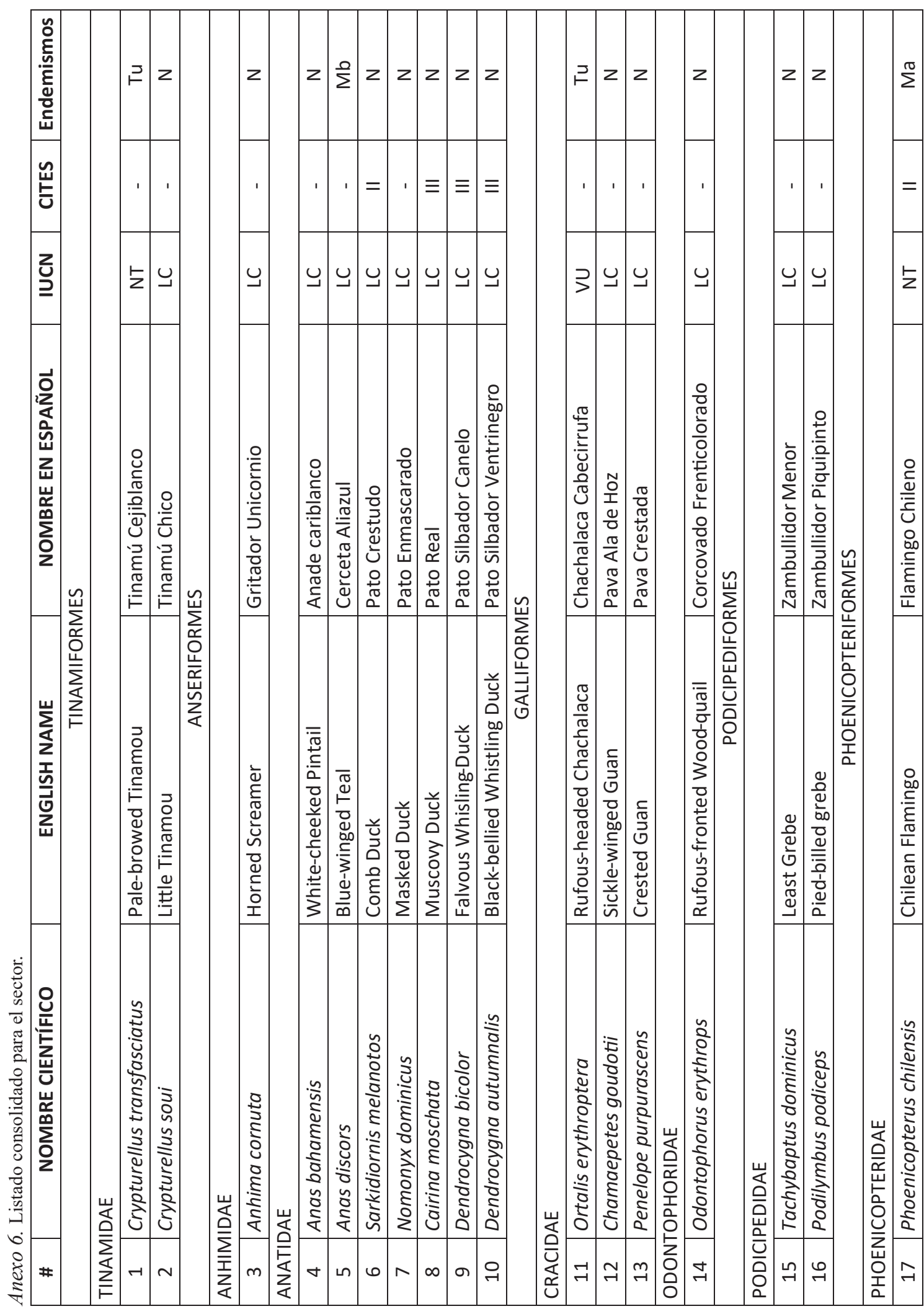




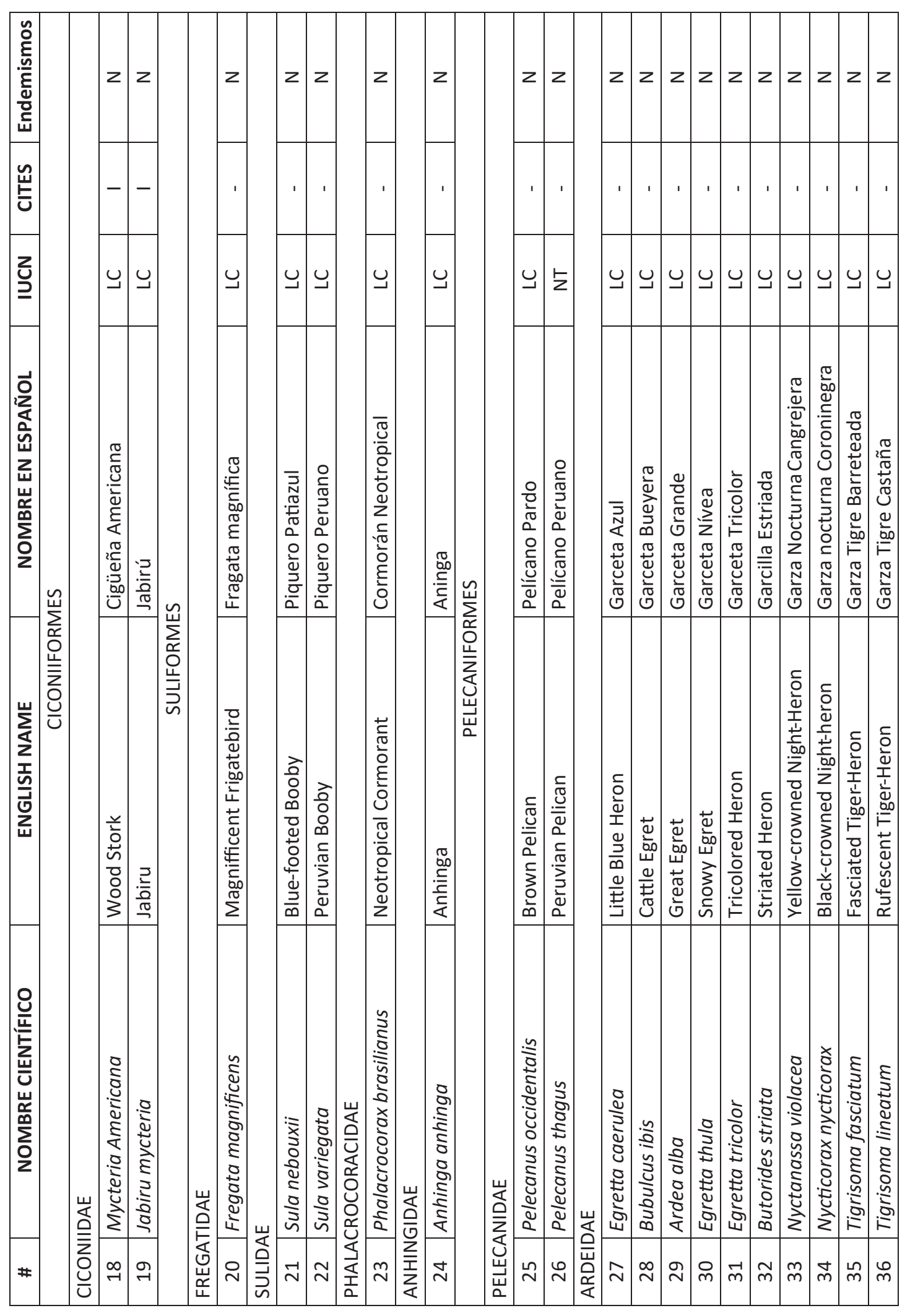

145

INVESTIGATIO No. 11, noviembre 2018,

Edición Especial, pp. 113-168,

ISSN: 1390 - 6399・ISSN-e: 2602 - 8336 


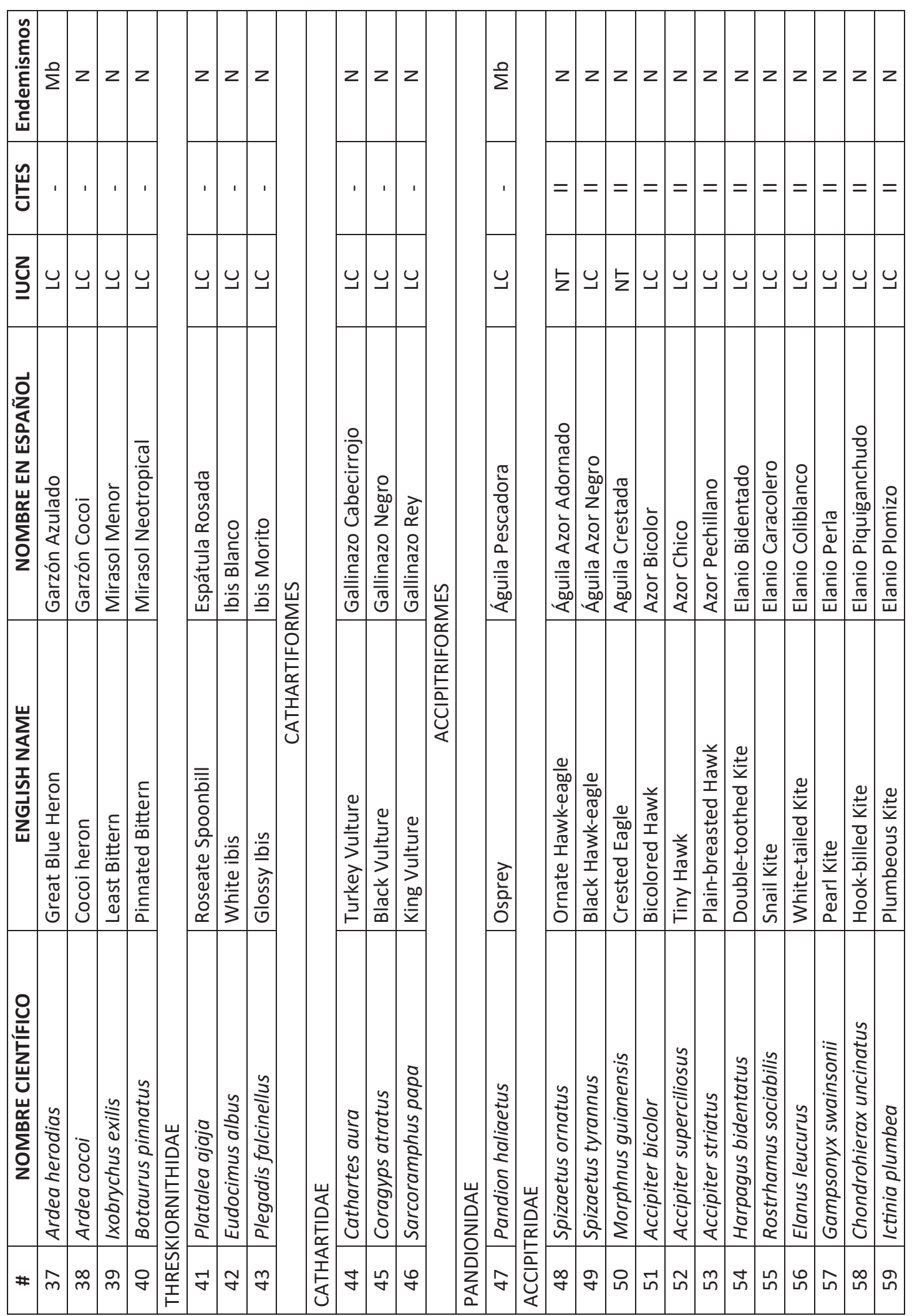

146

INVESTIGATIO No. 11, noviembre 2018 ,

Edición Especial, pp. 113-168,

ISSN: 1390 - 6399・ISSN-e: 2602 - 8336 

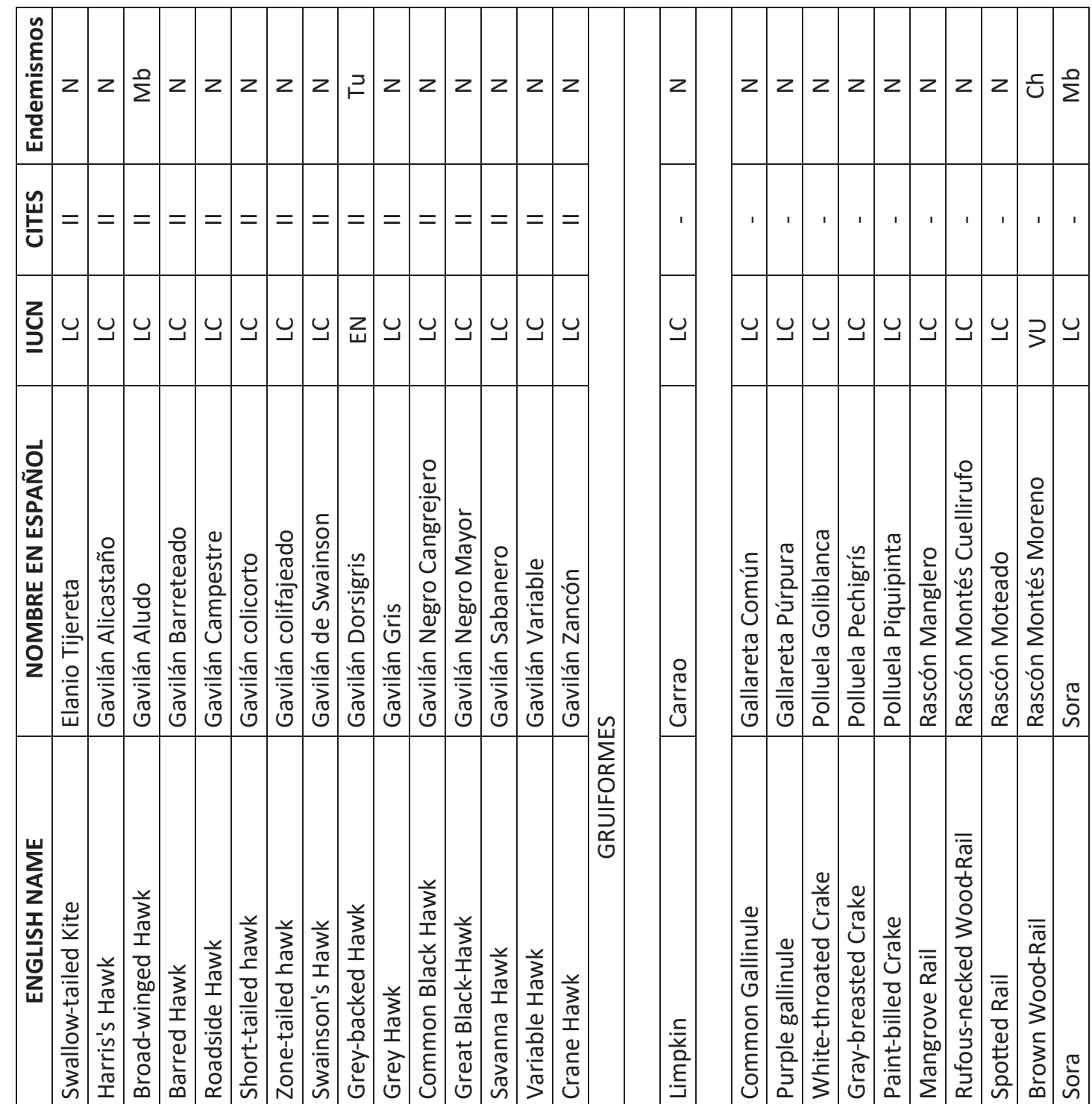

岕
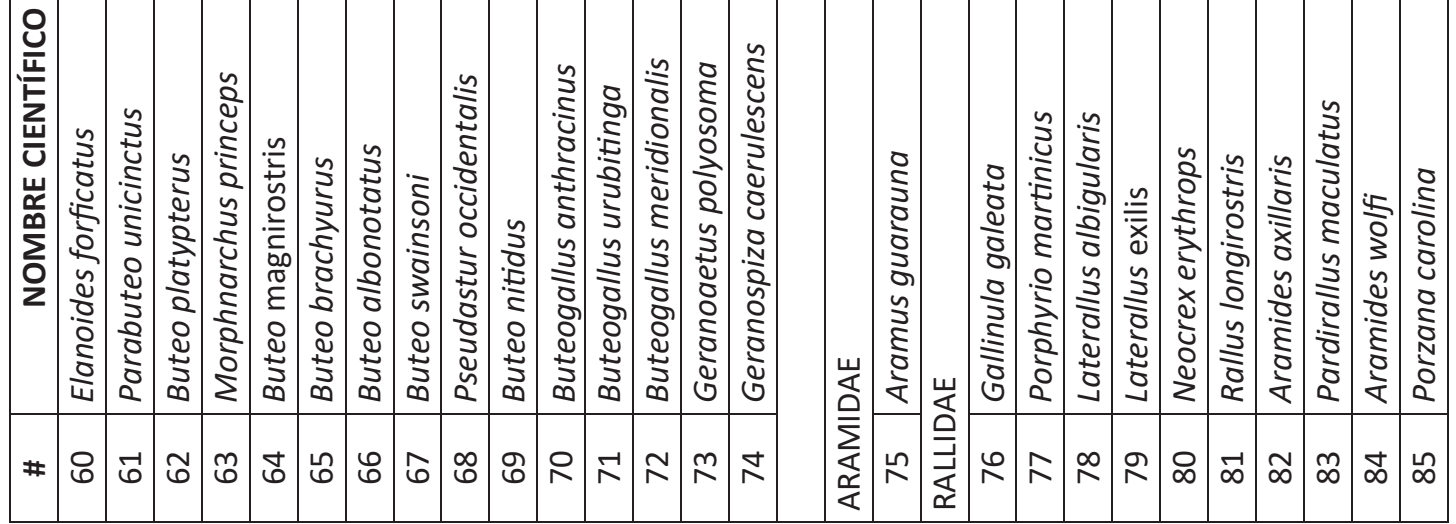


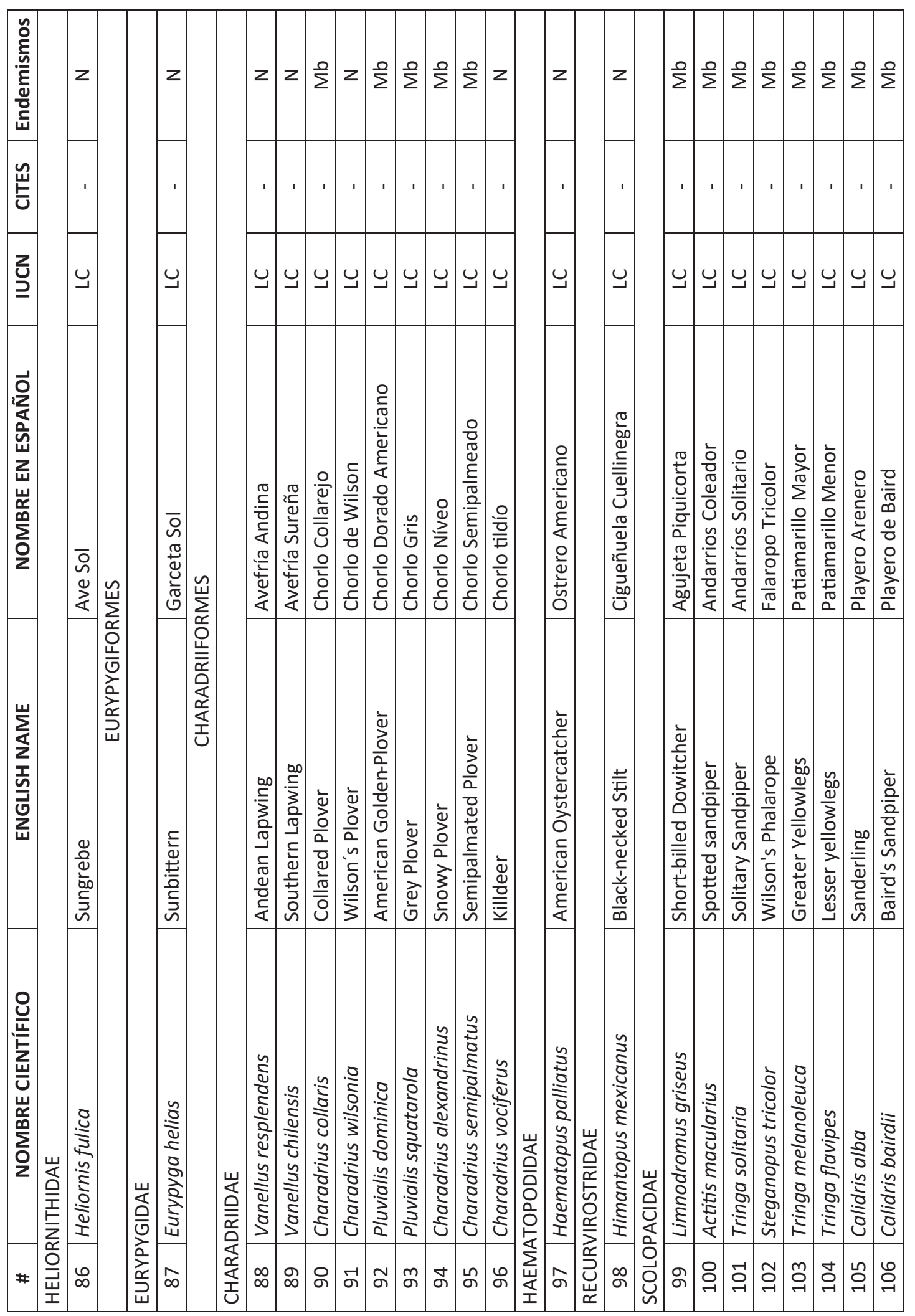

148

INVESTIGATIO No. 11, noviembre 2018,

Edición Especial, pp. 113-168,

ISSN: 1390 - 6399・ISSN-e: 2602 - 8336 


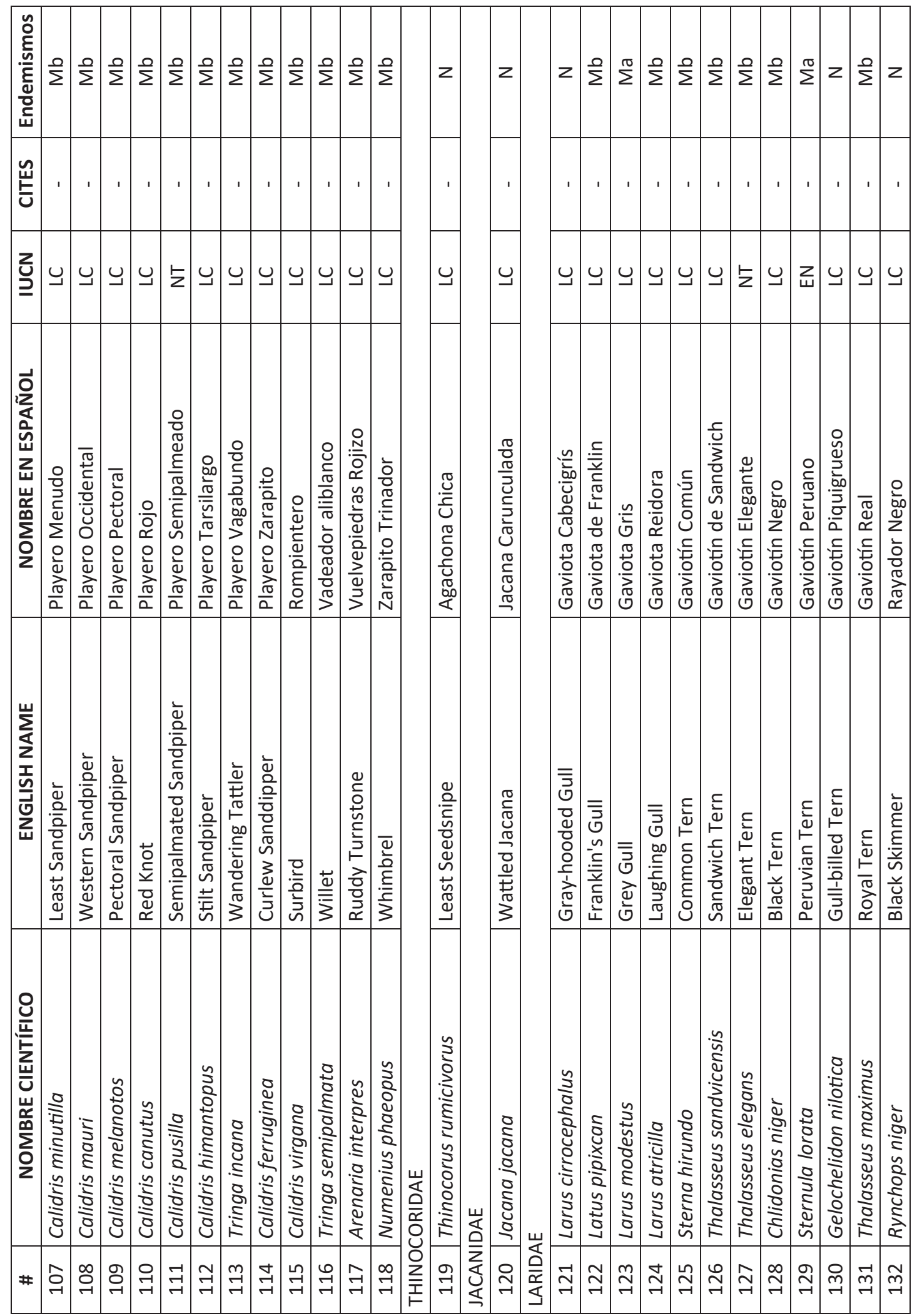

149

INVESTIGATIO No. 11, noviembre 2018 ,

Edición Especial, pp. 113-168,

ISSN: 1390 - 6399・ISSN-e: 2602 - 8336 


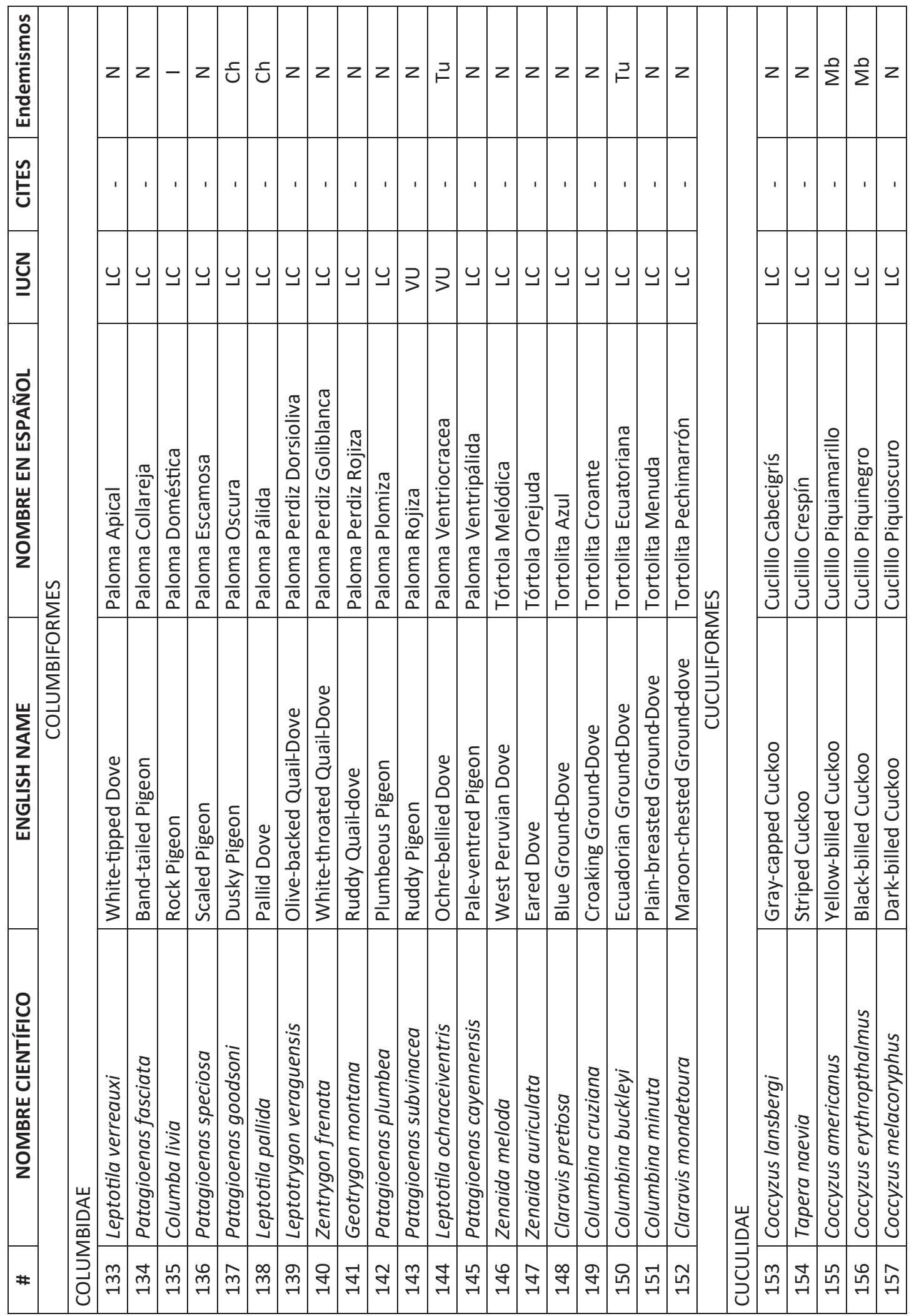

150

INVESTIGATIO No. 11, noviembre 2018,

Edición Especial, pp. 113-168,

ISSN: 1390 - 6399・ISSN-e: 2602 - 8336 


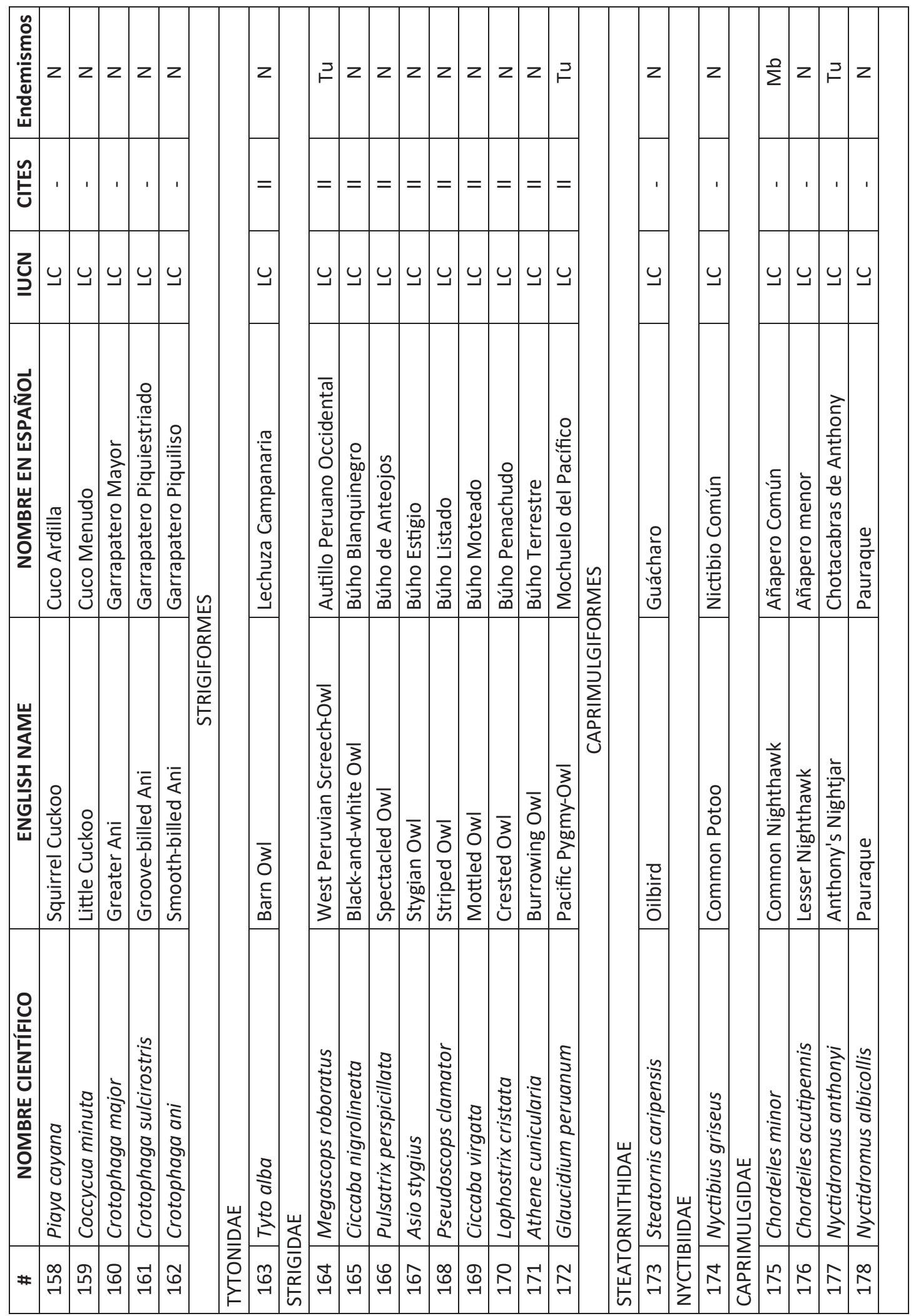

151

INVESTIGATIO No. 11, noviembre 2018 ,

Edición Especial, pp. 113-168,

ISSN: 1390 - 6399・ISSN-e: 2602 - 8336 


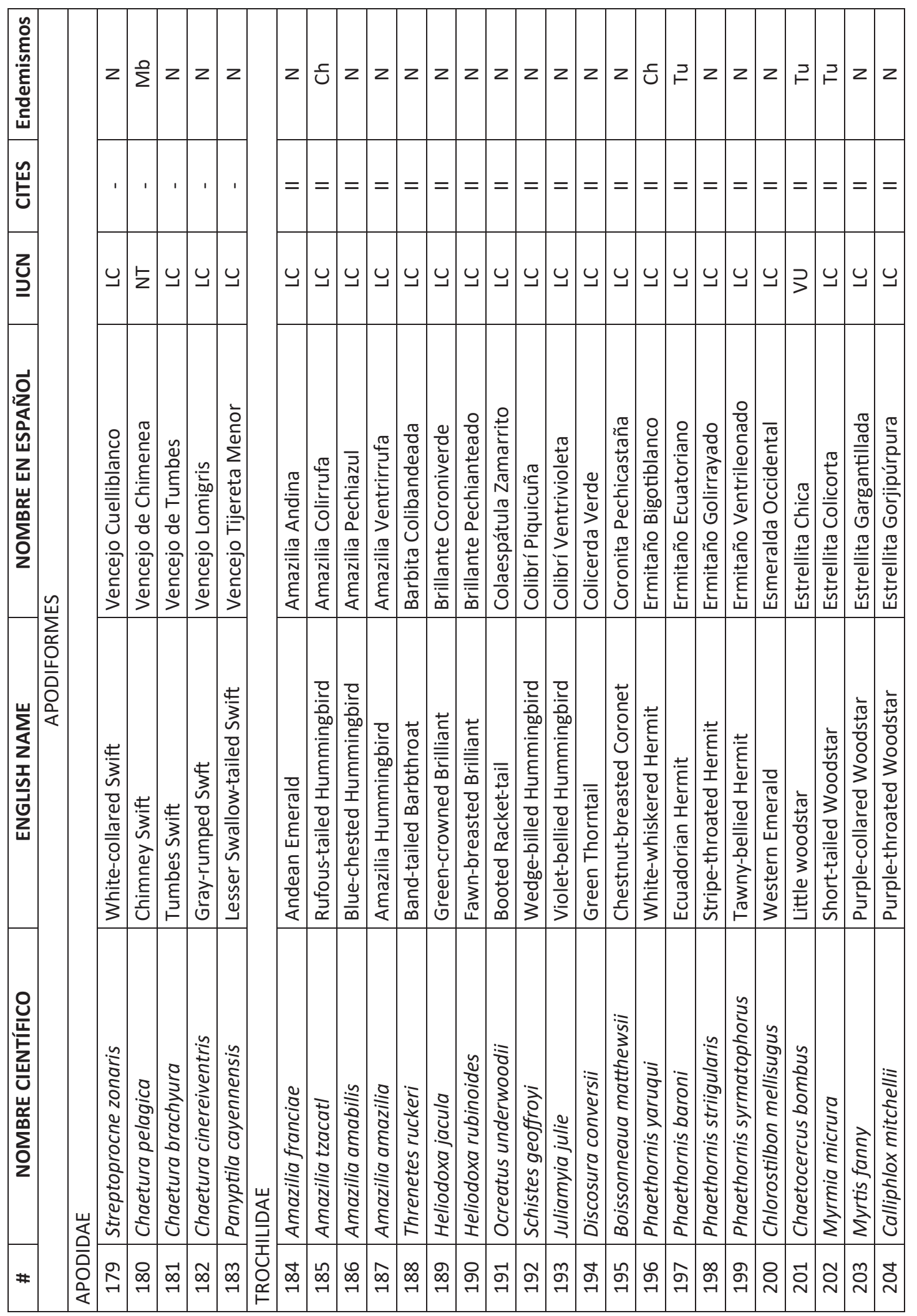

152

INVESTIGATIO No. 11, noviembre 2018,

Edición Especial, pp. 113-168,

ISSN: 1390 - 6399・ISSN-e: 2602 - 8336 


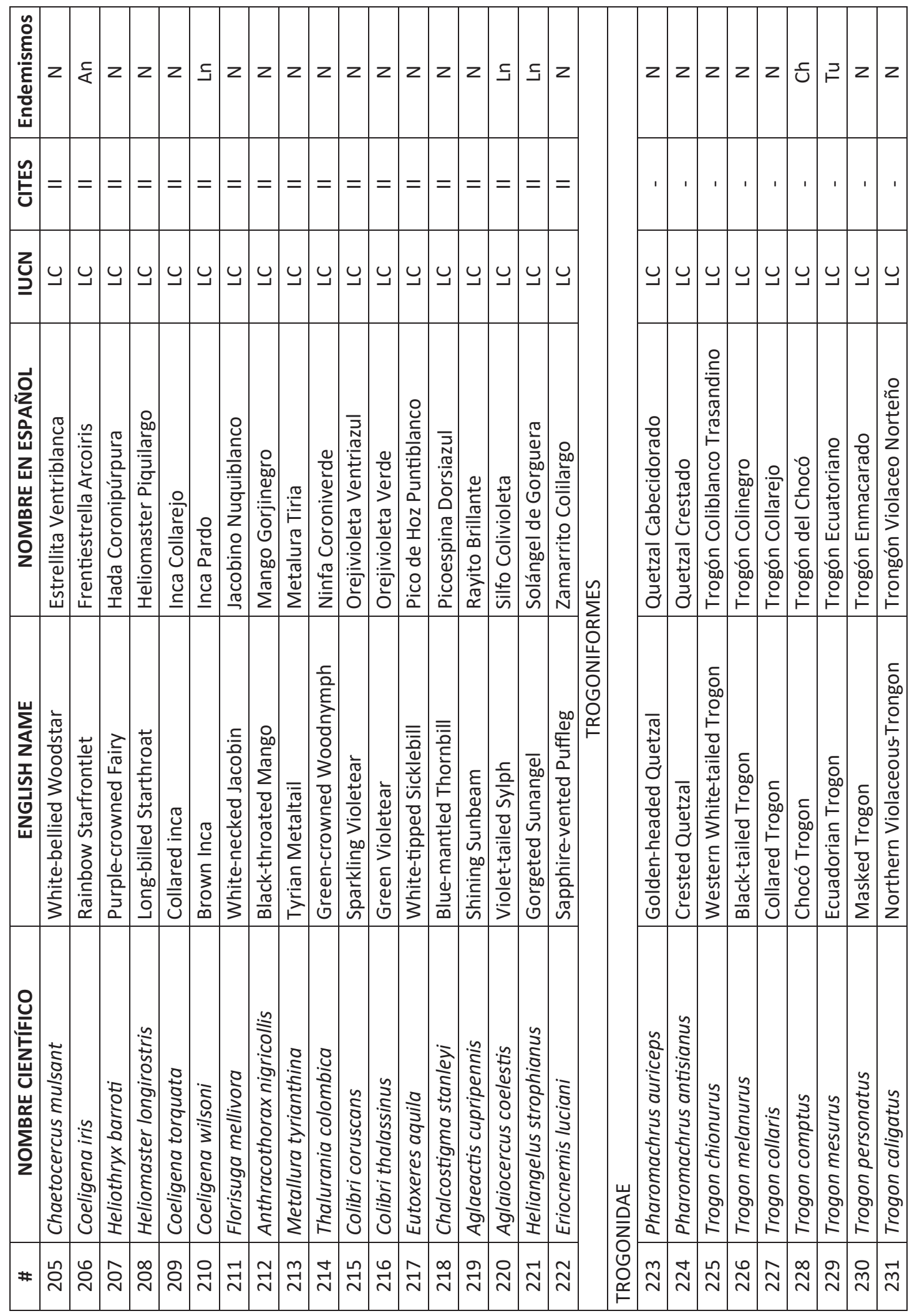

\section{3}

INVESTIGATIO No. 11, noviembre 2018

Edición Especial, pp. 113-168,

ISSN: 1390 - 6399・ISSN-e: 2602 - 8336 


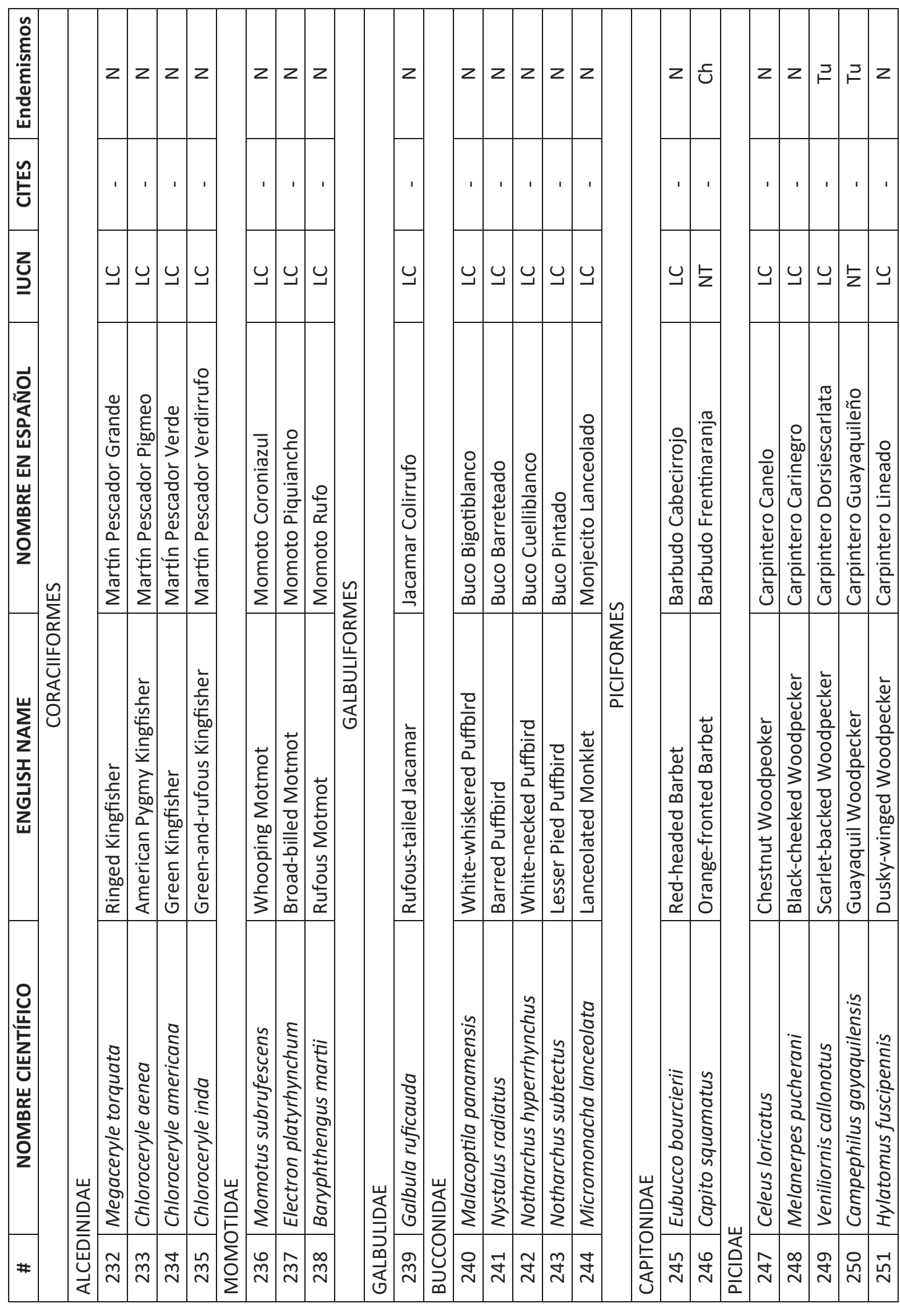

154

INVESTIGATIO No. 11, noviembre 2018 Edición Especial, pp. 113-168,

ISSN: 1390 - 6399・ISSN-e: 2602 - 8336 


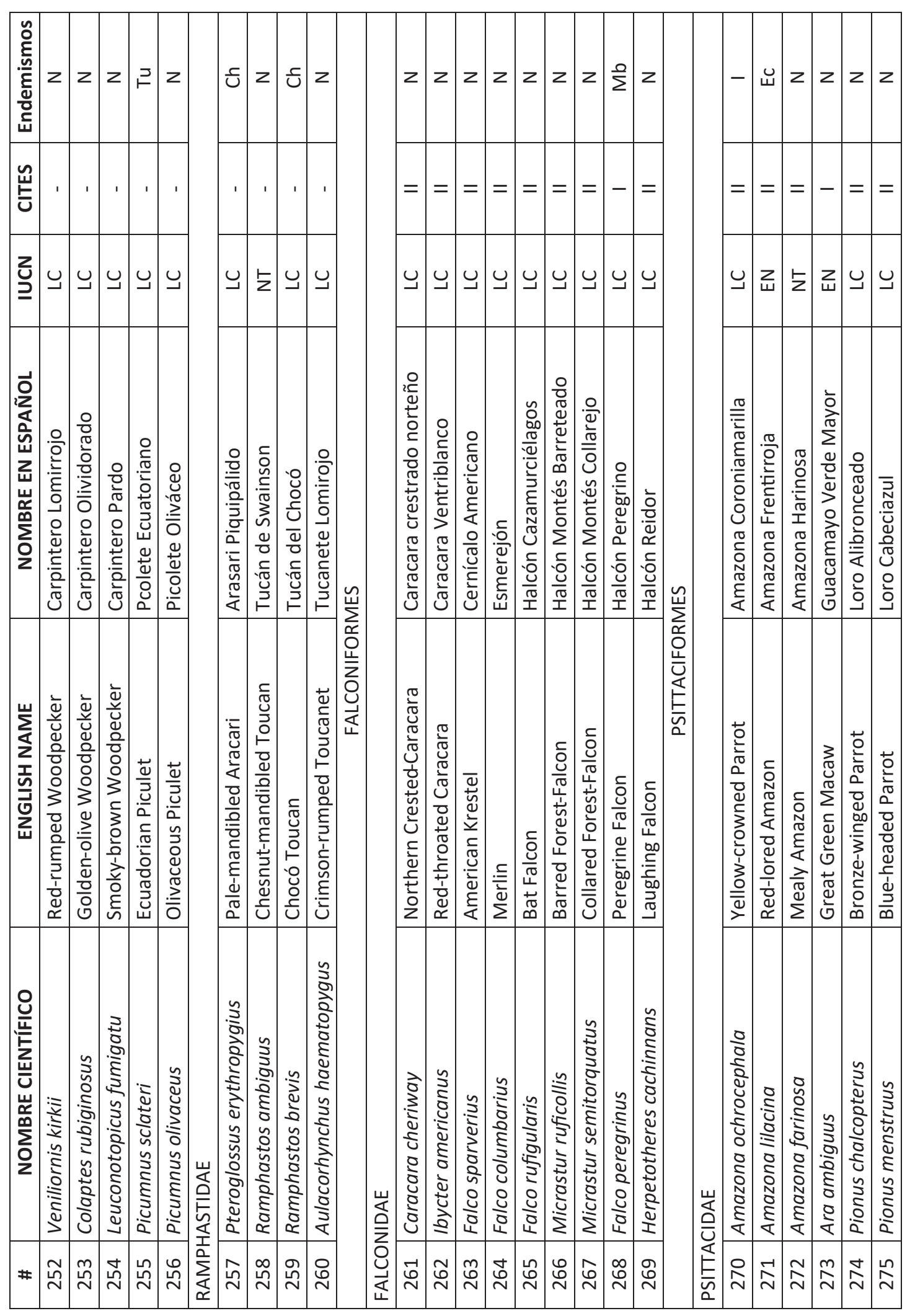

\section{5}

INVESTIGATIO No. 11, noviembre 2018,

Edición Especial, pp. 113-168,

ISSN: 1390 - 6399・ISSN-e: 2602 - 8336 


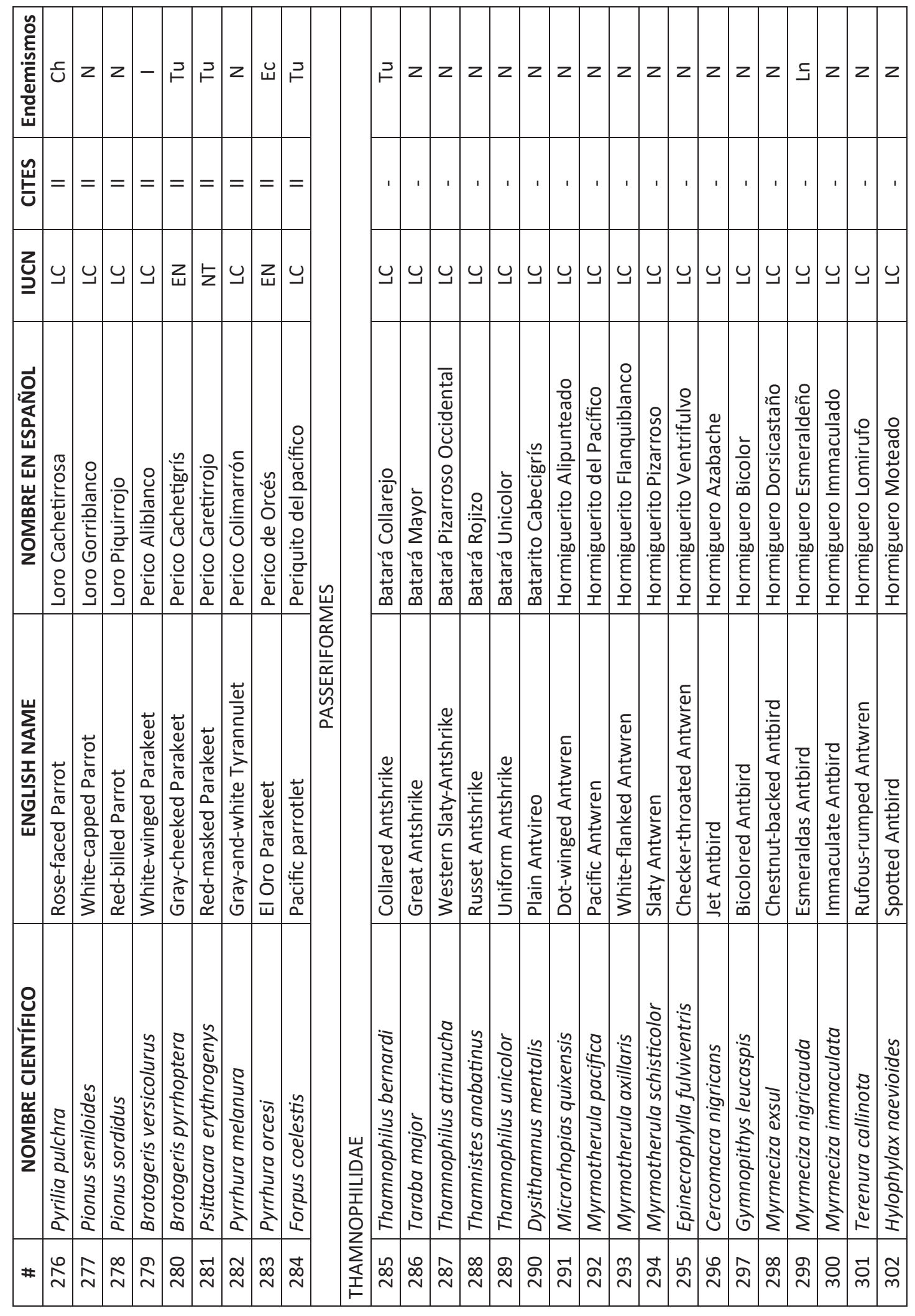

156

INVESTIGATIO No. 11, noviembre 2018,

Edición Especial, pp. 113-168,

ISSN: 1390 - 6399 • ISSN-e: 2602 - 8336 


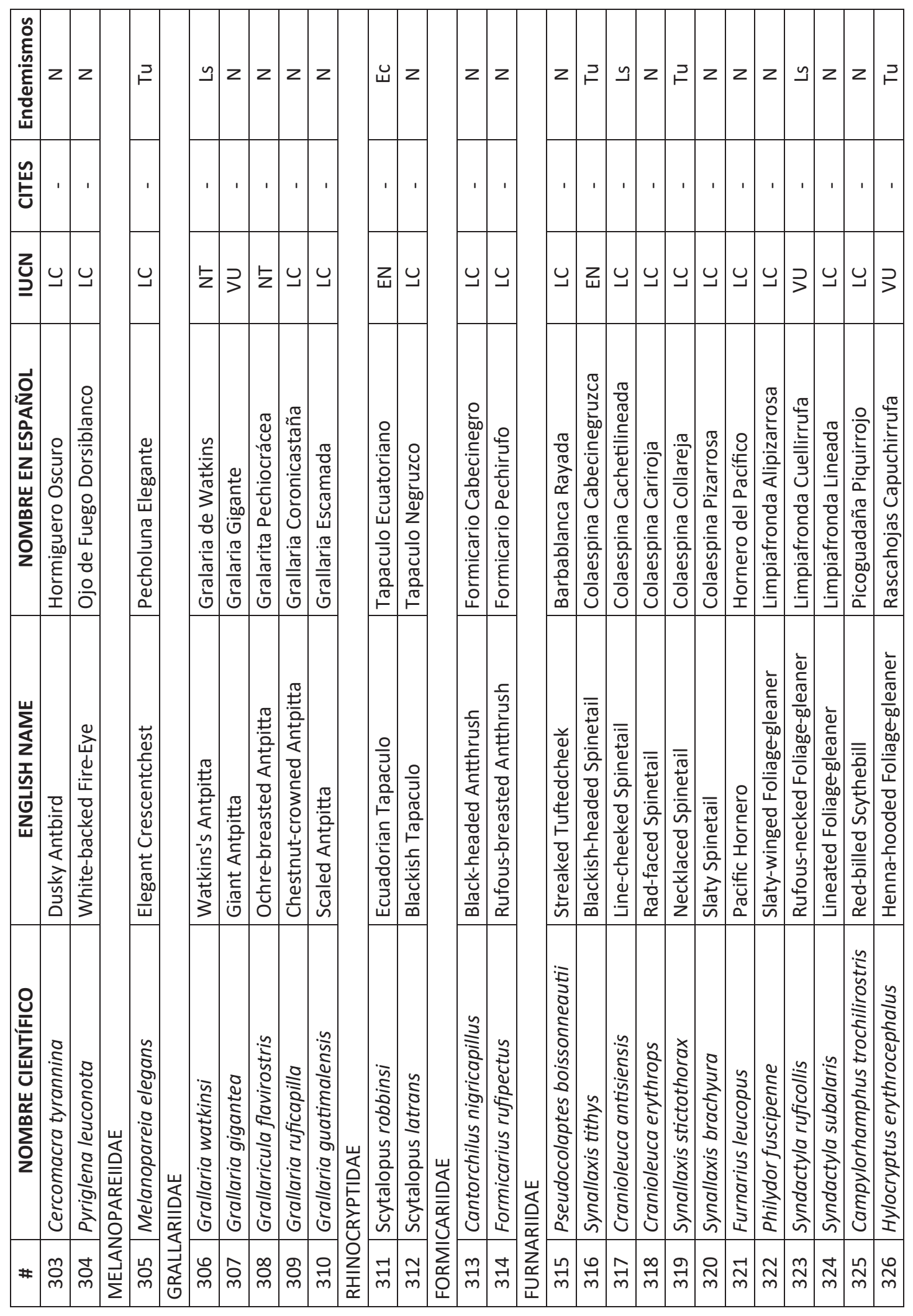

157

INVESTIGATIO No. 11, noviembre 2018 Edición Especial, pp. 113-168,

ISSN: 1390 - 6399・ISSN-e: 2602 - 8336 


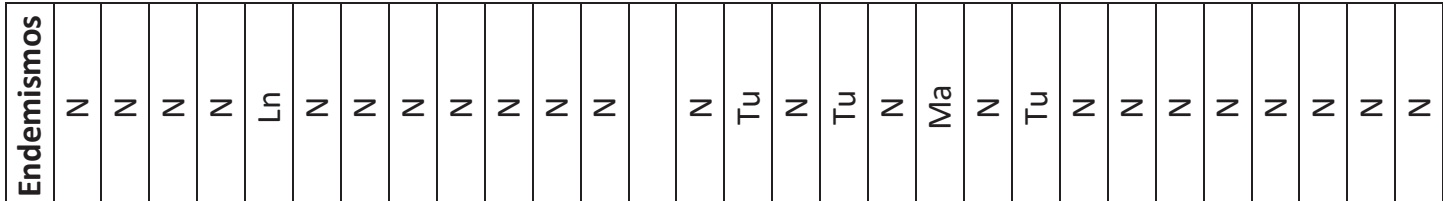

$$
\begin{aligned}
& \text { 莺 } \\
& \text { בֶ }
\end{aligned}
$$

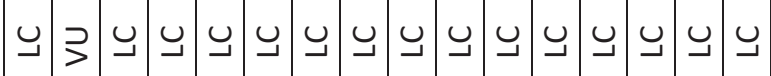
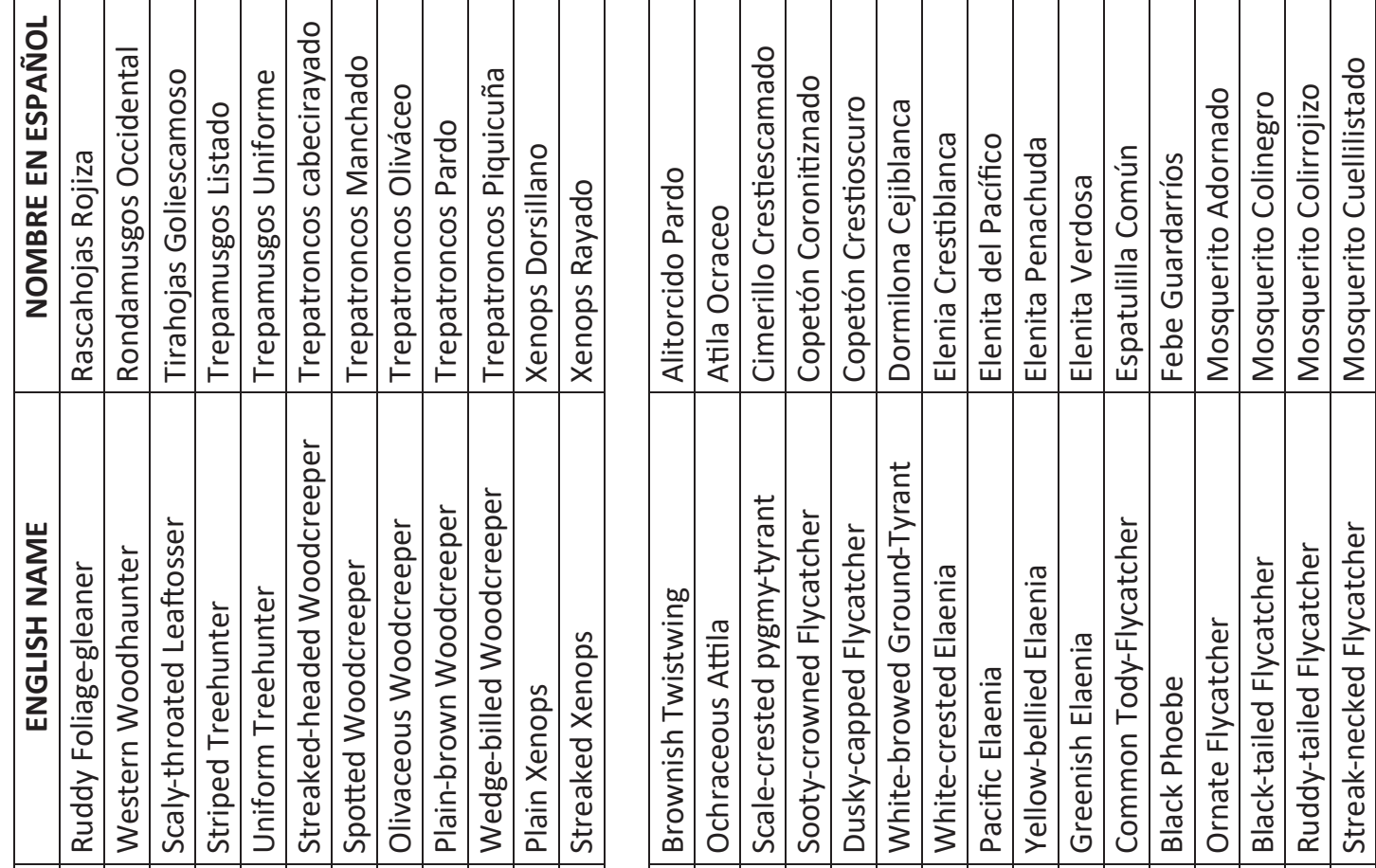

\section{을}

$\stackrel{?}{3}$

$\frac{2}{2}: \frac{2}{2}: \frac{2}{2}$

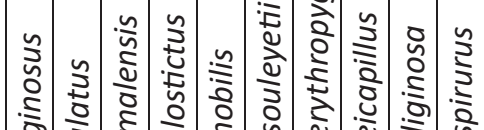

:ล

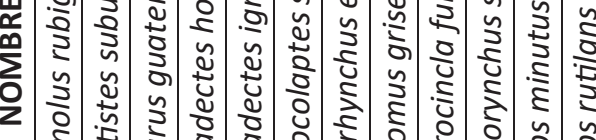

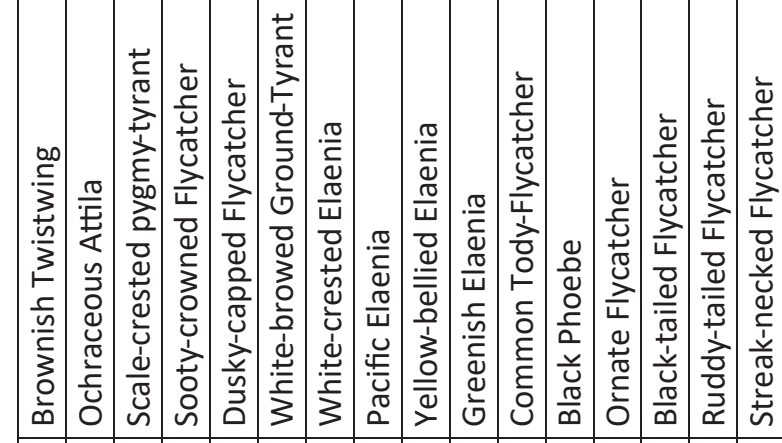
व.

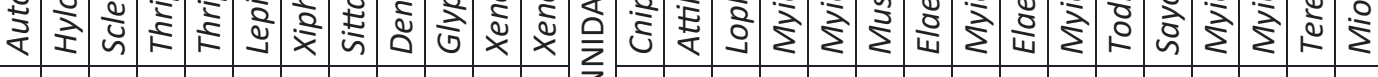

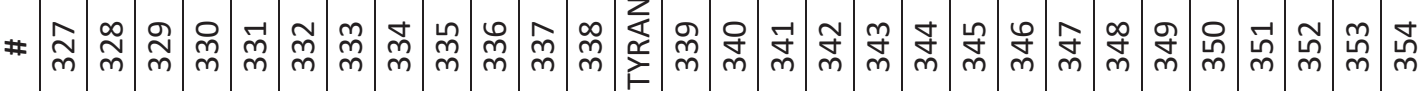

158

INVESTIGATIO No. 11, noviembre 2018

Edición Especial, pp. 113-168,

ISSN: 1390 - 6399 • ISSN-e: 2602 - 8336 


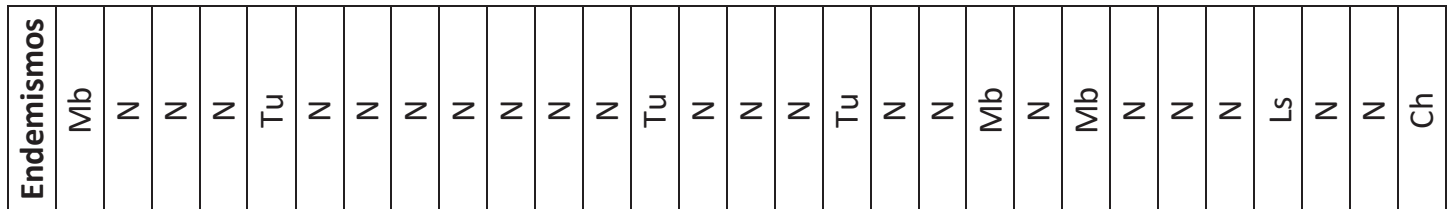

$$
\begin{aligned}
& \stackrel{\mathscr{U}}{\mathrm{U}} \\
& \text { כ }
\end{aligned}
$$
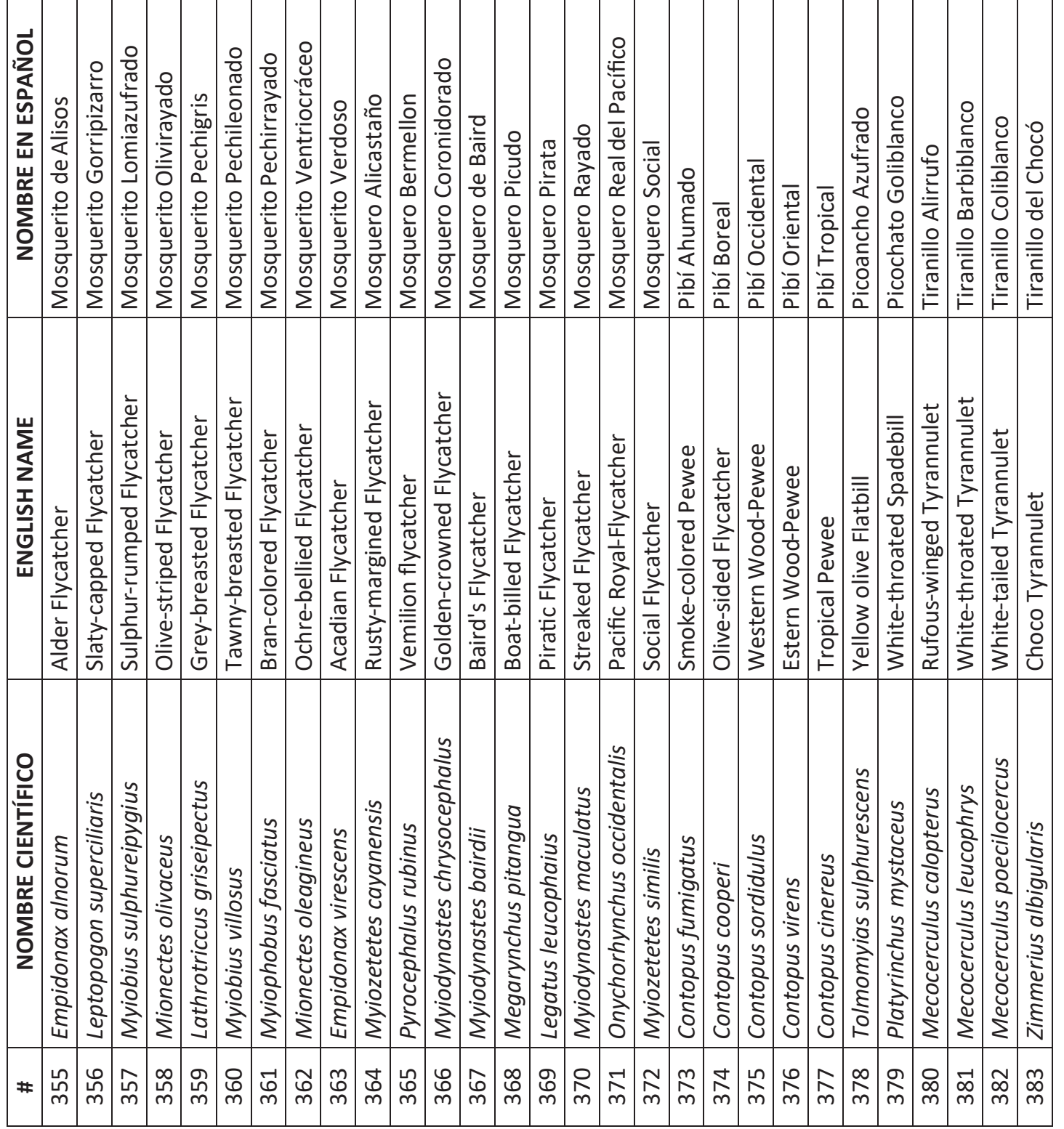

\section{9}

INVESTIGATIO No. 11, noviembre 2018

Edición Especial, pp. 113-168,

ISSN: 1390 - 6399・ISSN-e: 2602 - 8336 


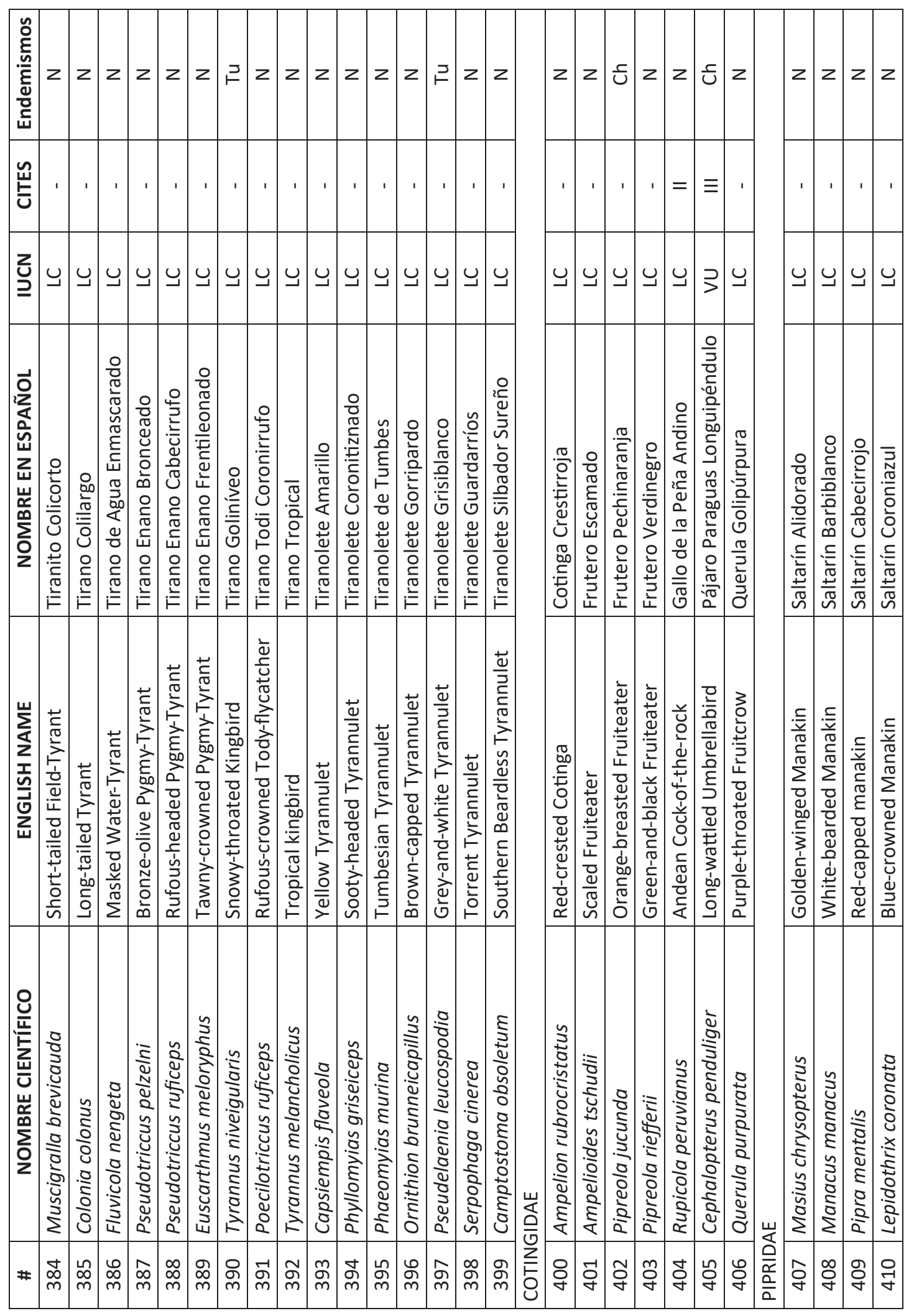

160

INVESTIGATIO No. 11, noviembre 2018,

Edición Especial, pp. 113-168,

ISSN: 1390 - 6399・ISSN-e: 2602 - 8336 


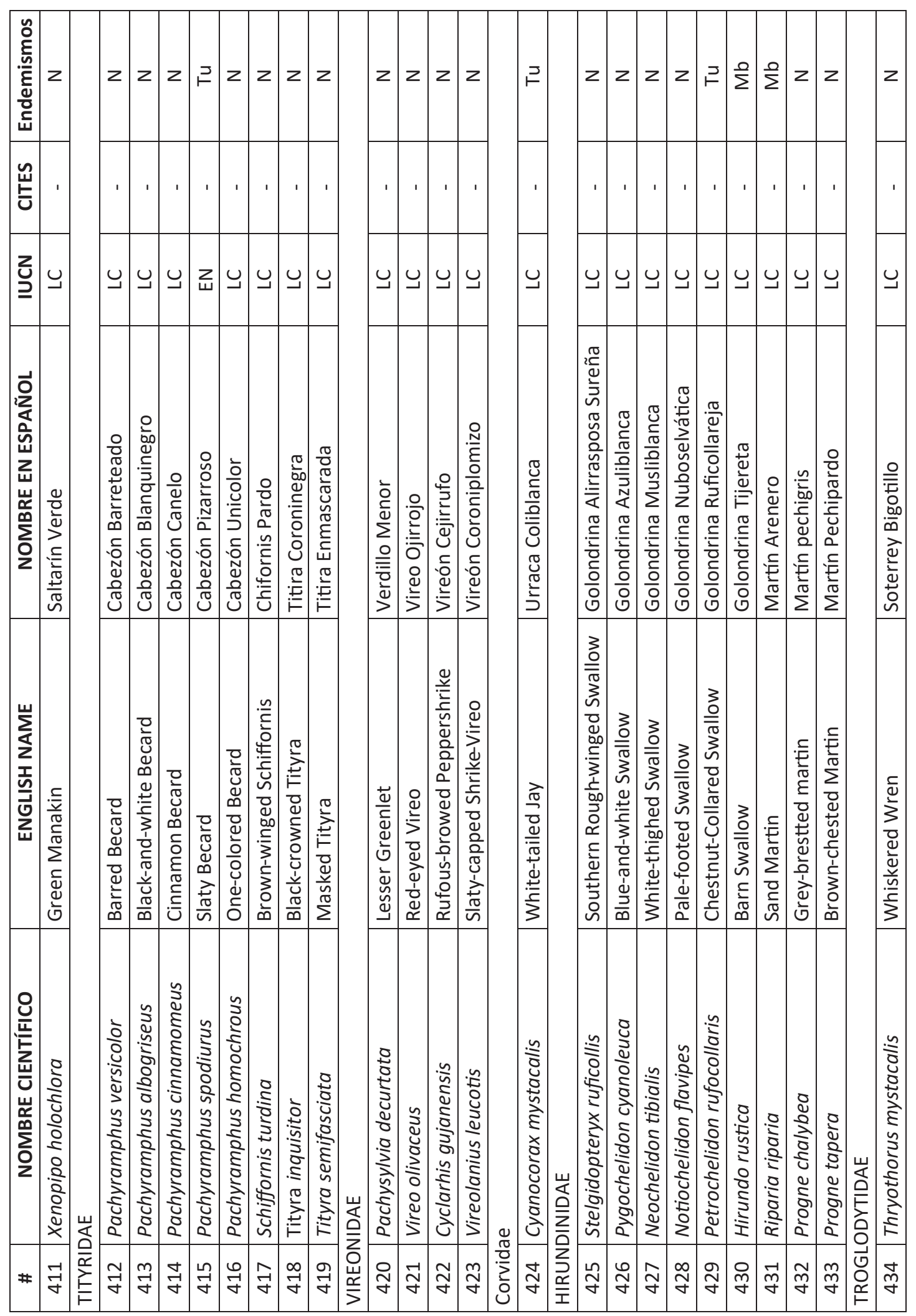

161

INVESTIGATIO No. 11, noviembre 2018

Edición Especial, pp. 113-168,

ISSN: 1390 - 6399・ISSN-e: 2602 - 8336 


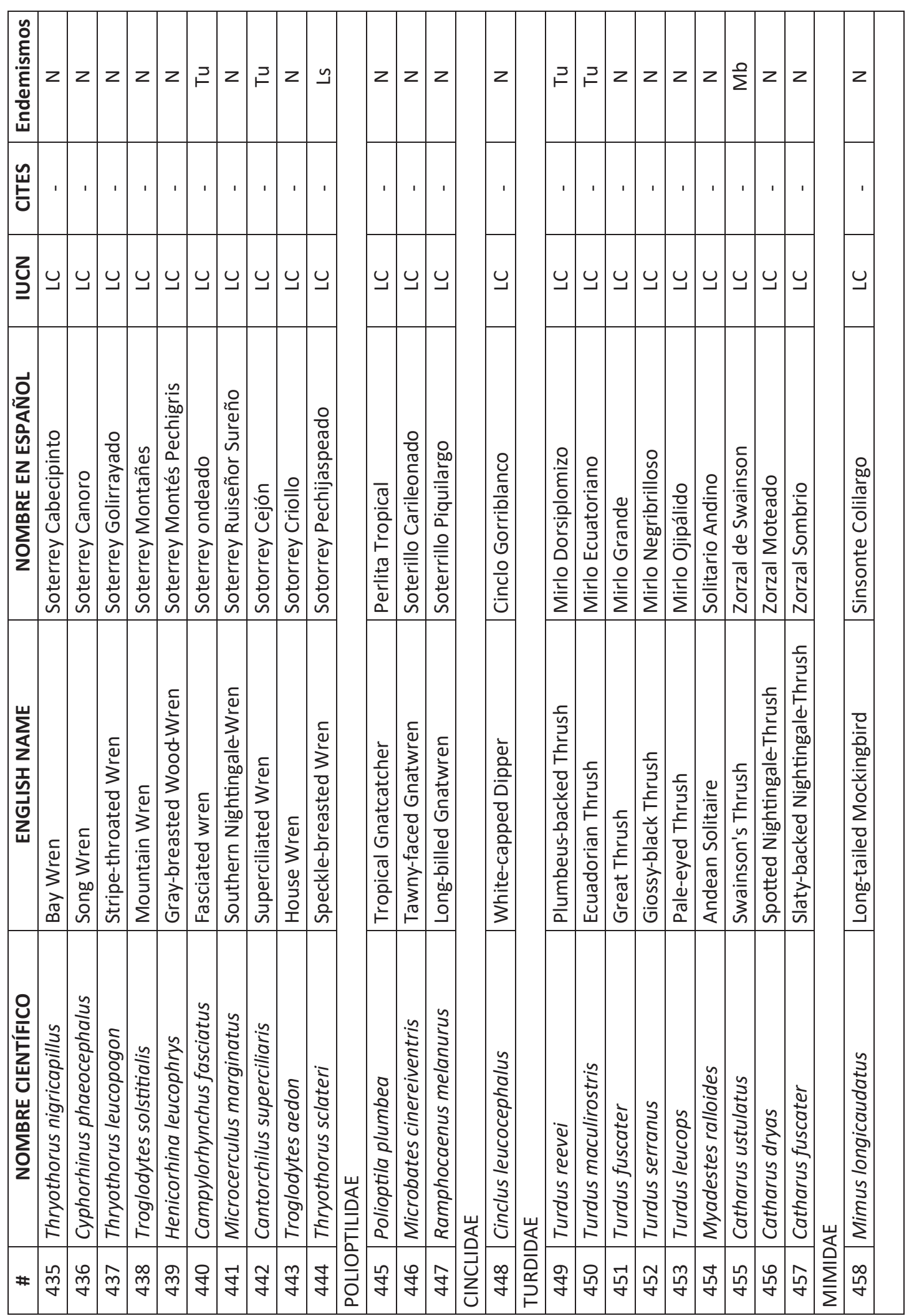

162

INVESTIGATIO No. 11, noviembre 2018,

Edición Especial, pp. 113-168,

ISSN: 1390 - 6399 • ISSN-e: 2602 - 8336 


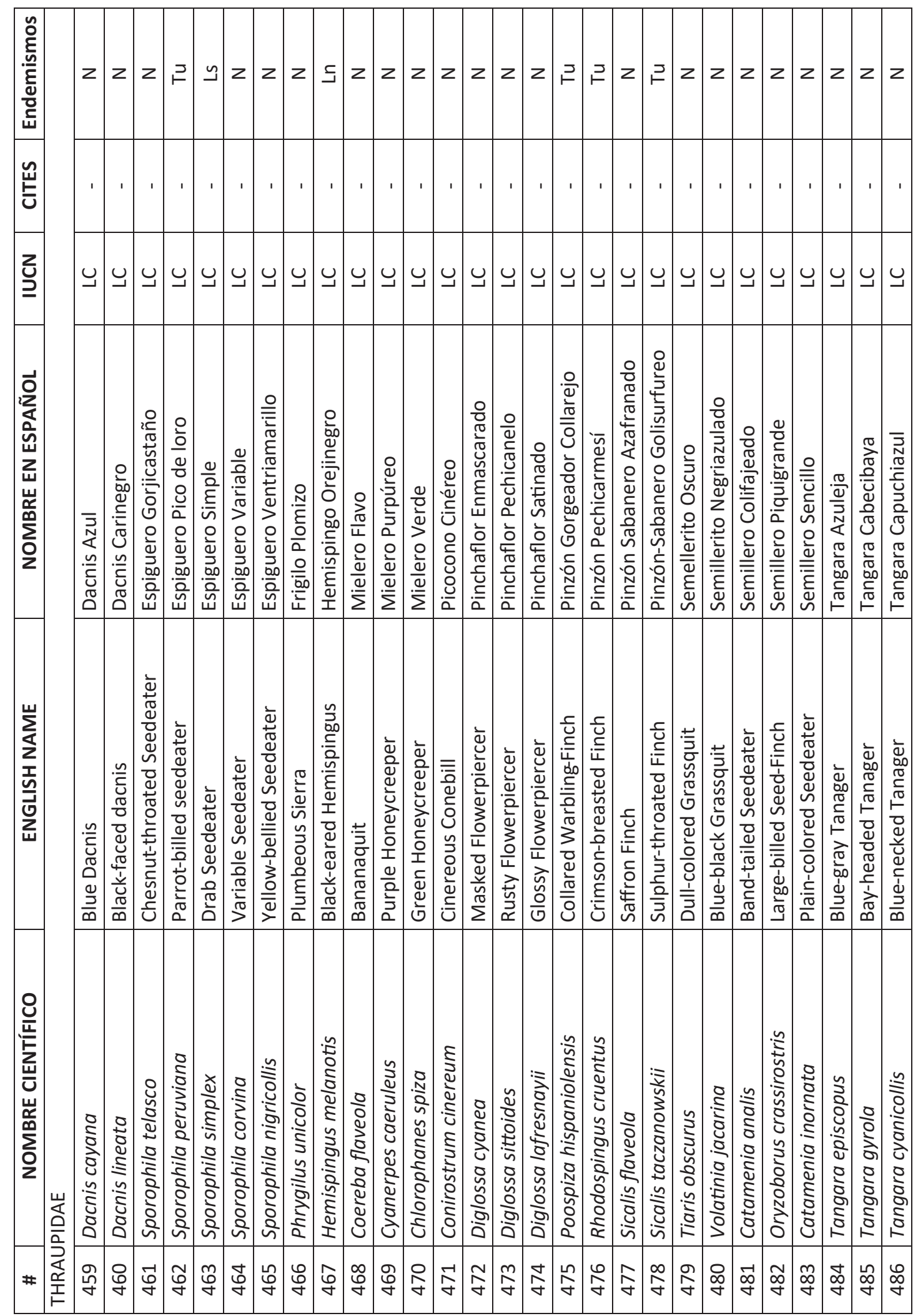

163

INVESTIGATIO No. 11, noviembre 2018,

Edición Especial, pp. 113-168,

ISSN: 1390 - 6399・ISSN-e: 2602 - 8336 


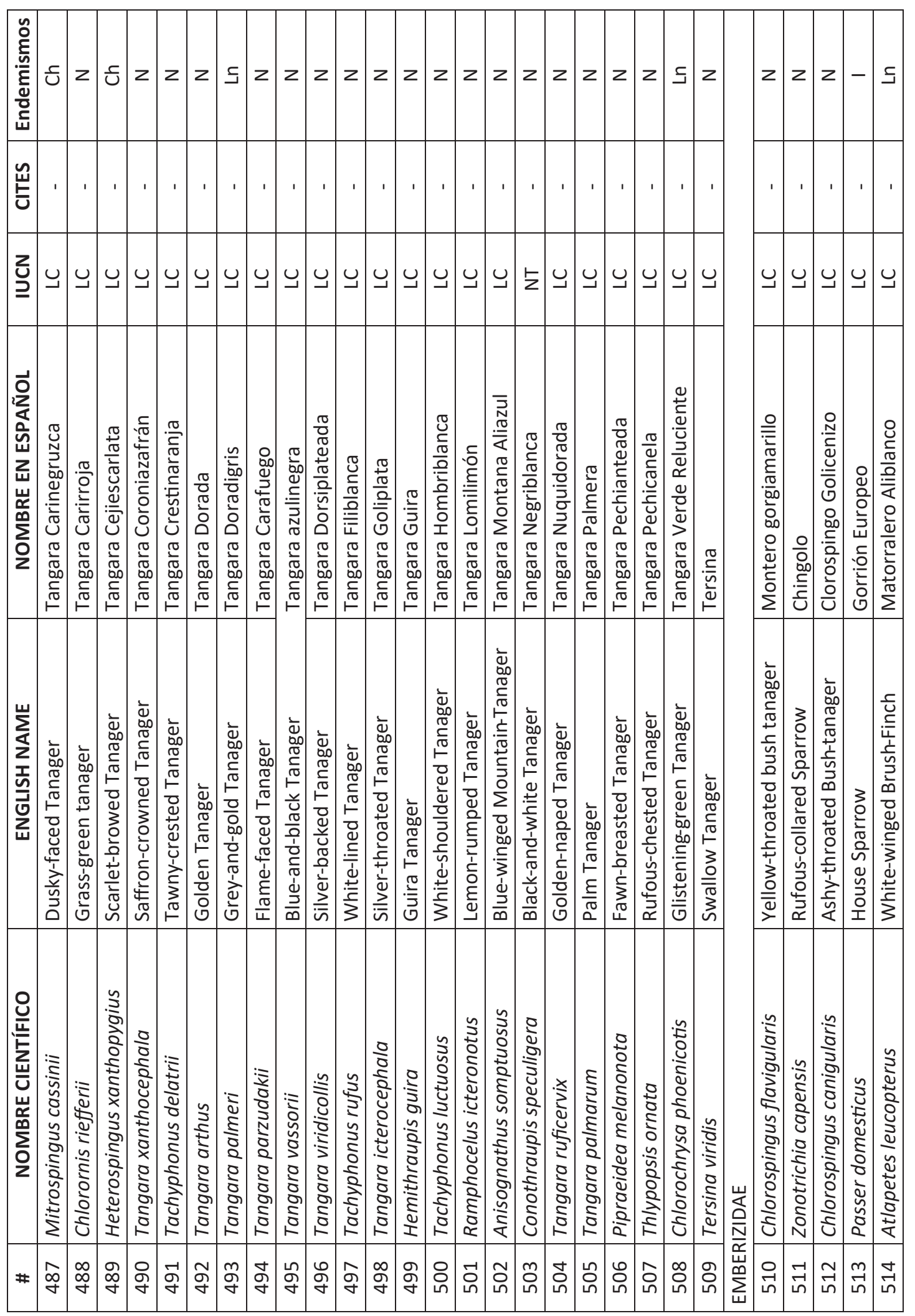

\section{4}

INVESTIGATIO No. 11, noviembre 2018

Edición Especial, pp. 113-168,

ISSN: 1390 - 6399・ISSN-e: 2602 - 8336 


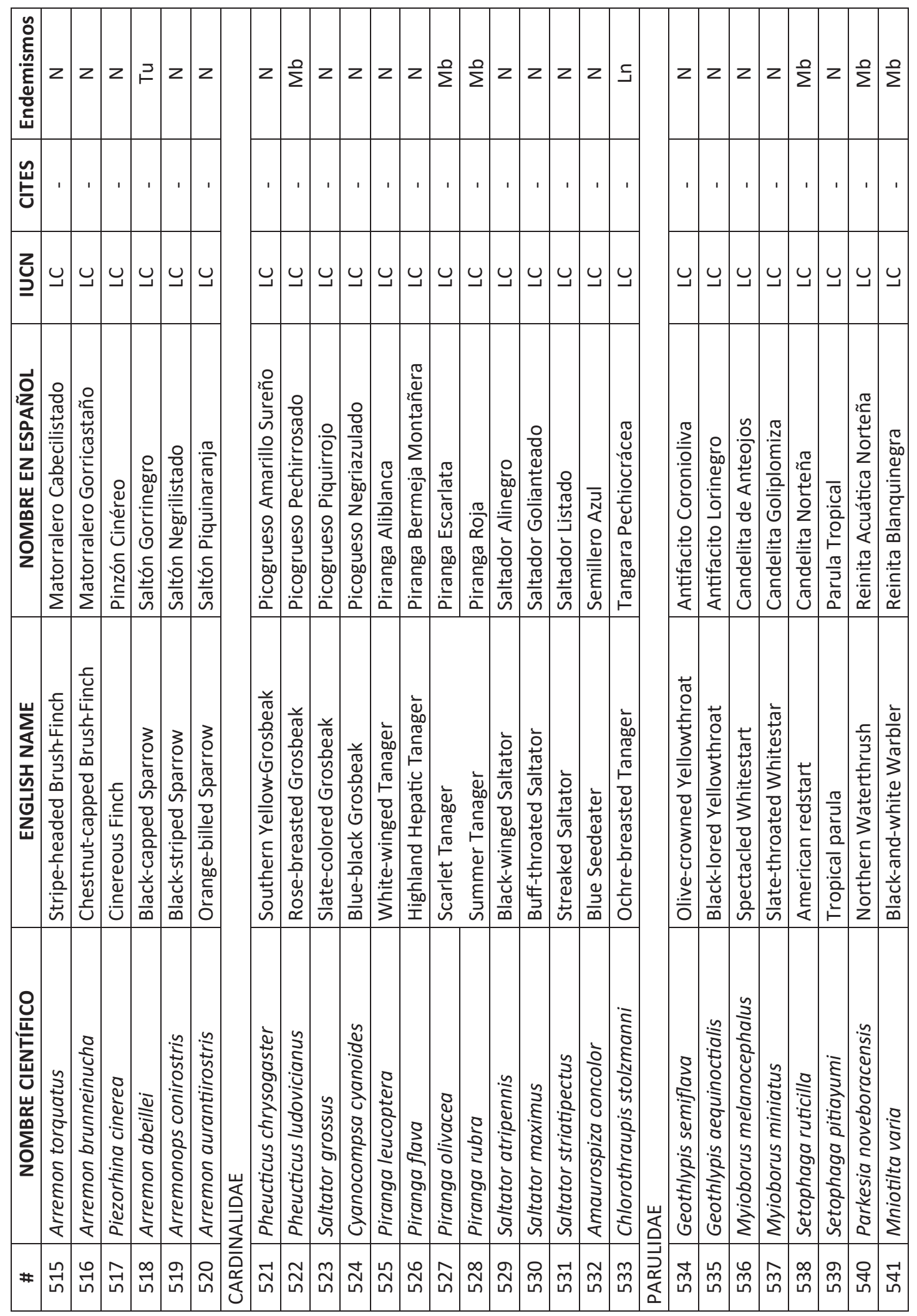

\section{5}

INVESTIGATIO No. 11, noviembre 2018,

Edición Especial, pp. 113-168,

ISSN: 1390 - 6399・ISSN-e: 2602 - 8336 


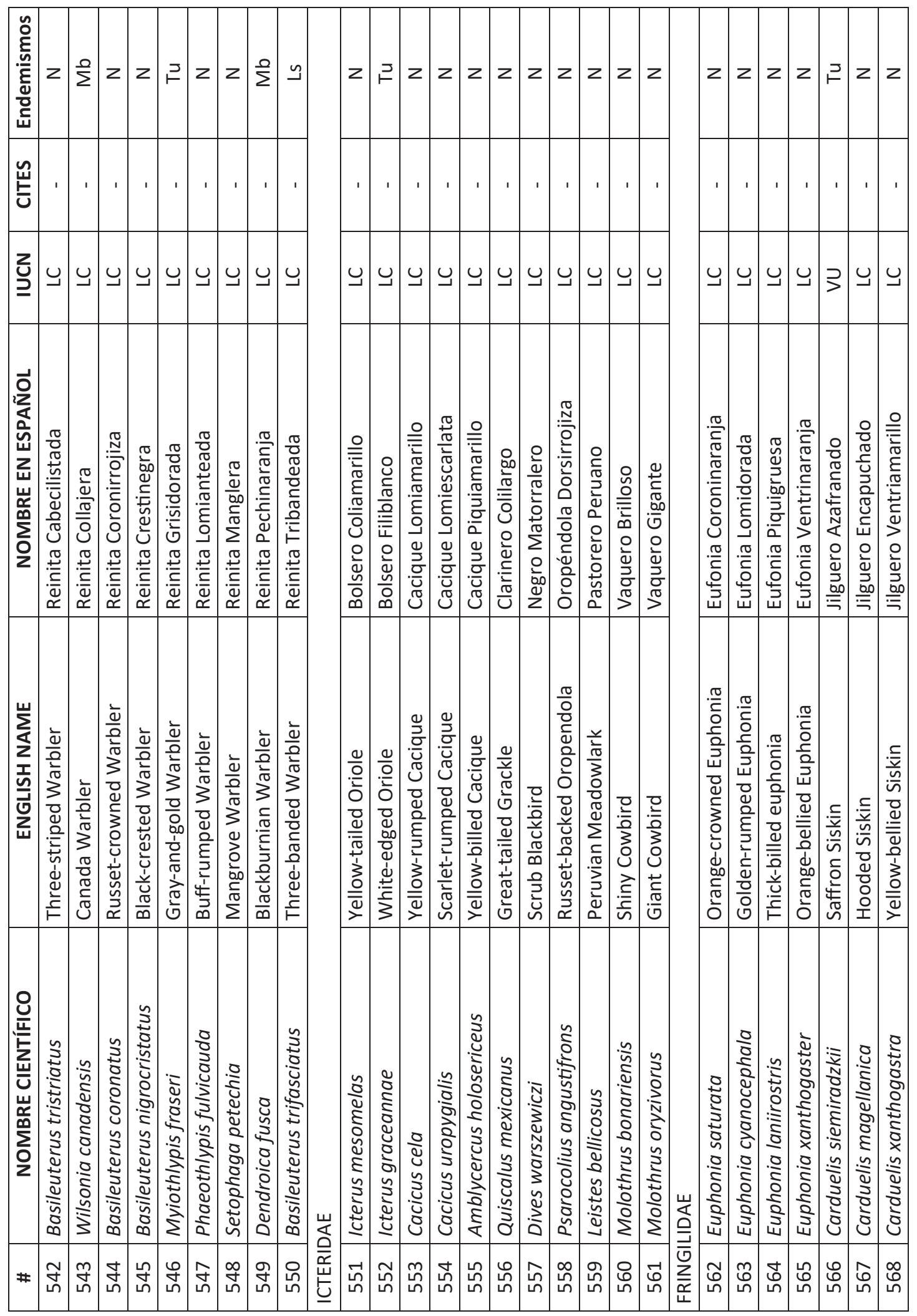

166

INVESTIGATIO No. 11, noviembre 2018

Edición Especial, pp. 113-168,

ISSN: 1390 - 6399 • ISSN-e: 2602 - 8336 


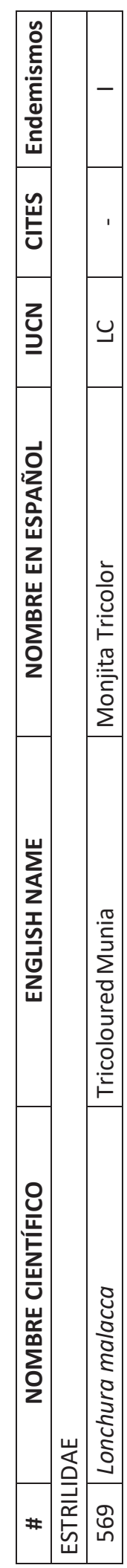


Felipe Espinoza, Emilio Testa, Carlos Cruz, Alexander Matecki, Julián Pérez, Diego Manosalvas, Carola Bohórquez

Anexo 7. Fotografías, equivalencias y coordenadas (x,y) de los sitios de muestreo.

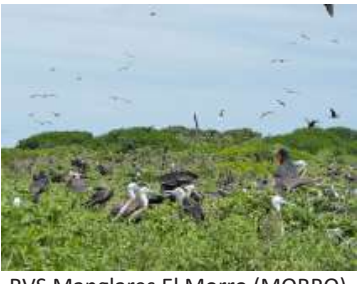

RVS Manglares El Morro (MORRO) (581581,9710968)

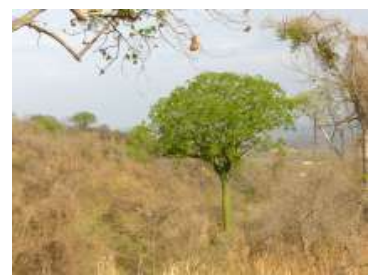

BP La Prosperina (PROSPERINA)

(613736,9762351)

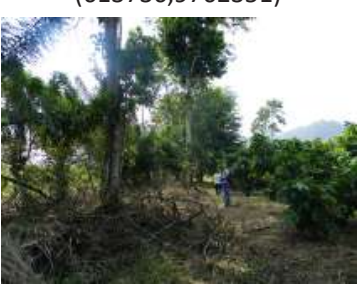

AR Las Pavas (PAVAS) $(693207,9739395)$

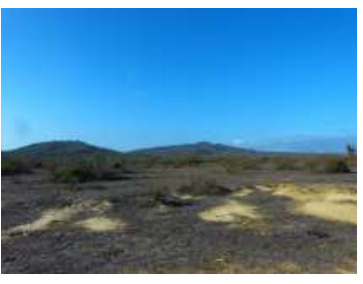

Engabao-Engunga (ENGABAO) $(553267,9719180)$

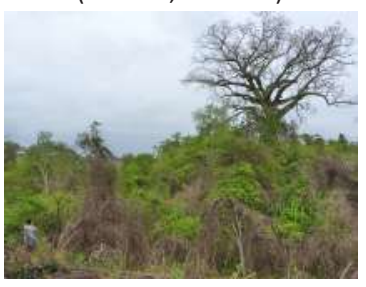

Isla Puná (PUNA)

$(593948,9687869)$

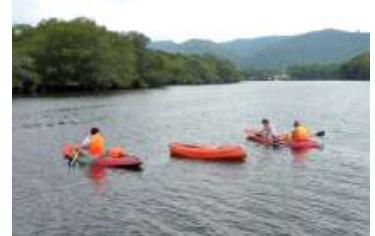

RPF Manglares El Salado (SALADO) $(610581,9756888)$

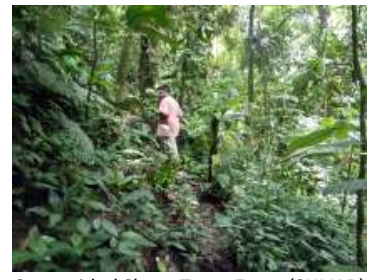

(650551,9690518)

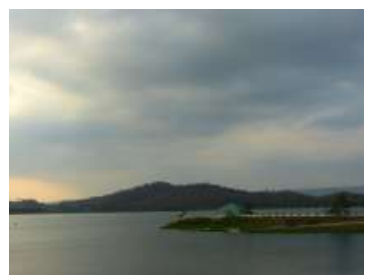

ANR Parque Lago (PLAGO)

$(600509,9755174)$

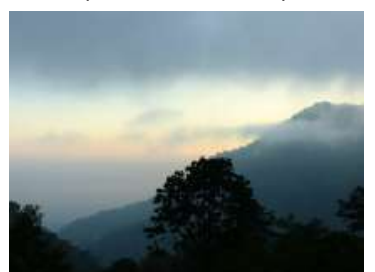

BP La Esperanza (BUCAY) $(709741,9762393)$

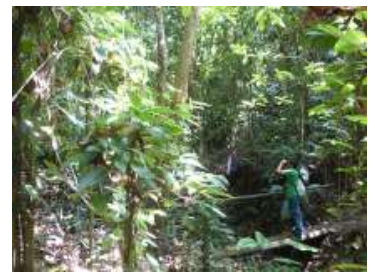

BP Bosque de los monos (BMONOS) (637943,9897919)

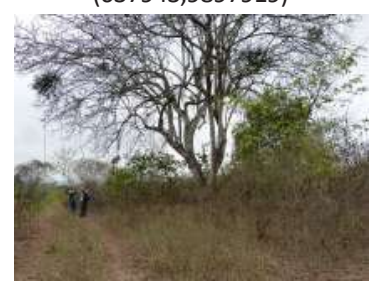

Hacienda El Castillo (CASTIUO) $(553275,9739384$

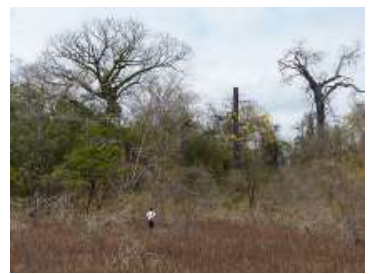

Chongon-Colonche II (PCARBO) $(578694,9812145)$

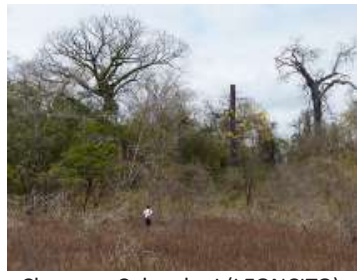

$(554455,9760262)$

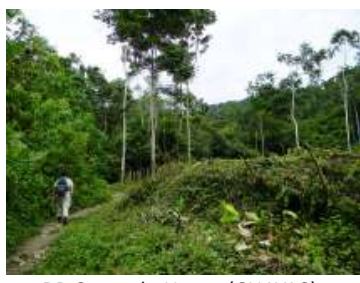

BP Cerro de Hayas (CHAYAS)

$(652414,9699392)$

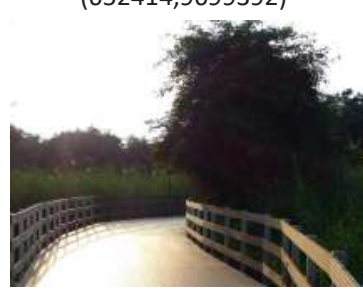

ANR Isla Santay (SANTAY) (625316,9755618)

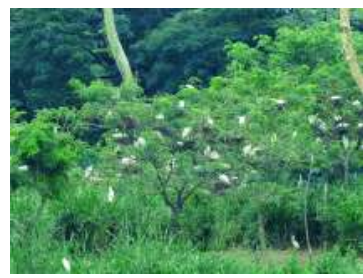

BP Bosqueira (BOSQUEIRA) (613313,9777798)

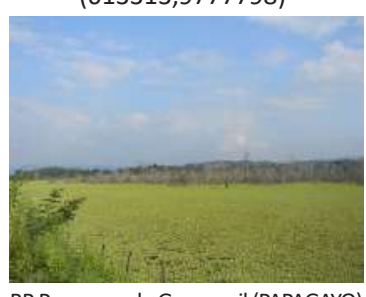

BP Papagayo de Guayaquil (PAPAGAYO) (616277,9774694)

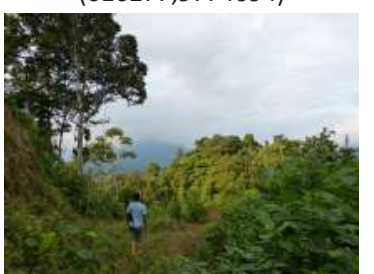

Rancho Alemán (RALEMAN) (698587,9742030)

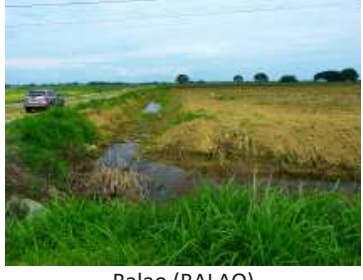

Balao (BALAO) (642694,9678703)

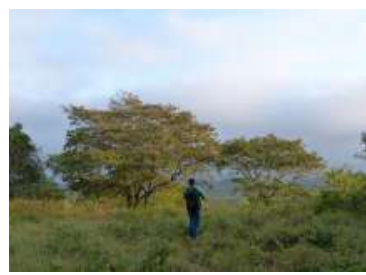

AR El Guayacán (VITERI) (592881,9757267)

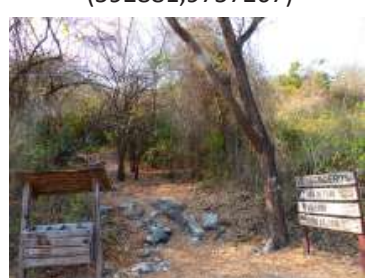

BP Cerro Blanco (CBLANCO) (611510,9760633)

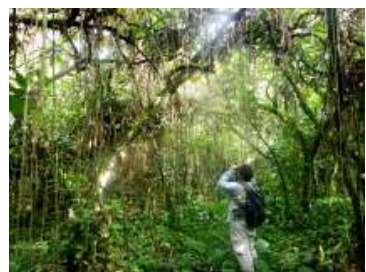

Hacienda Camino Verde (CVERDE) (630127,9679239)

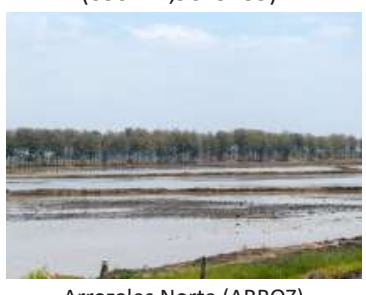

Arrozales Norte (ARROZ)

(614173,9823522)

168

INVESTIGATIO No. 11, noviembre 2018, Edición Especial, pp. 113-168,

ISSN: 1390 - 6399・ISSN-e: 2602 - 8336 